\title{
NARRATIVITY AND SEGMENTIVITY IN CONTEMPORARY AUSTRALIAN AND NEW ZEALAND \\ LONG POEMS AND POEM SEQUENCES
}

BY

AIRINI JANE BEAUTRAIS

\begin{abstract}
A thesis
submitted to the Victoria University of Wellington in fulfilment of the requirements for the degree of Doctor of Philosophy
\end{abstract}

Victoria University of Wellington 2016 


\section{Abstract}

The $\mathrm{PhD}$ in creative writing comprises a critical and a creative component. This thesis explores how poets utilise verse form in order to support and/or undermine narrativity in long poems or poem sequences, and asks the question: what possibilities are offered by verse form that distinguish poetry from other literary narrative genres? Using Rachel Blau DuPlessis's concept of segmentivity, I consider how segmentation at various formal levels, including sections within a book, poems within a sequence, stanzas, linebreaks, and metre, can affect the narrativity of a text. I also consider segmentivity in relation to the ways in which a text may be narrativized, and to the interactions between narrative and other text types such as lyric and argument.

The theoretical framework for the critical component involves a synthesis of approaches from within the fields of narrative theory and literary criticism. The methodology used is a close reading and analysis of case study texts by six New Zealand and Australian poets, written in the period 1990-2010: Dorothy Porter's The Monkey's Mask (1994) and What a Piece of Work (1999); Alan Wearne's The Lovemakers (2008); Tusiata Avia's Bloodclot (2009); Bill Sewell's Erebus: A Poem (1999) and The Ballad of Fifty-One (2003); Anna Jackson's The Gas Leak (2006) and John Kinsella's Divine Comedy: Journeys Through a Regional Geography (2008). These texts range in their degree of narrativity from verse novels through narrative sequences to lyric sequences. The local and contemporary context has been chosen for several reasons, including the strong history of narrative poetry in both countries, recent trends towards long narrative poems and poem sequences, a relative lack of scholarship on the poetry of this region and time period, and because of the relevance to my own creative work.

This thesis argues that segmentivity can be used with or against narrativity in a long poem or poem sequence, with a range of possible results: from strongly narrative texts such as verse novels through to antinarrative texts and lyric sequences. Different levels of segmentation have different effects on narrativity, the division of a text into individual poems being the most important in the texts under consideration here. It is demonstrated that narrative as a text type can exist alongside other text types, and that 
segmentivity is important to this interaction, with a bearing on the overall narrativity of a text.

The creative component tests and extends the findings of the critical component. It consists of a poem sequence in three parts entitled Flow, on the subject of the Whanganui river. The sequence takes a discontinuous approach to narrative, varies in its approach to temporality, features interplay between narrative and lyric modes, and incorporates underlying arguments on environmental and social themes. 


\section{Acknowledgements}

Many thanks are due to my two supervisors, Harry Ricketts and James Brown, who have spent untold hours reading drafts of this thesis and providing valuable feedback. Their dedicated and collegial approach has been much appreciated.

Over the past three years I have been fortunate to have been part of a talented and supportive cohort of fellow $\mathrm{PhD}$ students at the International Institute of Modern Letters. For their friendship and feedback, I thank Michalia Arathimos, Angela Andrews, Hannah McKie, Steven Toussaint, Anna Sanderson, Helen Heath, Kate Duignan, Sue Orr, Gigi Fenster, Therese Lloyd, Peter Cox, Allan Drew, Amy Leigh Wicks, Alison McLachlan, Monica Macansantos, and Valerie Arvidson. Special thanks to Sue for her careful proofreading of the final draft.

I thank Chris Price, John Newton and Elizabeth McMahon for their examination of this thesis, and for the constructive and thought-provoking readings given in their reports.

Damien Wilkins, Chris Price, Clare Moleta and Katie Hardwick-Smith, along with other staff of the IIML, have provided support and guidance in many ways.

Some of the poems in the creative component have been published in print and online journals and zines. Thanks are due to the editors of Landfall, Overland, Blackmail Press, Food Court, Sport, IKA and SWAMP.

I would like to acknowledge the people who have provided me with information and stories relating to the Whanganui catchment, river and town: Stephen King, Nelson Lebo, Lieze Thomson, Michael Goessi, and my parents Margie and Keith Beautrais. I would also like to acknowledge the tangata whenua and the people whose histories I have drawn from in writing the creative component.

Josef Beautrais provided generous assistance with the making of maps for Flow. Data from LINZ was used, along with imagery from Geographx.

For helping with my children, travelling with me, putting me up, and for being there, I would like to thank Emily Beautrais, Josef Beautrais, Tom McDonald, Linda Liu, Cat Atkinson and Ron Fisher, Lola and Calexico, Myles, Melissa, Cosette and Felix Guy, Bärbel and Wolfram Grübsch, Sarah Helm, Michalia, Ira and Niko, and Wai 
Ho. Most importantly I acknowledge the significant support of my parents in helping care for two pre-schoolers while I worked on this thesis.

I would also like to acknowledge the institutions in which my children have been cared for and educated over the past three years: Rapanui-Brunswick Playcentre, Central Baptist Kindergarten and Early Learning Centres, Onerahi Kindergarten, and Onerahi Primary School. It has been a blessing to know my boys have been in safe hands.

Much love and thanks to Norman, Lukas and Felix Grübsch. 


\section{Table of Contents}

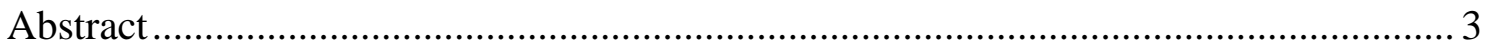

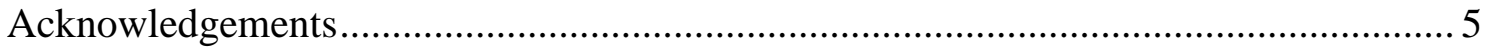

Critical Component: Narrativity and Segmentivity in Contemporary Australian and New

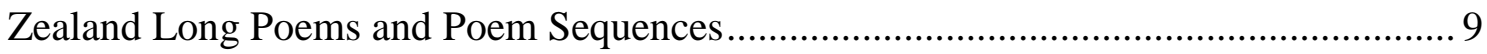

Part 1: Introduction to the Critical Component …..................................................... 11

1.1 Narrative in poetry: Historical contexts, the position of poetry within contemporary narrative theory, and the relevance of verse form to the study of

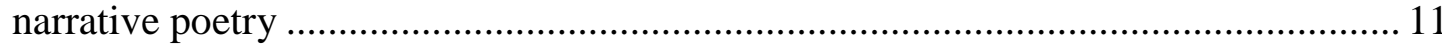

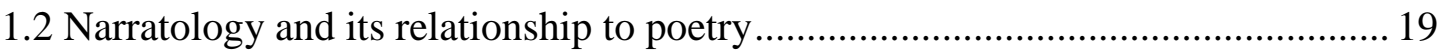

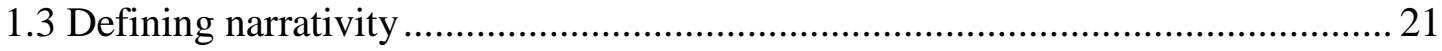

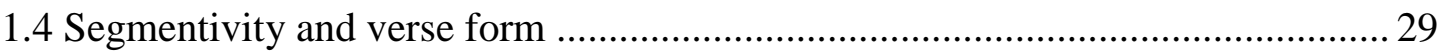

1.5 Contexts: Contemporary Australian and New Zealand long poems and poem

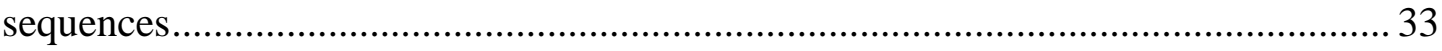

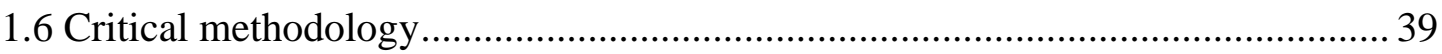

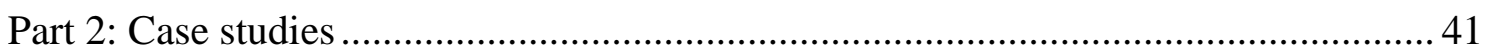

2.1 Dorothy Porter's The Monkey's Mask and What a Piece of Work ........................ 41

2.2 Alan Wearne's The Lovemakers ........................................................................... 57

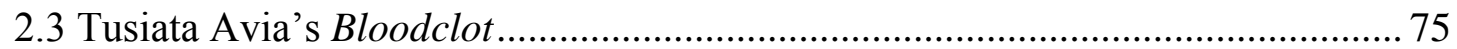

2.4 Bill Sewell's Erebus: A Poem and The Ballad of Fifty-One ............................... 89

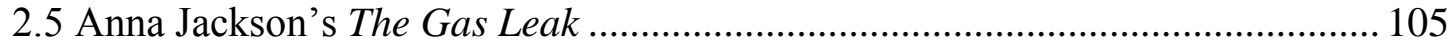

2.6 John Kinsella’s Divine Comedy: Journeys Through a Regional Geography .... 121

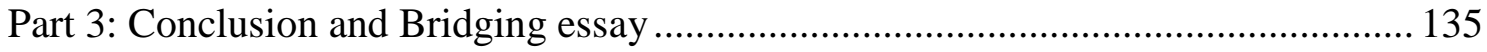

3.1 Conclusion to the Critical Component .......................................................... 135

3.2 Bridging essay to the Creative Component..................................................... 143 
Creative Component: Flow 149

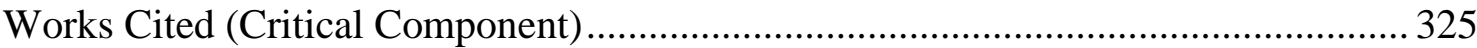

Selected Bibliography (Creative Component) .......................................................... 339 


\section{Critical Component: Narrativity and} Segmentivity in Contemporary Australian and New Zealand Long Poems and Poem Sequences 


\section{Part 1: Introduction to the Critical Component}

\subsection{Narrative in poetry: Historical contexts, the position of poetry within contemporary narrative theory, and the relevance of verse form to the study of narrative poetry}

It is a critical commonplace that the influential long poems of the modernist era deliberately avoided, frustrated or problematised narrative coherence, continuous narrative being incompatible with their poetic aims. ${ }^{1}$ One explanation is that writing in a lyric or non-narrative mode provided a distinction between poetry and prose, at a time when the prose novel had risen to precedence. As Marjorie Perloff puts it, "the poetry of modernism was wedded to a sharp distinction between poetry, the lyrical expression of personal emotions, and prose, the language of fiction, of the novel" ("From Image" 414). Exemplifying this distinction, and the uneasy status of the long narrative poem, T.S. Eliot wrote, in an essay published in 1933:

I by no means believe that the "long poem" is a thing of the past; but at least there must be more in it for the length than our grandparents seemed to demand; and for us, anything that can be said as well in prose can be said better in prose. And a great deal, in the way of meaning, belongs to prose rather than to poetry. (94)

The dominance of the lyric mode in modernist poetry has been linked to arguments put forward by Baudelaire in Paris Spleen (1869) (Perloff "From Image" 414) and by Poe in "The Poetic Principle" $(1850)^{2}$; however, it may predate this: Hermann Fischer postulates that the heyday of the "tale in verse" was over by the late 1820s (220). Whitman's Song of Myself (1855) has been called "the first modern poetic sequence" because it was the first modern poetic work of length whose ordering was lyrical, and

\footnotetext{
${ }^{1}$ Addison "Verse Novel" 541; Bates 160; Bernstein 4; Childs 14; Dickie 11; Friedman 22; McHale "Telling Stories" 250; Pollack 53; Sauerberg 444.

${ }^{2}$ Conte 108; Frye "Approaching” 36; Jarman 49; Litz 17; Perloff "From Image" 414; Pollack 54; Rosenthal and Gall 6.
} 
which was "not bound by thematic, philosophical or formal conventions in the way that so many earlier so-called 'sequences' were" (Rosenthal and Gall 16). ${ }^{3}$

Avoidance of narrative could be seen as an argument for avoiding long poems altogether, as could the Imagist qualities of intensity and brevity. Nevertheless, modernist poets wrote long poems, and many of these, such as Ezra Pound's The Cantos (1925-1969), T.S. Eliot's The Waste Land (1922), William Carlos Williams's Paterson (1946-1958) and Wallace Stevens's Notes Toward a Supreme Fiction (1942) have remained among the most influential poetry of that era. The long poem may have attracted modernist poets because of the epic's status within literary history; something almost every major poet had attempted. Margaret Dickie also suggests it may have provided them with the logical next step or challenge within their already successful careers. This "redirected the Modernist movement from its beginning in radical experimentation in the short lyric to its end in the long public poem" (3).

Around the middle of the twentieth century, further trends began to emerge in the writing of the long poem. A return to the narrative mode has been identified by critics of postmodern poetry (McHale "Telling Stories"; Perloff "From Image"). Postmodern long poems - such as Ed Dorn's Gunslinger (1968-1974), James Merrill's The Changing Light at Sandover (1982), and Lyn Hejinian's Oxota: A Short Russian Novel (1991) - tend to employ discontinuous, fragmented or unfinished narratives, which Brian McHale describes as "telling stories 'poorly', distractedly, with much irrelevance and indeterminacy" ("Weak Narrativity" 165). Standing in contrast are the continuous narratives of contemporary verse novels, a form immensely popular in the nineteenth century, and firmly re-established in the 1980s and 1990s. These phenomena can be seen as part of a wider trend: as Hayden White explains in The Content of the Form (1987), postmodernism is "informed by a programmatic, if ironic, commitment to the return to narrative as one of its enabling presuppositions" (11).

The characterisation of modern poetry as largely non-narrative and postmodern poetry as re-embracing narrative does not fully reflect the complexities of the situation. There are numerous examples of continuous narratives in long poems of the early

\footnotetext{
${ }^{3}$ It must be noted that the lyric sequence, if not the "modern" sequence, dates back much further than this, and that there were mid-nineteenth-century examples which predated Whitman's poem, such as Tennyson's In Memoriam. Rosenthal and Gall's phrasing "bound by . . conventions" also suggests an ideological taint to their theory.
} 
twentieth century; such as John Masefield's The Everlasting Mercy (1911) and Dauber (1913), Edwin Arlington Robinson's Arthurian trilogy (1917, 1920 and 1927), and David Jones's In Parenthesis (1937). There are also examples of juxtaposed narratives, such as Edgar Lee Masters's Spoon River Anthology (1915). Moreover, a closer look at the work of the influential modernists reveals that they had by no means abandoned narrative. Williams's Paterson articulates stories of a city's past and present inhabitants, through the use of found prose fragments, and through poetry. Eliot's The Waste Land contains a number of implied or even realised narratives, ranging from mythical allusions through to scenes which could be described as "short stories" - such as the bar scene in section II, or the typist scene in section III. Pound's Cantos are more heavily fragmented, but frequently employ third person narration, and are full of events, if not plots. Stevens's poetry has been the subject of a number of studies of submerged narrative (Perloff "Revolving in Crystal"; Schwarz; Bates; Glatt), posited as "a test case for [the] view that we respond to even the most lyrical and abstract poem as a narrative which organises at least the germ of a story" (Schwarz 3). Notes Toward A Supreme Fiction is described as "a tale that engages us by means of its wit, evocative language, and philosophical depth ... quite simply, a good story" (Bates 172). It therefore appears that in spite of dominant perceptions still having force, narrative in poetry has never entirely disappeared; rather, it has been deployed differently, at different times, and by different poets.

The varied historical approaches to narrative in poetry, particularly over the last two centuries, have led to a contemporary situation in which writers have wide-ranging precedents for the degree of narrativity in their work. These, paired with the necessary choices a poet must make regarding verse form, combine to produce a complex array of possibilities in the crafting of a long poem. Contemporary poetry (defined for the purposes of this study as poetry written in the late twentieth and early twenty-first centuries, up to and including the present) provides fertile ground for the analysis of narrativity as a scalar phenomenon, and for the analysis of interactions between narrativity and verse form. This thesis explores how poets use verse form in order to support and/or undermine narrativity in a long poem, asking the question: what possibilities are offered by verse form that distinguish poetry from other literary narrative genres? Specifically, I consider how different levels of formal segmentation 
affect the narrativity of a text, and the narrative(s) within it. The methodology is a fusion of concepts from within narrative theory, in particular its subfield narratology, and literary criticism of poetry, including the writings of practising poets, in relation to verse form.

In spite of recent developments, and of the long history of narrative in poetry, the relationship between the narrative of a poem and its verse form component has never been widely studied. On the one hand, literary critics of poetry have avoided the narrative aspect, considering the "fable and fiction" of an extended poetic narrative "its most detachable and translatable element" (Kinney 3). On the other hand, narrative theorists have avoided the formal aspect; where poems are studied, their poetry component is regarded as incidental, the poets treated as honorary novelists (Kinney 3; McHale "Beginning" 12). In the New Princeton Encyclopedia of Poetry and Poetics (1993), Leonard Nathan points out that studies of narrative have focused on prose, while studies of prosody, figures, schemes and tropes have been applied to the lyric (817); McHale makes a similar observation in the 2005 Routledge Encyclopedia of Narrative Theory ("Narrative" 356). There are a number of reasons for this separation. One is the distinction between narrative (epic) and lyric, based on Aristotelian genre theory. A conflation of "lyric" with "poetry", in opposition to "narrative", "fiction" and "prose", remains evident in recent criticism. For example, in an essay published in 2005, Margarete Rubik states: "Genre theory is based on the belief that there are distinctive differences between poetry and narrative (without which this allegedly 'intuitive' ability to recognise poetry would be impossible)" (189), and in an essay in the same volume, Werner Wolf asserts: 'no distinction between 'the lyric', 'poetry' and 'poems' seems to be appropriate any longer" ("The Lyric" 23). Maintaining a narrative prose/lyric poetry dichotomy leaves no category for the narrative poem, resulting in its misleading characterisation as a "hybrid" form, and ignoring the fact that pre-eighteenth-century narratives were mostly written as poetry. It also fails to consider that narrative and lyric modes can and do coexist across all literary genres. In a 2006 article on the subject of narrative-lyric interplay, Heather Dubrow argues that "rather than blocking narrative, lyric often enables it" (261). In Experiencing Fiction (2007) James Phelan identifies three modes: narrative, lyric and portraiture, which do not operate in isolation but are often found together, and isolates examples in both poetry and prose fiction 
(Experiencing Fiction). Furthermore, a variety of studies have focussed on the presence of narrative within lyric poetry, and/or vice versa. ${ }^{4}$

Few full-length studies have been devoted to interactions between narrative and verse form. Clare Kinney's Strategies of Poetic Narrative (1992) analyses Chaucer's Troilus and Criseyde, Spenser's Faerie Queene, Milton's Paradise Lost, and Eliot's The Waste Land. Her study considers the use of metrical and stanzaic forms as well as metaphorical language, lyrical qualities, and author relationships to source texts. She describes a poetic narrative as "a text in which the energies directed towards structuring content on an extended scale and in a unified and significant manner are entangled with and perhaps even reconfigured by the local pressures exerted by poetic form" (9), suggesting that formal patterning, such as the arrangement of the line, stanza and couplet, is "not so much a framing device for the unfolding of a distinct, separable 'plot' as a kind of emplotment in its own right" (10). Linda Weste's 2012 doctoral dissertation analyses a range of verse novels in English, finding a wide variety of relevant and productive interactions between poetic and narrative strategies in the discourse of verse novels.

Several full-length studies, although not devoted to the relationship between narrative and verse form, discuss it in some detail. In Milton's Grand Style (1963), Christopher Ricks argues that the use of iambic pentameter in Paradise Lost contributes to meaning rather than obscuring it. He suggests that the line endings are of significance in that they create suspense (47), and also that, if the lines are rearranged into sense units, they lose their "precision and emphasis" (100). In Making Tales (1984) Don Bialostosky discusses the importance of versification in a reading of Wordsworth's Lyrical Ballads, stating, in Bakhtinian terms, that the reader of metrical language "should read it dialogically, construing and reconstructing from its differentiated emphases the values of and relations among the diverse but similarly human narrator, hero, and reader it represents" (55).

A variety of further studies add weight to the argument that verse form is an integral, rather than an incidental, component of a narrative poem. In a series of papers published in 2003-04, Catherine Addison analyses the effect of the stanza on poetic

\footnotetext{
${ }^{4}$ Delmaire; Hühn "Plotting"; Hühn and Kiefer; Hühn and Sommer; Morgan Narrative Means, Lyric Ends.
} 
narrative in Dante, Tasso, Chaucer and Spenser ("Little Boxes"); Byron's use of the narrative stanza ("Heritage"); and the use of ottava rima by a range of writers from Ariosto to Alan Wearne (“Ottava Rima”). In her study of the stanza, she states: "a study of poetry's shape or form . . . has at times been criticized as 'empty formalism' because it does not focus first and foremost on linguistic meaning. It is seen metaphorically as a measuring of containers" ("Little Boxes" 140). However, she argues:

Writing a story in verse is not just a case of decorating with verbal felicities a meaning that is already "there" or that could be more simply communicated in prose. The verse exerts a determining force on crucial aspects of meaning, including ... on narrative progression, on the narrator's voice and its transitions, and on the genre to which the narrative can aspire (140).

In a 2000 study of Milton and Marvell, John Creaser states that seventeenthcentury poets "were as aware as any that verse-form is embodied meaning, not just an envelope" (1). Michael D. Hurley, in a 2005 study of Dante's Divina Commedia, argues that a non-aesthetic approach to the poem is inadequate (321). Elaborating on this, he explains that terza rima represents a divine order, but also the process of revelation, as the protagonist progresses on his journey (323). Andrew J. Bennett's 1992 article on Wordsworth suggests that this poet's narrative trajectory was derived from his idiosyncratic manner of walking (150-151), and that the rhythm of walking itself translates into the rhythm of language (147).

Most of the works these studies are concerned with are pre-twentieth-century poems written in rhyming and/or metrical forms. These forms encompass a vast and variable body of poetry, providing opportunities not only for the comparison of time periods but for the analysis of the differing effects of metrical structures, rhyme schemes and stanzaic patterns, amongst other things. A study of contemporary poetry must take into account the fact that the majority of English-language poetry published during the last fifty years is written in some form of "free verse" - which can be defined as "distinguished from meter by the lack of a structuring grid based on counting of linguistic units and/or position of linguistic features" (Wesling and Bollobás 425). However, although contemporary poetry is less likely to use regular schemes, rhyme 
and metre are often present, and their effects must not be discounted. Annie Finch's The Ghost of Meter (1993) shows that "numerous lines of free verse can be read fruitfully in terms of the metrical code" (30); Donald Wesling's The Chances of Rhyme (COR, 1980) identifies that free verse "has by no means abandoned rhyme" (51). The case studies to follow will investigate the role these devices play in works largely composed in free verse.

The following sections outline the theories and the terminology used in analysing the case study texts. Section 1.5 introduces the case studies within the localised contexts of Australian and New Zealand poetry, explaining the reasons for focussing on this region and for selecting each text; 1.6 introduces the critical methodology used in the analysis of the texts. 


\subsection{Narratology and its relationship to poetry}

Within the field of narrative theory, in particular its subfield narratology, the relationships of genre and medium to narrative have historically been considered unimportant. It is widely acknowledged that narrative exists in a variety of media: as Barthes puts it in his 1975 "Introduction to the Structual Analysis of Narrative", "Among the vehicles of narrative are articulated language, whether oral or written, pictures, still or moving, gestures, and an ordered mixture of all those substances" (237). However, it has been identified that narrative theory has concerned itself almost exclusively with fiction, rather than historical or factual narrative (Fludernik "Conversational" 68; Genette et al. 755; Ricoeur 13), and that written media have been privileged over non-written (Wolf "Cross the Border" 82; Ryan "Theoretical" 1). Furthermore, the object of the majority of narratological studies has been narrative structures in themselves, rather than the relative qualities of different narratives, or their respective media. In his 1964 essay "Le Message Narratif", Claude Bremond claims that a narrative message is "independent of the techniques that bear it along. It may be transposed from one to another medium without losing its essential properties" (trans. and qtd. in Chatman Story and Discourse (CSD) 20). Gerald Prince, a self-described "restrictive narratologist", has claimed as recently as 2003 that the study of the particular use of one medium or another is "narratologically irrelevant" ("Surveying Narratology" 9).

However, in the last few decades, transmedial and transgeneric approaches have expanded, both to identify narratives in media other than prose fiction, and to take into account the relationships between narrative and medium. In her introduction to a 2005 collection of essays on transmedial narratology, Marie-Laure Ryan observes:

We no longer believe that all media offer the same narrative resources and that all stories can be represented in media as different as literature, ballet, painting and music. Nor do we believe that the migration of a story from a medium to another does not present cognitive consequences. A core of meaning may travel across media, but its narrative potential will be filled out, actualized differently when it reaches a new medium. ("Theoretical" 1) 
While poetry falls under the media category "literature", narratological analysis of poetry is often categorised under "transgeneric" narratology (Nünning 252; Hühn and Sommer 229), reinforcing the distinction between poetic and prose narratives. It can also be assumed that the issues for transgeneric narratology are similar to those for transmedial narratology, in that different genres may also present differing cognitive consequences. The same material presented in a play, a novel or a long poem, must also, logically, be “actualized differently”. In a 2003 essay, Angsar Nünning explains:

The as yet undertheorized and unwritten narratologies of drama, poetry, and visual narratives will not only test the validity and rigor of previously developed narratological models and categories, but may well affect the models produced by narratology, resulting not just in terminological modifications and elaborations, but in a revised or extended transgeneric and/or transmedial narratology. (252)

In a 2005 study, Peter Hühn suggests that mapping narratology onto poetry is useful because of existing problems that have been identified in poetry criticism, namely that it is "largely intuitive, eclectic and lacking systematic organisation" ("Plotting" 147). He argues that "the more comprehensive scope and highly developed status of narratology as well as the discriminatory capacity of narratological terminology will both offer a fresh impetus to the theory of poetry and suggest new practical methods for the analysis of poems" (147). Hühn's studies are a useful point of reference for an investigation of narrativity in poetry; however, they do not venture into any sustained consideration of the significance of verse form. 


\subsection{Defining narrativity}

In its exploration of the narrative aspect of long poems, this study centres on the concept of narrativity. A term used to describe the properties that make a text or utterance narrative, narrativity is one of the central concerns of contemporary narrative theory. Criteria for narrativity are varied. One is mediacy, or the presence of a narrator. ${ }^{5}$ This was a defining feature in classical narrative theory but has since been called into question because it appears to exclude plays, films, comic strips and non-verbal media. On the other hand, Seymour Chatman argues in Coming to Terms $(C T T, 1990)$ that a narrator in the broad sense can either "tell" as in literature, or "show", as in theatre and film (113). A widely accepted criterion is temporality, or a sequence of events in time, ${ }^{6}$ although in some cases depiction of a single event suffices (Abbott 13). Some theorists require the "eventfulness" or "tellability" of the events depicted. ${ }^{7}$ Causal relation between the events is sometimes required (Richardson 170, Ryan "Theoretical" 4; Sturgess 52); which is the basis of E.M. Forster's well-known 1927 distinction between story and plot (116); some argue that a reader will infer causality without its being stated (CSD 46; Rimmon-Kenan 18; Schmid 20). Plot is sometimes named as a criterion (Bremond 390; P. Brooks 5; Wolf "Cross the Border" 84), while others, taking into account the lack of teleology in many modern and postmodern texts, dispense with this requirement. A key proponent of this approach is Monika Fludernik, whose Towards a Natural Narratology (TNN, 1996) puts forward the alternative criterion "experientiality", defined as "the quasi-mimetic evocation of 'real life' experience" (12). Rather than plot, narratives require a "human (anthropomorphic) experiencer" (13).

Some definitions of narrative are simple and relatively open-ended, such as Prince's 1982 definition: "the logically consistent representation of at least two asynchronous events that do not presuppose or imply each other" (Narratology 4). Such minimal definitions can present problems of classification: Werner Wolf argues that Prince's definition is a weak one which "could . . . also apply to a recipe" ("Cross the

\footnotetext{
${ }^{5}$ Genette Narrative Discourse (GND) 29; Bal 5; Phelan 3; Scholes and Kellogg 4; Smith 232; Stanzel 4.

${ }^{6}$ CTT 8; Prince Narratology 4; Ricoeur 3; Rimmon-Kenan 18; Sternberg 901; Schmid 17.

${ }^{7}$ Bruner 11; Hühn "Functions and Forms" 143; Leitch 117; Lotman 233; Ochs and Capps 23.
} 
Border" 85). Other definitions are more complex. In a definition developed in 1992 and subsequently refined, Ryan offers a "cognitive template" of narrative, made up of three minimal criteria: 1, a narrative text must create a world and populate it with characters and objects; 2, the narrative world must undergo changes of state that are caused by physical events; 3 , the text must allow the reconstruction of an interpretive network of goals, plans, causal relations and psychological motivations ("Modes" 371). The changes referred to in the second criterion must be "not fully predictable" and the changes "non-habitual": either "accidents" or "deliberate actions by intelligent agents" ("Theoretical" 4). The third condition "gives events coherence, motivation, closure, and intelligibility and turns them into a plot" ("Theoretical" 4). In the case studies to follow I assess the narrativity of each text against Prince's and Ryan's definitions. I also consider the issues of eventfulness and tellability.

Some statements described by Prince as narrative - for example "Mary drank a glass of orange juice then she drank a glass of milk" (Narratology 2) - are events by common definition, but hold little interest for the reader or listener. To clarify this issue, Hühn's 2005 discussion of eventfulness differentiates between two types of event:

Event I involves all kinds of changes of state, whereas event II concerns a special kind of change that meets certain additional conditions in the sense, for example, of being a decisive, unpredictable turn in the narrated happenings, a deviation from the normal, expected course of things. ... (“Event" 81)

Hühn's discussion of the latter event type draws on the works of Jurij Lotman (1977) and Jerome Bruner (1991). Lotman defines an event as "the shifting of a persona across the borders of a semantic field" (234). Lotman's "semantic field" denotes a particular set of norms and values, separated by a boundary or border from an opposing order with different norms. An event "always involves the violation of some prohibition" (236), examples being Romeo and Juliet falling in love, or Dante descending into the world of the dead. Texts without plot establish a particular world without violating its boundaries: the movement of a plot is enacted by "the crossing of that forbidden border which the plotless structure establishes" (238). Drawing on Roger Schank and Robert Abelson's theory of "scripts" for canonical behaviour in a given situation, Bruner 
argues that it is the violation of these expected behaviours that makes a tale worth telling, a formula he terms "canonicity and breach" (11). The breaches themselves can be highly conventional, and strongly influenced by narrative traditions - examples being the betrayed wife or the cuckolded husband (12).

In one of the more systematic discussions of eventfulness to date (2003), Wolf Schmid discusses seven criteria a change of state must display if it is to be described as an event. Two are absolute preconditions: reality and resultativity - in other words, changes must actually occur (rather than being dreamed) and they must reach completion (24). Five further criteria are relative or gradational: relevance, unpredictability, persistence, irreversibility, and non-iterativity (26-29). Schmid makes clear that eventfulness relates to the story-world: events may be unpredictable to characters even when they are highly predictable to readers (26). Elsewhere, Hühn makes the valuable point that eventfulness is "context-sensitive and consequently culturally as well as generically specific and historically variable" ("Functions and Forms" 143). A well-known example of context-specificity, given by Mary Louise Pratt, is the statement "Bill went to the bank today", which would normally be unspectacular, but is surprising if Bill is a miser who keeps his money in a sock (135).

The term "tellability" and the related concept "point" date from William Labov and Joshua Waletzky's 1967 study of oral narrative, and have since been extended to apply to written narrative. Tellability, also termed "reportability" (Labov 370; Prince Dictionary of Narratology (DON) 83) or "narratability" (Prince "Narrativehood" 23) can be defined as a quality that makes a narrative worth reporting or telling. The "point" of a narrative, in Labov's terms, is its raison d'être: why it is being told. He explains: "There are many ways to tell the same story, to make very different points, or to make no point at all" (366). Pointless stories are met with the rejoinder "So what?", whereas a skilled narrator will aim to elicit a response such as "He did?" (366). Tellability and point are usually indicated by evaluative devices, such as commentary by a narrator or reflections by characters (Labov 366; Prince "Narrativehood" 23; Ryan "Tellability" 589).

While some poems contain highly eventful or tellable stories, the interplay of narrative and lyric modes in poetry means that further concepts of eventfulness must be considered. Hühn describes plots in (lyric) poetry as "constituted by mental or 
psychological incidents, such as perceptions, imaginations, desires, anxieties, recollections or emotions" ("Plotting" 149). Such narratives, often found in confessional poetry, but also in many modernist lyrics and their precursors, would be of variable interest outside the context of the poem. "I went for a walk by myself and saw some daffodils" or "I saw a red wheelbarrow" are narratives unlikely to excite a listener if told outside the context of the poem. However, a reader is likely to recognise the significance of these narratives when they are embedded in poems. As Monique Morgan writes of the ice-skating episode in Wordsworth's The Prelude, "when the emotional and spiritual impact on Wordsworth is taken into account, the episode is of great importance" ("Narrative Means to Lyric Ends" 311). The killing of Mickey in Dorothy Porter's The Monkey's Mask is eventful becausea border has been crossed; the sighting of a wedge-tailed eagle in John Kinsella's Divine Comedy: Journeys Through a Regional Geography is eventful because of its significance to the poet, as well as the symbolic importance of the eagle in Dante's Divina Commedia.

The term "eventfulness" is used in quite a different sense by Wesling in The Scissors of Meter (1996), in discussing prosody. In Wesling's sense, "eventfulness" relates to the "complexity and density of deviance from syntactic and other norms" (61), providing a "pleasurable frustration functional to the enjoyment of rhythm and the construal of meaning" (61). This considered, a narrative poem can be seen to employ multiple types of eventfulness: narrative, lyrical, and prosodical, and may deploy these in complementary and/ or contrasting ways.

As with other narrative genres and media, it is useful to consider narrativity in poetry as a scalar phenomenon. The concept of scalar narrativity was first articulated by Prince in 1982 (Narratology 145), but has been addressed by a number of theorists since. ${ }^{8}$ Considered against a specific definition of narrative, such as Prince's or Ryan's, a text may meet all of the criteria, some of them, or none. The more criteria it meets, the more likely it is to be generally accepted as narrative; however, not meeting a particular criterion does not mean that a text displays zero narrativity. David Herman's Story Logic (2002) describes the scale of narrativity as "the continuum stretching from

\footnotetext{
${ }^{8}$ Herman 101-105; McHale "Weak Narrativity"; Phelan 215; Ryan "Modes" 369; Wolf "Cross the Border" 86.
} 
sequences that are nearly impossible to process as narratives to those immediately identifiable as such" (101). Prince claims:

The degree of narrativity of a given narrative depends partly on the extent to which that narrative fulfils a receiver's desire by representing oriented temporal wholes ... involving a conflict, consisting of discrete, specific, and positive situations and events, and meaningful in terms of a human(ized) project and world. (DON 65)

Furthermore, different texts may display different types, as well as different degrees of narrativity. Ryan suggests narrative should be regarded as a "fuzzy set, defined at the centre by a solid core of properties, but accepting various degrees of membership" ("Narrative" 345). Elsewhere, she describes different "modes" of narrativity, including "simple", "multiple", "complex", "braided", “diluted", “embryonic", "figural", "instrumental", "deferred" and "antinarrativity" ("Modes" 371$381)$.

A consideration of narrativity also needs to take into account other text types which may stand in contrast with, or coexist alongside, narrative. In the case of poetry, the traditional opposition, as discussed above, is between narrative and lyric. While it has been clearly shown that many lyric poems are also narrative, the two text types may be identified within poems or sequences. Definitions of what constitutes lyricality are as variable as those concerning narrativity. Theorists of the lyric often make reference to relative brevity (Frye “Approaching” 31; Culler "Why Lyric?” 203; Abrams 153), although it is acknowledged that this is not universally applicable (Wolf "The Lyric" 25; Johnson 714). In its original meaning, a lyric was composed to be sung; its musical aspect is highlighted by James William Johnson, who writes in his entry in the New Princeton Encyclopedia of Poetry and Poetics (1993): “The irreducible denominator of all lyric poetry must ... comprise those elements which it shares with the musical forms that produced it" (714). The presence of a single speaker or lyric "I" is often referred to (Abrams 153; Blasing 2; Cameron 23), the addressee to whom this "I" speaks being variable. Northrop Frye, in Anatomy of Criticism (1957) conceives of the lyric as an "overheard" utterance: "The lyric poet normally pretends to be talking to himself or to 
someone else: a spirit of nature, a Muse . . . a personal friend, a lover, a god, a personified abstraction, or a natural object" (Anatomy of Criticism 249). Considering a range of criteria and how these may be challenged, Wolf's 2005 essay on the lyric proposes a prototypical model, allowing for gradation of its different features, such as length or versification ("The Lyric"). Such a gradational approach is helpful when considering lyric alongside narrative, as there appears to be no absolute cut-off between the two modes.

As a generalisation, Phelan suggests that while narrative can be characterised as "somebody telling someone else on some occasion and for some purpose(s) that something happened" (3), lyric is "somebody telling someone else (or even himself or herself) on some occasion for some purpose that something is - a situation, an emotion, a perception, an attitude, a belief" (22) or telling someone "about his or her meditations on something" (22). Similarly, in a 2008 article, Jonathan Culler differentiates between the two modes by stating that "If narrative is about what happens next, lyric is about what happens now" ("Why Lyric?" 202). ${ }^{9}$ Both of these distinctions suggest lyric timelessness. I use the term "lyric" in a broad sense, allowing for the description of long poems as lyric if they display qualities of lyricality, such as atemporality or a focus on emotion or meditation above action.

Other text types besides narrative and lyric may be used within a single text. Alongside narrative, Chatman proposes the types description and argument. In his view, narrative "entails movement through time", having an "internal time sequence", descriptions "render the properties of things", and arguments "attempt to persuade an audience of the validity of some proposition" (CTT 9). Importantly, he notes that these types "routinely operate at each other's service"; for example, the narrator of a novel may also describe or argue (10). Fludernik's 2000 discussion of genre refines Chatman's theory by identifying five macrogenres: narrative, argumentative, instructive, conversational and reflective ("Genres" 282). She ascribes poetry to the reflective macrogenre; however, it can be postulated that any of the other four may be operative in a given poem.

\footnotetext{
${ }^{9}$ Culler acknowledges his comment as a paraphrase of a comment by Alice Fulton concerning fiction and poetry.
} 
Texts nearer to the non-narrative end of the scale of narrativity may still be interpreted as narratives by readers. Fludernik calls this narrativization, or "the process of . . making something a narrative by the sheer act of imposing narrativity on it" (TNN 34). Fludernik's concept is based on Culler's "naturalization", and occurs when readers are faced with difficult or inconsistent texts. Readers will "cast about for ways and means of recuperating these texts as narratives" (34). The emphasis on the reader affirms that narrativization is a process carried out regardless of authorial intent. Interestingly, Fludernik preserves a distinction between narrative and poetry by stating that where narrativity can no longer be recuperated, the narrative genre merges with poetry (36). As this thesis rests on the premise that poetry can be narrative, and narratives can be poetry, I cannot agree with such a concept of genre. Furthermore, if a text is unable to be narrativized, this does not mean it is a poem: it could be any number of other things, such as a product catalogue, a grocery receipt or a mathematical equation.

A familiar case of the narrativization of a lyric poem is that of The Waste Land. Regardless of Eliot's designs for the work, critics have often supplied it with a plot. Cleanth Brooks's 1948 reading interprets the poem within the frame of the grail legend suggested by Eliot's attribution of the symbols of the poem to Jessie Weston's From Ritual to Romance. He identifies a "protagonist" with a "private obligation to fulfil" (162) in relation to the preservation of faith. James Miller (1977) presents a reading of the poem as an elegy to Eliot's friend Jean Verdenal, in light of Eliot's troubled marriage and a possible romantic attachment to Verdenal. Calvin Bedient (1986) takes the view that a single protagonist is responsible for all the voices in the poem, basing much of what he describes on overheard conversation (ix). This protagonist is a version of Eliot himself, "daring to break with society and women and cut a road to hermitic saintliness through his pain” (5). In a different vein, Martin Rowson's graphic novel The Waste Land (1990) adds a protagonist intriguingly named "Chris Marlowe" who works as a detective trying to solve a classic whodunit, but also attempting to figure out the meaning behind the poem. In his 2010 critique of Rowson's novel, McHale suggests that Eliot and Pound had "drastically de-narrativized" the original, and Rowson has "renarrativized" it by filling the gaps left by the lost narrative material ("Narrativity" 34). 
A separate definition for the term "narrativization" - which I will also refer to in the course of this study - is given by White in an essay originally published in $1980 .{ }^{10} \mathrm{In}$ White's sense, narrativization is the organisation by the historian of factual material into a coherent, causally connected sequence of events which achieves narrative closure, often provided by a moral. Such coherence is produced by the historian rather than being inherent in the events themselves:"[i]t is because real events do not offer themselves as stories that their narrativization is so difficult" (4). Narrativization in White's sense is an issue faced by any poet working with autobiographical, historical or other nonfictional material, as the case studies on Tusiata Avia and Bill Sewell demonstrate.

\footnotetext{
${ }^{10}$ Fludernik navigates the issue of having two meanings applied to the same term by re-naming White's concept "storification" (TNN 34).
} 


\subsection{Segmentivity and verse form}

In my analysis of verse forms in contemporary long poems I focus on the physical aspect of segmentation. Using the term "verse form" in a broad sense to encompass visual (printed) and aural aspects of a poem, I consider various levels at which poetry may be segmented, including book, section, individual poem (or canto), stanza, line, and metre.

The term "segmentivity" was coined by poet Rachel Blau DuPlessis, as a defining feature of poetry. In her article "Manifests" (1995), she claims:

Poetry is the kind of writing that is articulated in sequenced, gapped lines and whose meanings are created by occurring in bounded units precisely chosen, units operating in relation to chosen pause or silence. Thus a fusion of reading, observing, and listening techniques are required to decode it. ... In short, all the meanings poetry makes are constructed by segmented units of a variety of sizes. ... Therefore, I propose that segmentivity - the ability to articulate and make meaning by selecting, deploying, and combining segments - is the underlying characteristic of poetry as a genre. (51)

DuPlessis's concept of segmentivity has been linked to analysis of narrative poetry by McHale ("Beginning"; "Narrativity"), who draws a parallel between this and John Shoptaw's notion of "countermeasurement."11 In a study of John Ashbery and Charles Bernstein, published the same year as "Manifests", Shoptaw defines a poem's measure as "its smallest unit of resistance to meaning" (212). Measure occurs at the level of "the character, the word, the phrase, the line, the sentence, and the section" (212). Countermeasurement occurs as measures overlap: "in conjunction with, and counter to, other measures" (213) - for example, a poem may be measured by the line and countermeasured by the sentence (213). Wesling considers the counterpoint of grammar and metre extensively in The Scissors of Meter (1996), using the term (taken from Peter

\footnotetext{
${ }^{11}$ It must be noted that this application is not without its detractors. In a 2014 paper, Bruce Heiden claims that a focus on the segmentation of a poem is misleading because "verse-phrasing and syntactical phrasing are usually complementary" (274), citing Spenser and Milton as examples. In response McHale argues that "these two approaches to verse - as segments divided by pauses vs. segments joined at junctures - are strictly complementary: two ways of capturing the same phenomenon" ("Thinking" 285).
} 
Wexler) "grammetrics". In regard to free verse, he applies the term "grammeasures", explaining that in this case "the relation of sentence to line will be a measure more crucial than in metered verse, which has in the foot or stress maximum a determining unit smaller than the line" (Scissors of Meter 79).

It can easily be argued that segmentivity is not the only underlying characteristic of poetry as a genre. Furthermore, segmentation is of course not limited to poetry: theatre, film, television, prose fiction and non-fiction, comics and many other genres and media also employ forms of division. McHale's application of segmentivity to poetic narrative has been further extrapolated by Sean O'Sullivan in a 2013 study of serial television, which conceives of contemporary televised serials as "a significant branch in poetry's genealogical tree" (59). The process of moving between sections in a poem has been also compared to cinematic cutting techniques (Hollander 283). Studies of narrative division in other media provide insights into cognitive processes which may be at work between units in poetry. A related phenomenon is the "gutter" in comic strips, as articulated by Scott McCloud: "Here . . . human imagination takes two separate images and transforms them into a single idea" (66). In his 1970 study of the chapter in novels, Philip Stevick describes this narrative division as "one of the most important perceptual means by which we understand fiction" (188). Although parallels can be drawn, the way in which segmentation works in poetry may differ from other genres and media. Furthermore, Chatman has noted that gap-filling in a narrative sense differs from that required by lyric, expository and other genres (CSD 31); it can therefore be considered that multiple types of segmentation may be operable in any given poem.

Segmentation can be used as an aid to narrativity, or as a disruptive or antinarrative device, with all possible variations in between, and combinations of the above. Furthermore, different units of segmentation have different effects on a poem and on its narrativity. As the units range in size from the macro to the micro, so do their effects on the text range from global to local. Divisions into books or sections tend to have an organisational or thematic purpose; divisions into lines or metrical feet may affect interpretation of particular sentences, phrases or figures. These effects may display interactions with one another, such as line-breaks drawing attention to motifs which occur in poems throughout a text. It can also be seen that different units of 
segmentation vary in the degree to which they affect the narrativity of a poem, and the interpretation of the narrative(s) within it. For all the texts under consideration here, I argue that the most important unit of segmentation is the division into individual poems. This division has wide-ranging effects which are elucidated in Part 2. Division into lines, although a focus of much writing on form in poetry over the last century, ${ }^{12}$ can be seen to be of secondary importance: in some cases effected by the patterning of an inherited form, in some cases deliberately worked in order to contribute to meaning, and in others arguably irrelevant.

Verse form can be seen as having two major functions: aural and visual. In inherited forms, the aural function is generally prominent, although the visual function is not without significance. In free verse, the visual function, particularly the devices of the line and what has been termed the "sight stanza" (Berry) takes on a greater importance than in metrical verse. ${ }^{13}$ Visual form has been related to performance and therefore the aural function, for example by Denise Levertov (79-81) and Charles Olson. White space is seen as serving a variety of functions: Olson calls this "space to be held, by the breath" (293); Glyn Maxwell similarly conceives of it as "time" (54). It has also been described as insignificant: Heiden argues "The spaces after and between printed lines of verse have no more significance than those separating letters and words" (273). Certainly white space has no relevance to an oral poem, and a poem with a regular metrical structure can be interpreted as such without being printed with line or stanza-breaks. However, in any consideration of contemporary poetry within the English literary tradition, it must be remembered that many poems, particularly long poems, will seldom be read aloud. Therefore, any effects of visual devices on silent reading must also be considered. Drawing insights from perceptual psychology, Carole Ann Taylor's A Poetics of Seeing (1985) makes the claim that the eye fixes longer at the ends of lines (101). There are multiple ways of profiting from the mental processing of

\footnotetext{
${ }^{12}$ Notable examples include Charles Olson's "Projective Verse" (1950), Denise Levertov's "On the Function of the Line" (1979), Charles O. Hartman's Free Verse: An Essay on Prosody (1980), Marjorie Perloff's "The Linear Fallacy" (1981), Robert Frank and Henry Sayre's The Line in Postmodern Poetry (1988), James Longenbach's The Art of the Poetic Line (2008), and Emily Rosko and Anton Vander Zee's A Broken Thing: Poets on the Line (2011).

${ }^{13}$ Eleanor Berry has described the "sight stanzas" of William Carlos Williams as "more visual than syntactical-phonological in their composition, the shape ... being repeated like a design in block printing" (886).
} 
this slight delay; for example, enjambment can be used to modify or invite new meanings of a word (Kinney 11). Where a line-break splits a word, as in Williams's "red wheel / barrow" (Hollander 110), it may "etymologize" the word and make the reader carry out a meditative act (111).

When interpreting the effects of visual devices, context must also be considered. As Derek Attridge points out in Poetic Rhythm: An Introduction (1995), "When we read prose, we ignore the fact that every now and then the line ends and we have to shift our eyes to the beginning of the next line" (5). Another division seldom, if ever, given critical consideration is that of the page. It is not uncommon in prose texts for a pagebreak to occur mid-sentence at a syntactically disruptive position. While greater care is likely to be taken when typesetting verse for publication, a page-break may still occur mid-stanza, with negligible effect on interpretation. It may be that as readers of contemporary poetry, we train ourselves to attribute significance to stanza- or linedivisions, paying particular attention to end-words or phrases. It can also easily be observed that different poets take different approaches to such divisions. In some cases the same poet will use different approaches in different poems. This means that both within and between long poems or sequences, effects of visual form will vary.

The term "verse" is of course not synonymous with poetry - mnemonic verse and advertising jingles being examples which are patently unpoetic - although most poetry is composed in some form of verse. What distinguishes verse from prose is not universally agreed upon. Some posit metre as the determining feature of verse, and therefore free verse as a form of prose poetry (Turco 5); others argue that the line is what distinguishes the two modes (Brogan 694; Hartman 11). Culler, in Structuralist Poetics (1975) goes as far as to suggest that lineating a piece of journalism "as a poem" substantially alters its effects for readers (161). However, non-poetic texts such as children's early readers or advertising copy are often organised in lines, without being read as poetry. It is therefore helpful to consider that poetry may be composed in either prose or verse, and that the distinction between prose and verse is influenced by a number of factors, including context, genre and the skill of the writer's craft. 


\subsection{Contexts: Contemporary Australian and New Zealand long poems and poem sequences}

Case study texts by six poets have been selected to serve as a basis for the exploration of narrativity and verse form. The texts are long poems or poem sequences ${ }^{14}$ written in Australia and New Zealand during the period 1990-2010. They have been selected to cover a range of genres, as well as varying degrees of narrativity.

Dorothy Porter's The Monkey's Mask (TMM, 1994) and What a Piece of Work (WPW, 1999), along with Alan Wearne's The Lovemakers (2008, first published in two volumes 2001 and 2004), are verse novels. Porter's works follow fairly conventional story-lines, and contain causally connected plots with beginning, middle and end; Wearne's novel involves a number of subplots concerning several central characters alongside a plethora of minor characters, and although events are causally connected, an overall plot is difficult to recuperate. Tusiata Avia's Bloodclot (2009) is a largely autobiographical sequence with a broadly narrative progression, offset by temporal disruption and significant omissions of information. Bill Sewell's Erebus: A Poem (BSE, 1999) and The Ballad of Fifty-One $(B 51,2003)$ are both sequences which feature historical events, although they approach these from a number of angles, rather than simply re-telling what happened. Both could be considered as lyrically rather than narratively ordered. Anna Jackson's The Gas Leak (2006) is a fictional sequence featuring three central characters, in which several potential plots are alluded to, but never fully developed; it can in many ways be seen as antinarrative. Lastly, John Kinsella's Divine Comedy: Journeys Through a Regional Geography $(J R G, 2008)$ takes inspiration from Dante, creating expectations of narrativity; however, I argue that this work is primarily a lyric sequence containing narrative elements.

The texts have also been selected for their approaches to verse form. Some of these texts employ an overall unified form: Kinsella's work is composed in unrhymed, non-metrical tercets throughout; Porter maintains a consistent short-lined form. The Gas Leak is loosely a sonnet sequence. The other texts employ a variety of forms. This

\footnotetext{
${ }^{14}$ Whether a text is described as a "long poem" or "poem sequence" is partly determined by paratextual markers: Bill Sewell, for instance, subtitles Erebus with A Poem. I consider that all of the texts selected for case study here could be adequately described by either term; however, as each text is divided into smaller units which are best described as "poems", "sequence" is often the more logical descriptor.
} 
enables consideration of the effects of different forms, the effects of consistency versus variety, and also the variable results of these differing approaches. All of the texts selected use forms which could be described as free verse, thus providing an opportunity to address the lack of research in regard to narrative poetry written in such forms.

There are several reasons for the selection of texts from a particular time-period and geographical area. These include the relative paucity of scholarship to do with the poetry of this region and time, the relevance to my own creative work - an important consideration given the creative component is the main focus of this thesis - and the importance of narrative within these poetic contexts. Although in a post-colonial setting notions of national literatures are of questionable validity, the poetries of New Zealand and Australia provide a useful context for a study of narrative poetry, as they display distinct historical developments and contemporary trends in this field. It must be noted that in each of these countries there exist older traditions of oral storytelling and poetry amongst their First Nations peoples. These oral traditions, along with those of the wider Pacific region, have continued into the present day and form part of the heritage and influence of many (though not all) contemporary indigenous poets. Within the English literary tradition, poetic narratives in New Zealand and Australia date back to the bush ballads of Banjo Paterson, Henry Lawson and David McKee Wright (among others), the rambling epic of Alfred Domett, and the anonymous poems of sealers and whalers. Terry Sturm suggests that early European poets in New Zealand drew on George Grey's translations of Māori myths as inspiration, Domett being a key example of this (295). Jessie Mackay and Blanche Baughan could be named as further examples.

The narrative impulse in New Zealand and Australian poetry appears to have continued into the present without any significant period of departure. Notable twentieth-century poets who have written extended continuous narratives include James McAuley, Kenneth Slessor, Francis Webb, Denis Glover, Robin Hyde and Allen Curnow $^{15}$. Verse form has also undergone some interesting developments within Australia and New Zealand. An early example is the flowering of the popular ballad in

\footnotetext{
${ }^{15}$ See, for example, Slessor's 'Five Visions of Captain Cook' (1931), Hyde's The Book of Nadath (composed 1937, published 1999), Webb's 'Leichhardt in Theatre' (1947) and 'Eyre All Alone' (1961), Glover's ‘Sings Harry' (1951) and Arawata Bill: A Sequence of Poems (1953), McAuley's Captain Quiros (1964), and Curnow's An Incorrigible Music (1979).
} 
the colonial period. It has been suggested that the ballad "reflected and helped to shape growing national settlement", and was often concerned with justifying European colonisation (Ackland 74).

The idea of a national poetics began to crumble in both countries in the 1960s and 1970s as diverse postmodern, postcolonial, feminist and indigenous voices came to light (Sturm 293), and the effects of globalization took hold (Dobrez 288). The influence of Donald Allen's 1960 anthology The New American Poetry, and in particular of Olson's essay "Projective Verse", have been well documented, ${ }^{16}$ and a formal freedom has at times been equated with political freedom (McCooey 161).

Empirical observation suggests that the long poem has been popular with New Zealand and Australian poets in recent years. Examples cover the range of genres sampled in my case studies, amongst others. One obvious trend is the resurgence of verse novels, which can be defined as "fictional works resembling the realist mainstream novel in all respects except for their mode of discourse, which is verse, not prose" (Sauerberg 439). Originally popular in the late eighteenth to nineteenth centuries, their revival in the late twentieth century is a global trend. Examples have appeared in England, the United States, New Zealand, India, Canada, and South Africa (Addison "Verse Novel" 539); however, the genre has been particularly popular with Australians. Christopher Pollnitz identifies around thirty verse novels published in Australia between the mid-1970s and 2004, "the number accelerating through the nineties into the turn of the millennia" (229). He suggests that Australian poets were pioneers of the trend, with Dorothy Porter's poem “Rat Tower" appearing in 1975, Les Murray's The Boys Who Stole the Funeral in 1980, and Alan Wearne's The Nightmarkets in 1986: all these examples being written prior to or concurrent with Vikram Seth's The Golden Gate, published in 1986 (230-231). Australian writers have certainly been important innovators in the revival of the verse novel, whether or not they have been its leaders. Although the reasons for this trend are uncertain, it has continued unabated to the present day. Alongside the works of Porter, Murray and Wearne, other notable Australian verse novels include Matt Rubinstein's Solstice (1994), Pi O's 24 Hours (1996), Paul Hetherington's Blood and Old Belief (2003), and young adult writer Steven

\footnotetext{
${ }^{16}$ Dobrez 289; Green “The Fifties” 157; Loney 95; Manhire 77; McCooey 161; Minter.
} 
Herrick's Love, Ghosts and Nose Hair (1996) and By the River (2004). In an essay on New Zealand poet Anne Kennedy, Anna Jackson describes how, at the 2001 Queensland Poetry festival, "every young poet I talked to had written, or was writing, a verse novel" (173). Verse novels written by New Zealanders include Diane Brown's 8 Stages of Grace (2002), Kennedy's The Time of the Giants (2005), and Albert Wendt's The Adventures of Vela (2009). The long poem in general, however, has centred on different trends in New Zealand. The primary fixation of contemporary New Zealand poets writing long poems appears to be history; both local and international. A notable precedent was Allen Curnow's "Moro Assassinato" (1979). More recent examples include Chris Orsman's South (1996) and Black South (1997), Bill Sewell's book-length works, Alistair Te Ariki Campbell's Maori Battalion (2001), Robert Sullivan's Captain Cook in the Underworld (2002) and Cassino: City of Martyrs (2010), Amy Brown's The Odour of Sanctity (2013), Chris Tse's How to be Dead in a Year of Snakes (2014) and my own Dear Neil Roberts (2014). Some of these historical works also function as political commentary: Sullivan's Captain Cook is a critique of colonisation; Cassino is, among other things, a meditation on war. Both Sewell's works contain an identifiable political stance.

Contemporary Australian historical long poems include Dimitris Tsaloumas's Six Improvisations on the River (1995), Jordie Albiston's Botany Bay Document: A Poetic History of the Women of Botany Bay (1996) and The Hanging of Jean Lee (1998), and Jessica Wilkinson's Marionette: A Biography of Miss Marion Davies (2012) and Suite for Percy Grainger (2014). Kate Middleton's Ephemeral Waters (2013) is perhaps a work of natural history; the poet observing environment and people along the Colorado river. Along with many of Kinsella's works, and those of various other poets, it could be described as an ecopoetic sequence.

Autobiographical long poems feature in both countries: examples include Anne Kennedy's Sing-Song (2003), Luke Davies's “Totem poem” (2004) and Interferon Psalms (2011), Jenny Bornholdt's The Rocky Shore (2008), and Jessica Le Bas's Walking to Africa (2009). The sequence on family history or memoir has also been popular: examples include Lynn Jenner's Dear Sweet Harry (2010), Jordie Albiston's The Book of Ethel (2013), Fleur Adcock's The Land Ballot (2014), Marty Smith's Horse With Hat (2014), Zarah Butcher-McGunnigle's Autobiography of a Marguerite 
(2014) and Diane Brown's Taking my Mother to the Opera (2015). Avia's Bloodclot employs a different structure in that it uses a Samoan legend as a frame for a representation of the author's life to date. Autobiographical content has often been rendered in the lyric mode, and many of these poems could also be described as long lyric poems, verse meditations or even verse essays. 


\subsection{Critical methodology}

In approaching a text, I assess three key elements: its narrativity, its segmentivity and the relationship between the two. As explained earlier, segmentation can be used to very different ends: some narrative, some less so, some decidedly antinarrative. Furthermore, the variety in genre of the texts under consideration means that in some cases other factors need to be taken into account. I also consider the importance of narrativization (in both Fludernik's and White's senses), and the presence of other text types or modes, particularly lyric and argument.

In assessing narrativity I first consider each text against two well-known definitions of narrative: Prince's "the logically consistent representation of at least two asynchronous events that do not presuppose or imply each other" (Narratology 4), and Ryan's three-part definition. Ryan's third criterion "the text must allow the reconstruction of an interpretive network of goals, plans, causal relations and psychological motivations" ("Modes" 371) is particularly useful in determining to what extent a long poem exhibits plot. I also consider the eventfulness and/or tellability of the narratives contained within or alluded to in poems, bearing in mind the importance of context sensitivity and the differences between eventfulness in a narrative and in a lyric sense.

In assessing segmentivity I consider the levels at which the text is segmented: as described above, these include book, section, individual poem (or canto), stanza, line, and metre. I also consider the use of aural devices, such as rhyme, assonance and consonance, syntactic structures such as anaphora and parallelism, and the use of inherited forms. In order to avoid privileging one formal approach over another, I do not use ideologically-driven descriptions of form, such as "formal constraint" or "fixed form"; nor oppositions, such as "open" and "closed" verse. I use the term "inherited form" to describe forms with a known system of patterning, such as the sonnet, villanelle, ballad or heroic couplet - what Levertov describes as "reusable form" (76). For want of a better term in describing forms that do not follow these systems of patterning, I use the term "free verse", according to Wesling and Bollobás's definition cited above. Alongside the formal aspects of a poetic text, I consider the relevance of paratexts - defined by Genette as “verbal or other productions, such as an author's 
name, a title, a preface, illustrations" which surround and extend a text "in order to present it" (Paratexts 1). The distinction between a main text and its surrounding material is particularly interesting in reference to works of poetry, in which there is likely to be a more marked contrast between the verse form of the main text and its prose paratexts than would obtain in a prose work. Of particular importance in the texts under consideration are prefaces and endnotes which contribute to reader narrativizations. In some cases epigraphs, jacket copy and/or cover artwork also play interesting roles.

In assessing the relationship between narrativity and segmentivity, I consider each unit of segmentation as it relates to narrativity and/or narrativization, and to narrative versus other text types. In each case the relative importance of these considerations varies: for example, narrativization is of greater importance in texts containing factual material or those positioned toward the less narrative end of the spectrum. The relationships between units of segmentation are also investigated where relevant.

A further consideration is that of the potential differences between the text in question and its hypothetical prose counterparts, whether novels, autobiographies, or works of history. An in-depth comparison of a specific related prose work with each text has not been the primary focus of this work; however, this would be an interesting investigation for further research. 


\section{Part 2: Case studies}

\subsection{Dorothy Porter's The Monkey's Mask and What a Piece of Work}

Dorothy Porter (1954-2008) wrote five verse novels, as well as several collections of poetry, young adult fiction, and opera libretti. In this case study I discuss two of Porter's verse novels: The Monkey's Mask and What a Piece of Work, investigating how segmentation through verse form can be used in support of narrativity.

\subsubsection{Narrativity}

Both of these works display a high degree of narrativity, clearly fulfilling all criteria for being narrative as articulated by Prince, and by Ryan. Each novel contains a sequence of events, and, importantly, these events are arranged in a coherent time sequence. In each novel a world is created and populated with characters; these characters remain consistently identifiable throughout the text. Changes of state occur which are caused by physical events. Each novel is narrated in the first person by its central protagonist, to whom goals, plans and psychological motivations are ascribable. Furthermore, the key events taking place can be described as highly eventful, as they clearly involve border crossings or breaches of canonical scripts. In The Monkey's Mask Mickey, an aspiring poet, is killed by her poetry lecturer's husband, and Jill, a private investigator attempting to solve Mickey's disappearance, is seduced by the lecturer. In What a Piece of Work the protagonist Peter suffers regular flashbacks to the incestuous affair he had with his mother; one of the greatest border-crossings that can occur in fiction. Peter has a sexual relationship with a patient, forces patients to perform sexual acts on him, tortures patients with electro-convulsive therapy, and leaves the institution he is in charge of unsupervised for a night, during which it burns down and many of the patients are killed. It can be seen that individual events within each work, as well as the overall plot of each, are highly tellable. The Monkey's Mask, in particular, with its fairly standard detective-story plot, could be positioned close to Herman's "upper limit" of narrativity, beyond which the tellable gives way to the stereotypical (103). However, it 
does not cross this threshold, meaning that, at the level of plot, the novel is entertaining and suspenseful. Here it is worth noting that The Monkey's Mask was made into a feature film in 2000 (with a screenplay written by New Zealand poet Anne Kennedy); one of very few contemporary poems to have received this treatment. Its deployment of the high tellability of detective fiction can also be seen as a deliberate, ironic play on established norms of high and low culture, and the place of poetry within these.

\subsubsection{Units of segmentation and their function in relation to narrativity}

In both of these novels, the key units of segmentation in evidence are the section, the individual poem (usually around 20-30 lines long), the stanza and the line. The poems are written in free verse, with stanzas of irregular length. Regular metrical patterning is absent; however, rhyme and other aural devices such as assonance and alliteration are regularly employed, and at times a stress pattern is discernible. Porter's lines are characteristically short: one- or two-word lines being frequent, which suggests that segmentation at the level of the individual word is also of significance.. These different units of segmentation serve different functions in relation to narrative.

Firstly, the titled sections aid the organisation of story into plot. They serve a similar function to the chapter in prose fiction: to shape the story material into what Stevick calls "intelligible and satisfying forms" (10). However, the sections are not entirely analogous to typical prose chapters. They are variable in length, ranging from 11 to 31 poems in What a Piece of Work, and from 5 to 41 poems in The Monkey's Mask. The content within these sections is diverse: they cover large chunks of plot and often move between settings, or from internal thought to external action, in a way that prevents extended focus on any particular incident. This suggests that while sections are structurally useful, the more important division in terms of plot development is that of the individual poem. The role played by the sections is largely a thematic one. In The Monkey's Mask, the third section, "Full moon", depicts the protagonist falling in love, while the third from the end, "The waning moon", deals with the end of love. In What a Piece of Work, the sections highlight the novel's alchemical conceit. Their titles including "Gold", "Red", “The Peacock's Tail", “The Dragon", and "Black" - are names of alchemical stages. The basis of the plot is the undoing, or alchemy in reverse, 
of the protagonist's efforts at Sydney's Callan Park Hospital. Thus the stages run from "Gold" through to "Black". Two of the book's epigraphs shed light on this conceit. One, from Mark Haeffner's Dictionary of Alchemy, reads "Latin alchemists nearly always commence with the nigredo, the dark, black stage of melancholy, death and mortification" (WPW xii). Another is taken from Jung's Mysterium Conjunctionis: "For it was clear to the more astute alchemists that the prima material of the art was man himself" (xii). The protagonist's name, Peter, draws on the biblical association (albeit metaphorical) with "rock" - making a link between the man and the alchemist's base material. At the beginning of the novel, we observe a man already deeply flawed and troubled begin a new job with "gold" intentions, as illustrated in "Fay's visit to my work":

Give me five years.

I won't rest

until there's not a sad

or sorry mind

I can't fix. $(49,48-52)^{17}$

By the end of the novel he has given in to "black" cynicism and moral failure, stating:

\author{
I don't have to explain \\ why I've had enough \\ of public duty, poor pay \\ and the ravings and the piss \\ and incessant shit of shot minds. $(274,8-12)$
}

Through the progression of the titled sections, Peter's flawed character is also gradually exposed to the reader; in Porter's own words, he "goes from pretty bad to heinous worse" (Porter "It's too hard").

\footnotetext{
${ }^{17}$ As the texts under consideration in this thesis are book-length works being discussed in their entirety, I have used the format (page number, line number(s)) for all citations of poetry.
} 
Segmentation of the narratives into individual poems provides a variety of effects. One of these concerns narrative movement, or the correspondence between story-time and discourse-time. Genette describes four types of movement: ellipsis (where a non-existent section of discourse corresponds to some duration of story); summary (where discourse-time is less than story-time); scene (where discourse- and story-time are equal); and pause (where a section of discourse corresponds to nonexistent story-time) (GND 93-94). Summary, although occupying "a limited place in the whole corpus of narrative," (96-97) was up until the end of the nineteenth century the "connective tissue par excellence" of novelistic narrative (97). After this time, it was used less. Genette notes that Proust tended to divide his scenes with ellipsis (98), suggesting this was the beginning of a trend towards this method; however, it could certainly be argued that much contemporary prose fiction still involves a degree of summary. In Porter's verse novels, this "connective tissue" is almost entirely absent. The reader moves from poem to poem with no explicit information as to the connections between them: how a character got from one place to another; how much time has elapsed; or why he or she is remembering a particular incident. Where summary occurs, it is conveyed through a character's thoughts. Chatman describes such instances as "not 'summaries' in the classical sense since the ratio is not between the duration of the events and of their depiction but between the duration of the characters' memories of those events and the time that it takes to read them, a ratio that is roughly equal, and hence 'scenic'” (CSD 76).

At times several poems are used to portray a single event. At others, one poem corresponds to one event. Narrative pause occurs frequently. In these instances the poem often focuses on internal contemplation. The insertion of such poems between others which narrate events facilitates interplay between narrative and lyric modes. Many of these lyric pauses involve the inclusion of material that is relatively uneventful, or displays low tellability. In "The cactus flower" Jill, the protagonist of The Monkey's Mask, contemplates a pot-plant before her final meeting with her lover Diana. In "Where the grass is greener", Peter thinks about Callan Park's lawns. Evidently such poems have been included for purposes other than action. Jill's flower functions as a metaphor for her love for Diana, which one assumes she also hopes "will have shrivelled / to nothing / by the time I get home" (TMM 251, 23-25). The meditation on 
grass draws attention to what is not said: the grass is described as greener "than anywhere / in the world" (WPW 12,4-5) because the narrator wants to avoid describing the interior of the hospital, and its inmates. This is echoed several poems later in "Lawns" where Peter states "the only things in order / are the lawns" (26, 27-28), again avoiding explicit description of what is not in order.

Although both verse novels contain multiple examples of such lyric poems, they occur more frequently in What a Piece of Work. This is due to differences in characterisation between the two protagonists. Jill is a working-class, uneducated excop who tends to avoid thinking too deeply: much of the plot of The Monkey's Mask rests on her refusal to reflect. Peter is an erudite psychiatrist who regularly delves into his own thoughts and memories. These differences demonstrate a flexibility in the formal device of the individual poem, in that it can accommodate a wide variance in voice: in this case between texts, in others (such as Wearne's) within a text.

Transitions between individual poems shift the narrative between different times and places, and between external action and internal contemplation. The reader is required to make inferences about these shifts, and their bearing on the plot. A sequence of four poems from The Monkey's Mask illustrates this process. "My throat" is narrated in the present tense: Jill and Diana are having sex at Diana's house. Diana strokes Jill's throat and tells her it's "“state of the art" $(101,16)$. "What it's like" has shifted to the past tense and an unknown location: Jill recalls Diana performing erotic asphyxiation on her, asking her "“Wanta see what it was like?" $(102,6)$ - in reference to Mickey's death by strangling. Jill states "I can't remember if it was nice / or not" (102, 13-14), making it uncertain how much time has elapsed between the two poems. In "What she is", Jill is driving home from Diana's place, telling herself to "just love her / love her // for what she is" $(103,13-15)$. In the next poem, "Word for today", Jill arrives home to find a death-threat on her answerphone - the second she has received since beginning her investigation. Two important inferences can be drawn from these four relatively short poems and the gaps between them. Firstly, it begins to be evident that Diana was involved in Mickey's death, and that Jill is wilfully deluding herself about Diana's character. The reader is prompted to wonder why Jill hasn't noticed she has received both death threats immediately after visiting Diana. This connection recurs later on between "Sentimental", where Jill talks to Diana on the phone, and "Wrong number", 
featuring another threatening phone-call. The shifts between these poems contribute to reader suspense: we know Diana is villainous; we don't know what she will end up doing to Jill; we become frustrated with Jill's continued ignorance.

Secondly, it is made clear that Jill is starting to identify with the victim. Although the two characters are markedly different on the surface - Jill is a 38-year-old butch lesbian ex-cop, whereas Mickey was " "petite, pretty and only nineteen"” $(52,5)-$ there are similarities in their stories. Both women are seduced by intellectuals, both are reckless in love. Mickey is killed; Jill narrowly escapes the same fate. Throughout the novel, physical seduction is used as a metaphor for the seductive power of poetry, made explicit in poems such as "Sex and poetry": "I never knew poetry / could be / as sticky as sex" (139, 7-9), and in "How poems start": "is this how poems start? // when the vein under her skin / hooks in your throat" $(144,4-6)$. The similar experiences of Jill and Mickey reinforce the idea that love, or poetry, could strike anyone at any time.

Similar methods can be observed in a series of poem-to-poem transitions in What a Piece of Work. The section "Silver" contains a sequence of poems that begins with Peter and his girlfriend Fay driving to the Blue Mountains to explore Peter's childhood haunts. "Driving to the Blue Mountains", "Megalong Valley" and "Driftwood" are focused on external events: driving, walking, observing the deserted tearooms. The narrator's comments, such as "my mind's most haunted / hotel" $(105,18$ 19), make us aware of his unpleasant associations with this place, but do not obscure action. In "Stillness", and "They don't make them like Fay anymore", Peter narrates his thoughts. He imagines Fay dead, and describes her as "toxically trusting" (109, 11-12). In "My big black dog", Peter reminisces about his mother's death. In "My own orders", Peter imagines himself as his own prisoner. No particular setting is identified in either of these poems. "Raining in Bedlam" moves back into external events, now at Callan Park, where Peter talks to his patient, Frank. "Mister Mercury" is also set in Callan Park; this time Peter makes a male patient fellate him. In "Drowning the Sirens", Fay gives Peter roses, which he puts upside down in a bucket, thinking: “it's a stupid gesture" $(116,7)$ and "I hate Blue Moons. / They reek of my mother's / garden. (116, 9). In "The ghost train" and "My out-for-a-duck dad", Peter's again narrates his thoughts, reminiscing about his past and his family. The "Silver" section then takes a 
different turn with a sequence of poems set in the present and featuring Peter's travels to the USA.

These poems require the reader to do much gap-filling. Again, the inferences a reader draws from these transitions are supportive to the narrative, rather than undermining of it. It can be deduced that Peter has had an incestuous relationship with his mother; that he is morally and professionally corrupt; that he is incapable of loving a woman; and that he is somewhat psychologically unsound himself. None of these things is explicitly stated or described; rather, it is due to the positioning of these poems as a sequence that the reader is able to infer them. The sexual overtone of "garden" in "Drowning the Sirens" and the Oedipal situation suggested by a cricket analogy in "My out-for-a-duck dad" play off the Blue Mountains poems and the dark emotions of "My big black dog" and "My own orders" to highlight the occurrence of the incest and its resultant psychological problems.

Porter's "fusion of overarching ideas and sequences with close, spare lyrics within" leads Felicity Plunkett to describe her as "the poetic heir to a tradition of discontinuous narrative in Australian fiction" (25). ${ }^{18}$ The spareness Plunkett describes, resulting from the relative shortness of both poem and line, contributes to a heightened intensity of language. Robert Graves claims that "the greater part of every long poem . . . is necessarily mother-of-pearl" (38). The challenge facing the verse novelist is to make every component pearl-like or engaging. Porter addresses this challenge by writing each poem in the manner of a short personal lyric. In every instance the poem suggests a strong emotional engagement on the part of the narrator and protagonist, which gives both novels an almost relentless intensity. Language and verse form work together to heighten this effect.

Porter's use of both line and stanza is reminiscent of Williams, whom she names as an inspiration. On seeing "The Red Wheelbarrow" written on a blackboard at school she remembers feeling "this extraordinary sense of possibility in its clarity and focus and short lines" (Minter). Another poet Porter cites as an inspiration is Emily Dickinson: "the condensation in her language is almost like a form of nuclear energy" (Minter). Porter identifies "the beat and passion of the things that were happening in

\footnotetext{
${ }^{18}$ It can be argued that Porter's work is "discontinuous" only up to a point; particularly in comparison with poems such as The Waste Land.
} 
music" in the 1960s as a source of inspiration in her formal approach (Minter), and describes having "written virtually all my poems to rock riffs and rhythm - the catchier, the darker, the louder, the gutsier the better" (Porter On Passion 26). It appears that the "passion" of music was more vital to Porter than the "beat", as the vast majority of her poems do not contain any identifiable stress pattern. If anything, rhythm is enacted by the line-break, which displays relative evenness throughout the poems. Both stanza and line are typically short. The ease with which these devices are used to convey characters as vastly different as a 1990s lesbian PI and a 1960s misogynist psychiatrist suggests that voice is not their main function. Furthermore, a reading of Porter's other verse novels, as well as her earlier collections of poetry, reveals that a similar formal approach was used throughout her poetic career. While there are recurring themes in Porter's poetry (passion and the breaking of taboo being important examples), the range of content expressed through these similar forms demonstrates that the effects of line and stanza on content are limited, lending weight to the idea that the division into individual poems is the more important unit of segmentation in terms of narrativity.

Line and stanza do, however, have important and clearly observable effects, including emphasising particular ideas, and highlighting motifs. Repetition of words or phrases occurs at times, giving a poem a chant-like quality. In The Monkey's Mask the poem "Fear me" uses the refrain "I'm violent", along with descriptions of parts of the female body, as a preface to a scene in a park at night, in which Jill faces a man armed with a knife. Here the repetitive format, reminiscent of a pre-fight chant, serves to remind us of Jill's vulnerability as well as her strength. In "Whose neat scissors?", anaphora serves as a way of recapping information as Jill pieces together the facts of the case:

shift to fear

shift to a fire

shift to Bill

soundlessly screaming. . . . (248, 17-20) 
In "AZT and sympathy", anaphora works in a way reminiscent of a list poem:

'she's an opportunistic infection

she's a tongue-load of thrush

she's needles and shingles

she's the kiss of herpes

she's a wasting flu'.... (225, 18-22)

In this instance the repetitive form serves to emphasise Jill's anger at the lover who has betrayed her. With its chant-like, rhetorical qualities, this poem is also reminiscent of a curse.

At times Porter's line-breaks draw attention to particular words in a way which has a bearing on plot interpretation. In "Your floating hair", Jill discusses one of Mickey's poems with Diana:

'Infatuation is blind,' Diana says

'and anyway she nicked the floating hair

from Coleridge.'

I watch my smoke floating

over her messy curls. (TMM 111, 12-16)

The line-breaks on "floating" and "curls" draw attention to Diana's link to Mickey's poem, and by extension her part in the killing. The unnamed subject of Mickey's “floating hair" poem is Diana's husband Nick, Mickey's killer, who has been described earlier as having a "blonde pony tail" $(33,9)$. In narrating these lines, Jill betrays her suspicion and subsequent denial of the facts. In "Fishy", Jill wakes from a nightmare: "I reach across my wet pillow / for my smokes" (220, 21-22). The line-break after "pillow" draws attention to the pillow's wetness, prompting the reader to recognise Jill has been crying in her sleep. In the next line, by contrast, we are returned to the “smokes" and Jill's familiar tough-girl persona. 
Line-breaks are also used to draw attention to rhyme or other aural effects. Often sound supports sense, for example in "Sublimation":

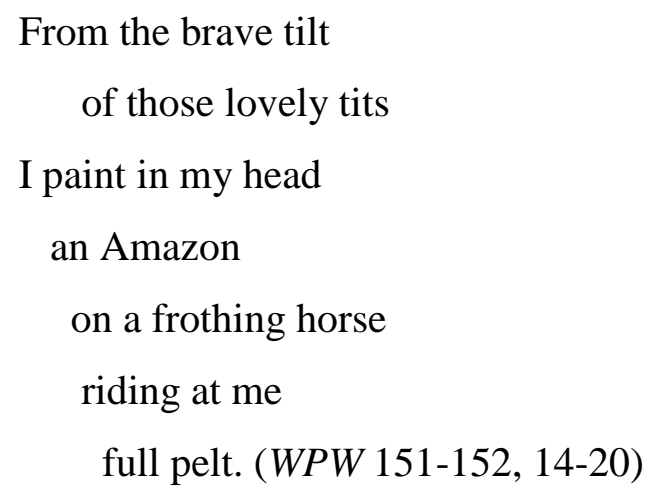

Here the off-rhyme of "tilt" and "pelt" combined with the consonance of "tits" contribute to a sensory portrait compounded by strongly visual imagery. In "Free Frank", words ending in "-ing" lend rhythm to a portrayal of the institutionalised poet:

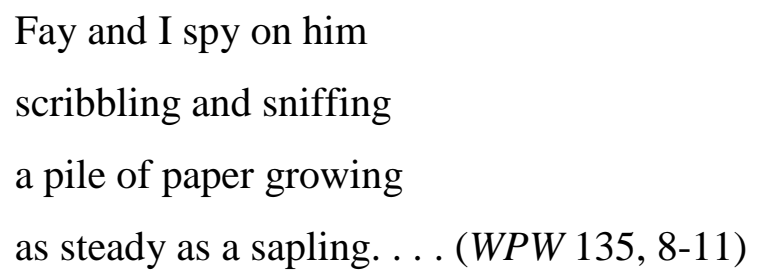

With its present participle line-endings, this stanza is reminiscent of the opening lines of The Waste Land, which Porter is perhaps deliberately echoing. In "Twinings", the lines "her mother stands / brushes down her flowery frock" (TMM 10, 25-26) are echoed a few lines later by "the sun flattening / the withered rockery" (10, 31-32). The linking through rhyme of Mrs Norris's frock to the "withered rockery" underscores the portrayal of her character as sexless.

The single-word line, sometimes isolated by a stanza-break on either side, is a common feature. It serves to draw attention to particular words, and to prompt the reader to consider why a word is important. In some instances, the word denotes action, for example:

there is something 


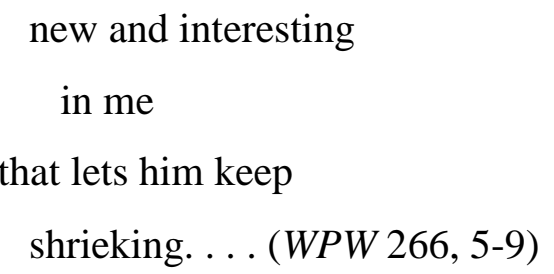

In others, the word draws attention to a particular sensory experience, as in "New woman": "not the creepy-crawly / musk / of the bitch on heat (WPW 34, 18-20); or "Her tiger": "growling through my fur / as I drive to Tamara's rank / smoke" (WPW 239, 57). The single-word line affects a word in a similar way to a regular line-break; however, it suggests these words are intended to receive a fraction more attention. In an analysis of Williams's verse forms, Stephen Cushman argues that the single-word line does not emphasise a word; rather it momentarily defamiliarises it: "Emphasis limits the range of possible meanings. Typography breaks those limits" (60). On the other hand, Wesling suggests that emphasis and defamiliarisation work together: "The detachment of a segment of speech (word or phrase) generally results in emphasizing that segment. . . . Emphasis usually takes the word out of the context, and vice versa" (Scissors of Meter 82). In either case the seemingly simple formal device of the single-word line allows a word to do more work than it might in an unlineated prose sentence.

Within-line segmentation is at times effected by the use of end-stopped words or phrases, often repeated, and in the lower case, for example, in What a Piece of Work, “green. green" $(12,6)$; "statistics. statistics" $(90,26)$; "hot. hot. hot" $(232,7)$; or "not. not. not” $(202,27)$. In The Monkey's Mask, Nick is described as “pretty. pretty” $(33,8)$. In both novels this technique is used to represent thought of an involuntary, irrational nature. In "Pig in a silk purse", Peter can't prevent himself thinking about the fire at Callan Park:
Burning. building. twelve bodies.
like barbecued things. they keep bringing
them out. out of me. and Penny-Jenny.
my little fat dear one. in her big bad ghost
white sheet. (WPW 236, 4-8) 
The longer, punctuated lines provide a contrast to the character's usual witty, intelligent voice, highlighting his disturbed emotional state. The heavy alliteration and the rhythm enacted by the fragmented sentences also contribute to a sense of horror or obsessiveness.

In both novels, stanzas and lines also function as a way of drawing attention to recurrent phrases or motifs. These reverberations between segments at times assist with interpretation of plot. The opening poem of The Monkey's Mask, "Trouble", ends with the lines: "I want you, trouble, / on the rocks" (3, 24-25). This is echoed in "Advice", where Jill's friend Lou tells her:

'Shut up.

That woman's trouble.

I'm telling you

big bloody trouble.' $(143,8-11)$

A further example is the contrast between lines in the early poem "I'm female": "I'm female / I get scared (4, 8-9) with the lines in "Fear me": "fear me fear me fear me // I'm female" (167, 13-14). This example shows the opposing sides of Jill's character: her vulnerability and her potentially violent strength. Knowledge of these qualities contributes to an understanding of the significance of Jill's behaviour in various situations. In these examples, line-breaks interact with segmentation by poem to produce a heightened awareness of particular words and their meanings, and therefore plot development. This counterpointing also increases a reader's motivation to make connections between segments, as pattern recognition becomes unavoidable.

In What a Piece of Work, a recurrent motif is saliva: "slobbering"; "slavering"; "spittle"; "drool". This is tied to a recurrent dog metaphor: "My big black dog", "Dogged"; the patient "Rex, the Dog" who "often drools on my hand" $(56,13)$; "here, doggie, / fetch the kiss!" (208, 13-14); "I want this smelly dog / off my lap" (237, 10$11)$; “deserted dirty mongrel" $(273,13)$. It is also linked to recurring depictions of other bodily fluids, such as snot, tears or semen. Bodily fluids have been identified as a common motif in much of Porter's poetry (Plunkett 19), exemplifying her desire to 
break taboos - The Monkey's Mask contains numerous references to menstrual blood and vaginal fluid.

Another recurrent motif in both novels - in this case effected by the divisions into sections and poems rather than lines - is the use of song titles, either original or modified.. Examples include "I saw her standing there"; "Money for nothing"; "If you don't know me by now"; "Hey Joe"; "Crossroads"; "I put a spell on you"; "It ain’t necessarily so", and "Stand by your poet". These titles are probably due in part to Porter's fascination with popular music, but also stem from a desire to incorporate popcultural references into poetry, thus challenging its status as a purely academic genre, and making it more likely to appeal to a wider reading audience. ${ }^{19}$

Porter's use of verse form supports statements she made about the emotionally charged, seductive power of poetry: that "it has always been a lightning rod for the sacred, the extreme and the daemonic" (Porter "Dorothy Porter"), that it "gives that sixth dimension - that subterranean psychic landscape - that can give the most evil character a vivid, even sympathetic, luminosity" (Porter "It's too hard"), that "the poems I enjoy cut to the chase" (Minter). Such statements are reminiscent of Pound's distinction between poetry and prose in "How to Read", which Porter was likely familiar with: "The language of prose is much less highly charged, that is perhaps the only availing distinction between prose and poesy. Prose permits greater factual presentation, explicitness, but a much greater amount of language is needed" (Literary Essays 26). The spareness of language and its resultant heightening in Porter's works contributes to her wider project of making poetry passionate, exciting, and potentially appealing to a wider audience than the typical readership of contemporary poetry. Porter writes of The Monkey's Mask:

I wanted ingredients that stank to high heaven of badness. I wanted graphic sex. I wanted explicit perversion. I wanted putrid language. I wanted stenching murder. I wanted to pour out my heart. I wanted to take the piss. I wanted lesbians who weren't nice to other women. I wanted glamorous nasty men who

\footnotetext{
${ }^{19}$ Here it is worth noting that, as well as song titles or lyrics being recycled frequently in poetry, popular musicians have often borrowed lyrics or ideas from poets - Paul Simon, Bob Dylan, and Nick Cave being examples of this..
} 
even lesbians wanted to fuck. I wanted to say that far too much Australian poetry is a dramatic cure for insomnia. But I still wanted to write the book in poetry. (Porter "It's too hard")

The Monkey's Mask fulfils all of the intentions listed above. The novel's depiction of female sexuality, including its "lesbians who weren't nice to other women" has led to controversy amongst feminist critics (Moorhead; Fallon). The extreme nature of much of the content in Porter's verse novels positions them away from social realism. The Monkey's Mask has been described as "a Gothic tale of spiritual sadomasochism and Evil. It's full of scaly things, slimy things, floating things with hair and fins, like the visions from the Gothic imaginations of Gustav Moreau or Redon or Goya" (Fallon 192). Highly dramatized ethical dilemmas are presented, open to multiple interpretations by readers. Porter's verse form supports this content. Line- and stanzabreaks draw attention to language and to imagery. Evil has a strong sensory presence throughout both texts. An example occurs in The Monkey's Mask in the poem "Like her":

My breath

my pants still sticky

in the tree

something black

squeaking. . . . (242, 1-5)

Another occurs in What a Piece of Work in the poem "Crossroads":

is there a devil

in this room

burning something

filthy? (177, 16-19) 
Here the single-word lines draw attention to the sensory experience of "evil": the thing that is "squeaking", that smells "filthy". As with the examples cited above, this lineation prompts the reader to consider various senses or possibilities of a word.

An analysis of these two verse novels suggests that segmentation at various levels can be used as a significant aid to narrativity. The division into individual poems is the most significant level of segmentation in this regard. This division both affects and effects narrative movement, enables events to be positioned against one another in such a way as to assist coherence, and facilitates interplay between narrative and lyric modes in a manner ultimately supportive of plot. The use of a conventional detectivestory plot in The Monkey's Mask and the familiar tale of a character's gradual undoing in What a Piece of Work demonstrate the ease and effectiveness with which the division into poems can be used as a means of conveying an eventful and tellable narrative. Furthermore, differences between the protagonists of each of these novels demonstrate the ways in which narrative-lyric interplay may be used in support of characterisation a key component of narrativity as identified in Ryan's criterion of a world being created and populated with characters. At the same time, the division of a conventional narrative into poems plays on genre expectations to create a layer of irony.

Other units of segmentation are also used in support of narrativity. Sections organise material thematically, adding to the development of plot and to overall coherence. Lines and stanzas encourage inference-making and connections between segments, drawing attention to particular words and phrases which may provide information essential to the plot, and highlight recurring motifs and themes. Interplay between levels of segmentation makes a further contribution to narrativity, making both works satisfying stories as well as engaging poetry. 


\subsection{Alan Wearne's The Lovemakers}

Alan Wearne's The Lovemakers is, at 686 pages of text, one of the longest verse novels ever written. In this case study I argue that segmentation through verse form can operate on a number of levels to allow interweaving of multiple subplots, differing perspectives on particular events, portrayal of different characters, and representation of vernacular speech. In turn, these things allow a poetic narrative to act as a portrait of a diverse culture and place, over a period of time.

\subsubsection{Narrativity}

Wearne's novel features a large cast of characters, many of whom are employed as narrators and/or focalizers, and a number of interwoven subplots. Despite these factors, it exhibits a high degree of narrativity. As it depicts a number of events, arranged in a time sequence, it satisfies Prince's definition of narrative. Furthermore, although its approach to plot is much less straightforward, and less teleological, than that of The Monkey's Mask or What a Piece of Work, it also meets all three of Ryan's criteria: a fictional world is created and is peopled with characters; it undergoes changes of state; and an interpretive network of goals, plans, causal relations and psychological motivations is present. Ryan's mode of "braided narrativity" can clearly be applied to The Lovemakers. A narrative of this type "follows the intertwined destinies of a large cast of characters" and "presents no global plot, but a number of parallel and successive subplots developing along the destiny line of characters" ("Modes" 374). Furthermore, "since this mode of narrativity presents no macro structure, it does not end in an event motivated by the demands of narrative closure, but may be continued ad infinitum by stringing new episodes along destiny lines" (374). Ryan gives soap operas as one of her examples of braided narrativity, and The Lovemakers certainly displays parallels with this genre, including the number of characters and subplots, and the highly interwoven connections between characters which at times stretch the likelihood of coincidence. Some of Wearne's subject matter is also similar to that of soap opera, although the ways in which events are articulated are less formulaic. The novel also displays an interesting approach to closure. By the end, various subplots have reached their conclusion: a 
number of characters have died or been murdered; some relationships have failed; a marriage has been made; a speculator has gone bust; the surviving members of a drug syndicate have been arrested; the South-East Asian bar they owned has been burnt down. On the other hand, other subplots are left relatively open-ended, and, as with a conventional soap-operatic narrative, the possibility of continuance is apparent. Wearne's deployment of soap opera conventions works in a similar way to Porter's use of the detective plot: to import familiar and tellable narrative, while at the same time undermining it through irony. As with Porter's novels, the use of poetry as a narrative genre has significant effects in this regard.

The degree of eventfulness is variable within The Lovemakers. Parts of the novel are highly eventful: Barb Heath, a public servant, married to Roger, defrauds the department she works for and has an affair with her workmate Neil Spencer; Wal, a young gay man, is beaten to death; Sophie Cross, a law graduate, meets the drug czar Kevin Joy through her work, and they begin a relationship which leads Sophie into the drug trade; later, Sophie is involved in hiring the hit-man Johnee Kwok to kill Kevin. Other episodes are decidedly uneventful: a poem early in the novel is titled "Finale: Louise and Neil go to Monica and Hannah's flat-warming. Chrissie sings 'The Universal Soldier'; Louise and Neil sing 'Friendship' and the 'Toilet Song'. Saturday, 5 September 1970, 8.30pm onwards" (123). This title is a faithful description of the action taking place in the poem; a reading adds finer detail in the form of the characters' thoughts and opinions of one another. A later sequence, entitled "Group portrait with Benny and Wal" depicts a number of central characters giving and receiving invitations, preparing for, and attending a dinner party, at which nothing outside of conventional behaviour occurs. Much of the content surrounding sex and relationships could be considered uneventful: we expect these things to happen in a novel entitled The Lovemakers. Barb's affair with Neil is eventful due to what we know beforehand about the characters, and the emotional overload which reverberates throughout the novel. This is an example of what Bruner would term a "highly conventional" breach (12); however, as in Schmid's conception of eventfulness, the affair is unpredictable to the characters involved. Its eventfulness is underscored by its status as the central subplot of the novel, intersecting with the stories of various other characters and creating various repercussions. 


\subsubsection{Units of segmentation and their function in relation to narrativity}

The novel's sheer length, its large number of characters, its multiple subplots and its frequent shifts in narration and focalization combine to make the role of segmentation crucial. On the macro level, the novel is segmented into Books One and Two. Each book is divided into eight parts. The parts contain varying numbers of poems, which are in many cases divided into titled sub-poems and/or numbered sections. Many of the poems are stanzaic; all contain line-breaks. Around half of the novel is written in free verse, while the remainder is written in inherited forms, including villanelles, sestinas, limericks, ballads, ottava rima, couplets, quatrains, tercets, and variations on the sonnet. These forms determine stanza and line in many poems, although Wearne is prepared to modify these to suit his own purposes. The inherited forms also introduce the device of metre.

It is of significance that The Lovemakers was initially published as two separate volumes, three years apart. This had a bearing on the responses of the novel's original readers and reviewers: Don Anderson, for instance, writes that Book One "might have ended with "To Be Continued"" (89). ${ }^{20}$ As well as making the novel digestible to a reader, the division into two books would have helped to make it writeable for the poet. Important contrasts are also observable between the two books. Book One begins with many of the central characters as adolescents; the suburban Sydney "Shire", and several Melbourne suburbs, are seen through their eyes. By the end of Book One they have reached their late twenties/early thirties. The key event, Barb's and Neil's relationship, has reached its unhappy conclusion. We are introduced to Sophie, and Sophie is introduced to Kevin; however, there is no indication of their wider importance. Having Sophie appear at the end of Book One serves as a kind of book-end, figuratively speaking, as her father, Cross QC, was an important character in Part 1, and has not been mentioned again until now.

\footnotetext{
${ }^{20}$ In 2001 when this review was written it was known that Book Two was underway, and this reviewer appears to have made the assumption that Penguin, who published Book One, would also publish the second instalment. In fact, as the jacket copy of the Shearsman edition tells us, ABC Books published Book Two, and both publishers pulped their remaining stocks prior to the publication of the single volume.
} 
In Book Two the novel moves its emphasis from suburban swingers to the drug trade between Australia and South-East Asia, and is considerably darker in its subject matter. Through Kevin, Sophie meets Kim Lacy, one of the original Shire adolescents turned criminal mastermind. Carrie, another character introduced early on in Book Two, becomes a prostitute, giving an inside view of Sydney's sex-trade. During Book Two, several characters introduced in Book One die. Nothing is resolved for Neil and Barb, who go on living relatively unfulfilling lives. Thus, Book Two could be seen as a deliberate contrast to Book One, as well as a development and intensification of the themes introduced therein. Book One depicts the decline and death from heroin overdose of the poet Toby; Book Two depicts the trade which facilitated his death, and those of others. In Book One we are shown unhappy marriages; in Book Two some of these end, and the ways in which romantic relationships can become disastrous are shown in all their complexity. In a sense the books mirror each other. This is suggested by a link between the first poem of Book One, "Jack's Progress (I)", and the last poem of Book Two, “Jack's Progress (II)”. Jack, one of the novel's most amoral characters, changes very little, apart from growing older. Contemplating his deceased associates, Jack's thoughts serve as a reflection of the novel's wider themes:

$$
\text { So please, }
$$

since only he's survived, appreciate how such deaths

and lives can roll something into nothing

and back into something again. $(676,114-177)$

The sixteen parts function somewhat like chapters in prose fiction; however, like the titled sections in Porter's verse novels, they vary in discourse-time, and in the period of story-time they cover. Parts 7 and 10 contain a single poem, Part 6 is a novella in its own right. It is also noticeable that some of the parts contain much more eventful material than others. These variations make it difficult to interpret any thematic role for these divisions. The most important function of the parts is to shift the focus between different characters, and therefore different sub-plots. At the beginning of each part, we are given a list of characters, along with a brief description, similar to the Dramatis Personae in a script. Part 1 , for instance, introduces the following: 


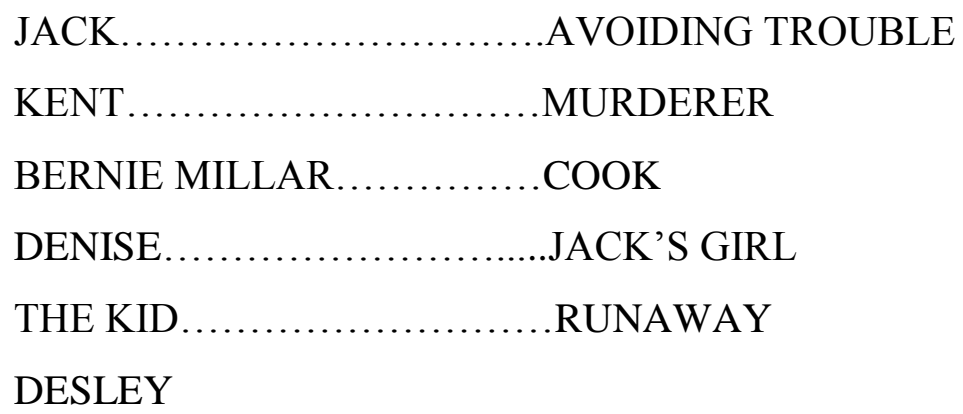

\}$\ldots \ldots \ldots \ldots \ldots \ldots \ldots$ WHO HELP THE KID

IRIS

CROSS QC BARRISTER (11)

Recurring characters receive different descriptions in each of these lists, allowing the reader to track their progress; Bernie Millar, for example, is variously described as "Cook", "Jack's friend", "Deadshit", "Pimp", "Barman in The FucFuc", and "On the run". The descriptions create expectations of the nature of the characters and the actions they are likely to carry out. In their resemblance to Dramatis Personae, the lists also highlight performative qualities in the novel as a whole, which are also borne out by the use of dialogue and monologue, as described below.

Titled poems occupy two levels of segmentation. Longer poems or sequences are demarcated by a capitalised title and by beginning on a new page. These are often divided into smaller sections or sub-poems, which may be titled, numbered, or separated by asterisks. Segmentation by poem provides a range of effects.

One of these effects is the use of poem or sequence titles to provide information and to orient the reader in regard to the characters' situation. At times, the titles of the sub-poems give factual detail, for example: "Romanza: Liz and Bob are engaged. At their party Liz introduces Neil to Naomi and Neil introduces Kim to Louise. September 1969". These dry descriptive titles suggest the notes preceding a dramatic scene; they also call to mind the lengthy chapter titles popular in the nineteenth century. At other times, Wearne's titles simply name the character(s) who feature in the poem, or through whom the narrative is focalized. In the sequence "Catholics for friends (II)", the titles refer to pieces of music: "Prelude"; "Theme and Variations"; "Arias"; "Intermezzo"; "Danza"; "Finale"; "Coda". This gives the poems, which feature various parties, 
engagements and marriages, a sense of being a performance. In the sequence "Someone to Make Us Feel Happy (The Shane Price Recollections Continued)", the titles read like a list: "The speed"; "The quicksand"; "The magic"; "The life!"; "The lounge suite"; "The girlfriend". Juxtaposed in this way, the titles give a comic slant to the episodes, which in themselves are depressing rather than humorous.

A further effect of the division into poems is the functioning of narrative movement. As with the separate parts, poems contain varying amounts of information, and cover varying periods of time. "Lovelife (I)" at the beginning of Part 6 runs for 420 lines, and covers a period of almost ten years. "Group portrait with Benny and Wal" in Part 11 runs for 1535 lines, and concerns a single evening. There are many instances of scene, and of ellipsis between poems and parts. Where summary occurs, it is most often narrated by a character: either to another character within the story, making it an example of scene, or to an unnamed narratee, making it an example of pause. There is very little indication of an omniscient narrator: poems in the third person are always focalized through one or more characters. The novel contains few descriptions of settings: it is understood that The Lovemakers is set in Sydney, Melbourne, and SouthEast Asia; however, its primary preoccupations are people and their relationships. Furthermore, the novel contains very little in the way of lyric. Occasional poems could be described as lyrical (for example, some of those in inherited forms), but this mode is more likely to occur in groups of lines within a poem. In many instances, the novel comes closer to drama: a number of the poems could easily be cast as performances.

Of the poems written in the first person, some are narrated to an unnamed narratee ("Lovelife (I)", "Sophie"), while others are addressed to a particular character. Several of these dramatic monologues ${ }^{21}$ are lengthy: Roger's confessions to his psychiatrist in "Lovelife (V): Roger, Or Of Love and its Anger" take up 25 sonnets. "Nothing But Thunder", Kevin's drug-induced rant to Chrissie, in free verse with no stanza divisions, but occasional rhymes, runs for 806 lines. In "Stubbsy: A Success", fallen speculator Craig Stubbs tells his story to a bar patron addressed alternately as

\footnotetext{
${ }^{21}$ I use the term "dramatic monologue" as defined by M.H. Abrams, in that it is addressed to one or more other people (70). This is the sense in which it applies to some of Browning's monologues, such as "My Last Duchess". Prince uses "dramatic monologue" as a synonym for "interior monologue", (DON 23) which does not fit the instances described here. Prince also states that a monologue is "not addressed to other characters" (DON 54).
} 
"Fella" and "Hotshot". These, and other shorter monologues, have a similar function to the monologue in drama: to provide a portrait of a character, and in some cases act as summary. In the three instances mentioned above, verse form plays an important role. Though a reader can sympathise with Roger's plight, the sonnet form helps to sustain interest in what is essentially a repeating narrative. The varying rhyme schemes create expectation and provide impetus to continue reading the sequence. The use of a sonnet sequence to depict the problems of romantic love also locates the poem in relation to the European sonnet tradition dating back to the thirteenth century, as well as sequences written during the twentieth century by writers such as John Berryman and Marilyn Hacker. The poems featuring Stubbs and Kevin present other challenges: both of these characters are relatively unknown to the reader at the point at which the poems appear; both are portrayed as largely repellent. Stubbs is describing in minute detail his career as a speculator; Kevin is under the influence of drugs - "Nothing But Thunder", taken from Shakespeare's Measure for Measure, an apt title for his rant. At times the listener's brief involvement in the conversation is signalled through the speaker's comments, such as Stubbs's: "You name us, Fella, the least fashionable room / in any house. Correct: the laundry" (536, 1018-1019), but the monologue is unbroken, cementing the portrayal of the character as self-obsessed. Here, line-breaks and indentation make the poems digestible to the reader. Each of these devices could be read as a breath-pause by the speaker: the line-break a regular breath, indentation a longer pause as the speaker briefly thinks about what to say next. In "Nothing But Thunder" frequent rhymes, though irregular, give the monologue qualities of recurrence. At times rhymes occur at line ends: "Well? Who needs the collective will / of a few hundred fat virgins caked in Clearasil? (356, 200-201); “Just by wanting it love can be smack. I Don't I know what the world needs now, Mister Bacharach!” (363, 450-451). At other times the rhymes are internal:

Our game's on hold, the pack has been shuffled and cut, the dice are poised to roll, he hangs up and the call unfolds like some huge and magic cum: the deaf hear, the dumb speak, on, on, just like a religion miracles et cetera, person after person, happier and happier. $(366,604-608)$ 
where "dumb" and "cum" are a full rhyme, "on", "religion" and "person", and "roll" and "call" are off-rhymes, and "hold", "roll" and "unfolds" are assonant. In "Stubbsy: A Success" repetition and rhyme at times feature in conjunction:

On television Osbourne was blitzing his way from debt: comeback ninety-nine. All it ever seemed to show were Aussies, sure in themselves, for BoomCon: white coated boffins held up test-tubes for BoomCon; workers strode grinning from their building sites for BoomCon; teenagers discoing night-after-night away; diggers round a cenotaph on Anzac Day: BoomCon: we're with ya total, Oz! (540, 1178-1185)

Combined with repetition and rhyme, Stubbsy's crass, slang-filled manner of speaking verges on nonsense at times:

Then, one day, years back, Kevin sells out to me and Kim, heads to Manila.

'At The Horse,' he told me, 'we've AP. Over at The FucFuc, approximate AP.'

\section{Did Craigo get it?}

Does Fella? Asian Pussy here, drag queens up the road: call them my virtual girls: pre-op, post-op, ev'rywhere an op-op. (530, 780-787)

Through these and other instances, the reader is given an unambiguous portrait of Stubbs's character. In both long monologues, rhyme, repetition and other aural effects contribute to the performative qualities of the poem.

A significant challenge for any narrative poet is combining poetic craft with first-person narration, particularly by an uneducated or plain-speaking character. Porter navigated this challenge in The Monkey's Mask by the use of terse lyrics incorporating 
slang and Australian vernacular. In "Nothing But Thunder", Wearne tackles this problem by having Kevin admit, early on, that drugs are affecting his speech:

Yeah? Me, I'm happy wondering

what exactly were those pills before the last lot since tonight, tonight, it all seems clearer than it ever was.

Notice how I'm saying words I've heard and known

but hardly ever used? You might. Till then let's make that

lesson one on me: it's as if the pills supply a fuse

set on burning back. (351-352, 8-14)

This accepted, the way is paved for the reader to accept regular occurrence of rhyme as part of Kevin's speech, and the interspersion of his Australian slang with such lines as:

and I know she caught

the damp stench they tried to excuse as plumbing.

Supposed to be October. I shrugged as this

slow, cracked heater tried numbing the room.

Had to talk, clear the muggy tension. $(354,114-118)$

In addition to the impetus or interest provided by the formal devices, the stories being summarised propel the poems forward, making narrative and verse form mutually dependent.

Another key function of segmentation by poem is to provide alternating perspectives on the same events. This has a bearing on frequency, making The Lovemakers full of repeating narrative; it also contributes to narrativity by allowing subsequent narrators to fill in details an earlier narrator has omitted. In "Karl at Leo's", a sub-poem in the sequence "Lovelife (IV)", Karl tells Benny the story of his affair with Sophie. The same affair is narrated by Sophie in "Sophie". Karl's version is merely bragging; Sophie's contains more detail, and is less euphemistic. In a later sub-poem in "Lovelife (IV)", entitled "Benny, Watching, or Blow it up!", Benny recalls Karl, describing him as "that appalling man in Melbourne" $(281,27)$ and thinking "Why 
didn't he just start / a suburban gigolo agency: Housewives' Choice?” (281, 32-33). "Karl at Leo's" is set at Leo's thirty-fifth birthday party, which is re-visited in "Non in spatia sed in muneribus capitus" from the point-of-view of Geoff and Bess Cattermole, with no mention of either Karl or Benny.

Segmentation by poem also presents an opportunity for disruption of chronology through anachrony. In "Nothing But Thunder" Kevin talks to Chrissie in a bar. The following poem, "Holding the Drug Czar's Hand", narrates in the third person how Chrissie came to be involved in the Joy Boys drug syndicate, which precedes her meeting Kevin. Later in this poem, the conversation with Kevin is narrated again, in a more succinct format. The sequence then moves forward in time to Kevin's decline and murder.

Anachrony also occurs within individual poems, with line-breaks or delineated sections used to divide one time from another. In "1971", (I) portrays poet and heroin addict Toby's mother grieving after his death. (II) moves back three years to a scene in which Toby is speaking about his parents to a friend at a party. (III) returns to the mother grieving; (IV) portrays an unspecified time, in which Toby is talking about his mother, saying "Meet the old lady though, we sorta like her" $(144,48)$. (V) returns again to the present, and Toby's mother struggling with an influx of friends come to pay their last respects. The analepses in this poem do more than recounting past events: they introduce information which Toby's mother, through whom most of the rest of the poem is focalized, would not have had access to. Toby's offhand comments contrast with the complex emotions expressed by his mother, and prime the reader for her final comment, “Toby was ratshit!” $(145,79)$.

An example of prolepsis occurs in "The Kid in St Kilda", in which a street-kid is given refuge by a pair of prostitutes and their associates, one of whom will be executed in the following poem:

If only she'd known to inform Kent

(that night or any time) but who would?

For Kent, a trim man under his little hat,

had only eighteen months to live.

In a fortnight he and a mate would 
find themselves a job and botch it:

and cornered by two cops would panic:

a cop would get the mate, Kent would get

that cop, then, after next summer

when nothing but the cricket, the heat and Kent's appeals

made news, they'd string-up Kent. . . . (23, 124-134)

This short segment is the only narration of this event in the novel. In the following poem, "Cross QC: Three Villanelles", two of the poems are speeches made by Kent's defence lawyer in court, and the third is Cross's reflections following the hanging. The crime is referred to again in "Sophie", in which Karl and Sophie discuss Kent's case and its consequences for Sophie's father, but no further details are given about the actual events of cop-killing or execution. These and other examples allow a variety of events to be narrated within short sections of text; they also encourage a reader to make links between poems or parts.

A further effect of within-poem segmentation is the creation of an episodic structure. An example of this is the sequence titled "The Phil Price Limericks", part of the longer sequence "Lovelife (II)". Containing 39 limericks, the sequence is also divided by numerals into seven sections, which relate to specific incidents or periods of time: in section 5 Phil is arrested for offensive behaviour, and is shunned by his friends after the police discover his "stash" in his friend's car and arrest his friend; in section 7 Phil "dries out" and joins the air force. A short verse form such as the limerick, or the sonnet in "Lovelife (V)", is ideally suited to such a string of episodes, narrated within limited discourse-time.

As is the case in many poems, line- and stanza-breaks in The Lovemakers create potential for juxtaposition of information. Due to its potential for segmentation, the verse novel provides ideal ground for insertion of material outside the scope of the main narrative. Some of the ways in which this manifests in The Lovemakers are metapoetic and/or metanarrative comment, and metalepsis. An example of metapoetic comment occurs in "Geoff, Julie, St. Edwin's and the world": 
for Geoff, Julie, St Edwin's and the world

it's sure to sound inevitable. They'll sow it

you'll reap it as if a crueller deity has found in them

clients for fate or the bomb or some poet

anticipating rhymes and shaping lines around them. $(69,131-136)$

This also functions as metanarrative; the author draws attention to his own actions in creating unfortunate destinies for his characters: despite the word "or", the close proximity of the two analogies suggests the poet is the "crueller deity".

A further instance of metapoetry occurs in "Non in spatia sed in muneribus capitus", where, after thirty ottava rima stanzas describing Geoff, Bess and their arrival at Leo's party, Wearne digresses from the narrative in Byronic manner:

[But to accommodate this party's tones, nuances, shading, one sound stands supreme.

Bel canto? Be-bop? Robeson's mighty groans?

Well it isn't Lully and it isn't Cream.

Ladies and Gentlemen . . . the Rolling Stones!

They've sung The Earth from Chile round to Cheam!

So here's to Mick and to his partner Keith

(whose prospects 'round this time were rather brief).

And to their rivals from some decades back:

John, Paul, George and Richard nicknamed Ringo.

Who caused upheavals equal to the sack

of ancient Rome, they certainly did by jingo!

But I must get The Lovemakers back on track,

for few, I fear, can understand this lingo;

nor rhymes which getting Wearnier and Wearnier

could give the English language quite a hernia.] (316: 241-256) 
Both quotations above are also examples of metalepsis, defined by Genette as the transition of a character or narrator between one narrative (diegetic) level and another (GND 234). In each case the poet-narrator disrupts the fictional narrative, drawing attention to its status as fiction, narrative, and poetry. The second example is acknowledged as a digression by the use of square brackets, and the poet-narrator identified via the term "Wearnier"; the first is a more subtle allusion to the author's presence. Wearne makes a further reference to the poet's role in "Gibbo's Coast-toCoast": "Enjoy the moral sweep of my journey? / This poem's been Gibbo's and it ain't yours Wearney!” (566, 602-603). In a separate instance of metalepsis, Wearne inserts a fellow Australian poet, Shelton Lea, into the fictional narrative (with Lea's permission acknowledged in a note). Lea appears as a passenger in a taxi driven by the drug-dealer The Alien, and recites a poem at The Alien's request. The Alien's thoughts and spoken comments intrude into the recitation:

So Could you I'm asked.

Could I what? Kill a dog with a hammer?

Would you 'Go on,' I encourage. Stammer

when you crushed the skull of a child?

And I understood: although you might enjoy it,

the quieter living, as I do, here's the problem:

you come out mighty under-prepared.

And if you fought a man to death

with boots would you be beguiled

by his blood? So when you stepped

into that world beyond yours,

what were you doing? (590-591, 64-75)

Metapoetry, metanarrative and metalepsis generally have the effect of undermining narrativity by disrupting the reader's immersion in the story-world, as well as the progression of the narrative itself. In this sense, these techniques can be seen as antinarrative devices, complicating the narrativity of the novel as a whole. On the other 
hand, they might also be seen as reinforcing narrativity, by adding the narrative of the text's composition, or by blurring the boundaries of diegetic levels.

The novel features a wide range of inherited verse forms, ${ }^{22}$ prompting a consideration of their purpose, and raising the question of the concept of organic form, a popular subject of polemic for many writers and critics of poetry, particularly during the nineteenth and twentieth centuries. Charles O. Hartman writes: "No matter what his specific formal decisions, the poet after Coleridge understands form less as a box than an incarnation. Contemplating the "idea" - less content than matter - the form constitutes its only adequate expression" (89-90). Hartman's argument for “discovered form" (92) can be linked to the writings of Olson and Levertov; the quotation above suggests Olson's statement (attributed to Robert Creeley) that "form is never more than an extension of content" (289). On the other hand, Wesling describes organic form as "the primary myth of post-Romantic poetics" (COR 2), defining it less prescriptively as "what the successful poem has when it justifies the arbitrariness of its technique; and what the failed poem lacks, when its technique seems obtrusively imposed" (2). The arguments put forward by Olson, Levertov, and Hartman become problematic in regard to writers such as Wearne, as in many instances his formal choices can be seen as nonessential. Firstly, as many narrative theorists have pointed out, narrative itself is transposable between media as diverse as written language, dance and painting, suggesting that a poetic narrative does not have to be realised in any specific verse form. The brothel sequences in The Lovemakers, entitled "Making the world revolve" (I) and (II), are written in sestinas, but the sestina is far from being the "only adequate expression" of the content therein. The same events could easily have been narrated in free verse, or in prose. The sestina, with its recurring words, is an appropriate form for a sequence about what makes the world go round, although the content of this sequence is not particularly cyclical in itself. It must therefore be accepted that, in line with the wider concerns of this thesis, different verse forms have certain determining, localised effects on content, but do not represent the only possible choices the writer could have made. Rather than being integral to narrative, Wearne's virtuosic approach to form may

\footnotetext{
${ }^{22}$ In another review of Book One, Thomas Shapcott writes: "The only major verse form that I don't think I encountered ... was the sestina" (133). It is possible that this statement encouraged Wearne to include a large number of sestinas in Book Two.
} 
add to some readers' enjoyment of and engagement with the text by providing an additional focus to that of plot. However, other readers may become frustrated or distracted by the double demands of narrativization and formal patterning.

One of the evident, though inconsistent, functions of inherited form within The Lovemakers is the portrayal of particular characters. Examples include the use of the limerick, a familiar folk form, for the voice of uncouth and bawdy Phil Price, the rhyming couplet for the banter of comedian and radio host Gibbo, and ottava rima for the Cattermoles. This function is far from global: Gibbo also has a radio speech in free verse, and the character Neil is portrayed through a variety of forms.

The rhyming forms Wearne uses range widely in their effects, from comedy to counterpoint. The rhymes in "The Phil Price Limericks", "Non in spatia sed in muneribus capitus", "Radio Chook Raffle (I)" and "Gibbo's Coast to Coast" are certainly designed with a comic function in mind. On the other hand, "Lovelife (V)", though its rhymes are witty, deals with subject matter that is not portrayed as humorous. Here, rhyme adds depth to the poem rather than detracting from it: the aural recurrence has a hypnotic effect which supports the emotional truth of Roger's confessions. A counterpoint is also set up between the narration of events and the unfolding of rhyme.

Wearne's poetic style has been called "vernacular formalesque" (McCooey 164), and this is an apt description of the way in which Wearne uses inherited forms for monologue and dialogue. A commonly held view is that verse is an unnatural way to represent speech: Patrick Murphy, for instance, writes that as poetry moves closer to everyday speech, it moves closer to prose (60). An opposing view is that metre is in fact quite close to speech, in that spoken English is stress-patterned. Attridge explains: "This preference for an alternating rhythm, oscillating between stressed and unstressed syllables, means that poetry which has such a rhythm will often be felt to be closely related to the spoken language, heightening and clarifying the movements of speech" (40). In a continuum of movement in language, Lotman positions poetry as closer to speech than artistic prose (94). Rhyme, on the other hand, is dissimilar to spoken language: while occasional rhymes inevitably occur in speech, a patterned rhyme scheme immediately demarcates a text as verbal art. A rhyme scheme compels the reader of a narrative poem to maintain a double focus: following a sound pattern and at the same time following the narrative. Part of the appeal for the reader is the 
appreciation of the skill with which speech may be represented through rhymed language.

In Wearne's case, verse form (both free verse and inherited forms) is used effectively in speech representation. Metre, rhyme, repetition, consonance and assonance contribute to the sound of speech; and, as discussed earlier, particular forms contribute at times to the voices of particular characters. The physical lines on the page are also a useful way to portray speech, similar to the lines in a verse drama, or a denotation of spoken language for linguistic analysis. Wearne frequently employs indentation and line-breaks mid-line, which at times signal a pause by a single speaker, and at other times allow separate speakers to make utterances within a single line. The following example contains five line-breaks, yet forms only the first two lines of an octave:

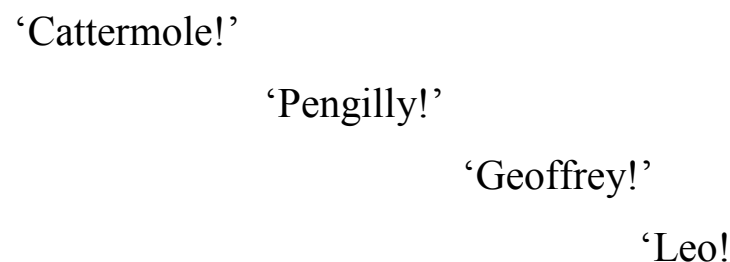

Meet Bess my wife.'

And there's a bow: 'Enchanted! . . ' $(313,129-130)$

Again, the use of vernacular is an important concern. Wearne's lines and line-breaks are accommodating to the depiction of plain speech, slang and noise:

'No seriously, I've taken clients to the Corroboree Rex.

Let's go, they've a clinker bar and little darlings.'

'What y' flog 'em? Six inches of bone-structured sausage?'

Syd returned to The Valley: 'Sites you know ...

gee this is a beautiful country, a lucky country,

so much land; if only we had as much stray talent

as land heh heh heh...'

Oh nghyh nghyh nghyh nghyh nghyh!

And Dick said Jeez Lins I need a beer. ... . 
(186-187, 310-318, $1^{\text {st }}$ two ellipses in original)

In "The Music of Poetry" (1942) Eliot observes: "The music of poetry . . must be a music latent in the common speech of its time. And that means also that it must be latent in the common speech of the poet's place... . [I]t is the poet's business to use the speech which he finds about him, that with which he is most familiar" (Selected Prose 58-59). Through the combination of verse form and vernacular speech, Wearne addresses what is perhaps the chief task of The Lovemakers: to portray a cross-section of Australian life in the late twentieth century. In doing so, he draws on, and complicates, familiarity: the soap operatic storylines and the everyday language both enhanced and counterpointed by his use of verse form.

An analysis of narrativity and segmentivity in The Lovemakers has shown that a novel highly segmented both in narrative and verse form can still display a high degree of narrativity. Verse form contributes to narrativity by enabling connections between characters, events, times and settings, by facilitating the portrayal of characters, and by effectively representing speech. The variety of forms used in the novel, as well as the large cast of characters, mean that the interactions between narrative and verse form are complex. Occasional instances of metapoetry, metanarrative and/or metalepsis serve to undermine narrative at times. However, the novel as a whole shows a mutually supportive relationship between narrativity and segmentivity. 


\subsection{Tusiata Avia's Bloodclot}

Bloodclot is a book-length poetic sequence described by its author as "automythography 23 . . a blend of myth and autobiography" (Avia, "Tusiata Avia"). The text merges the legend of the Samoan goddess of war, Nafanua, with the poet's own life story, and her inventions (Liang). The term "automythographical" is also used in the jacket copy, the "auto" highlighting that this material is presented as autobiography, rather than the story of a fictional character. In this case study I investigate how myth and autobiography can be fused within a poetic narrative, how verse form aids this relationship, and how this is conducive to narrativity.

\subsubsection{Narrativity and narrativization}

In considering narrativity in Bloodclot, it is helpful to assess the narrativity of its two stories: that of Nafanua the goddess, and that of "Nafanua" the "afa kasi ${ }^{24}$ girl from Christchurch" (Avia "Tusiata Avia"), as separate entities, as well as in unison. The reason for this is that from the outset, the two characters and their stories are presented as separate yet intertwined: the Nafanua of legend functioning as a frame for the autobiographical Nafanua. An analysis of segmentivity contributes to the understanding of how the two stories work together.

The legend of Nafanua is summarised in a short untitled preface, preceding the first section of poems. This summary could be considered narrative according to both Prince's and Ryan's definitions. Several events are described: Nafanua is born as a bloodclot; she is buried in the earth to grow; she is called forth to defend her people who are humiliated and enslaved; armed with battle clubs given to her by her father, she kills her enemies and frees her people; she establishes Samoa's traditional system of government and prophesies the coming of the Palagi. Clearly this sequence of events also involves goals, actions and plans which are causally linked. Closure is provided through Nafanua's victory. This summary, although short, contains a plot. Furthermore,

\footnotetext{
${ }^{23}$ Although unreferenced, this term likely derives from Audre Lorde's autobiographical work Zami: A New Spelling of My Name (1982), subtitled "A Biomythography”.

${ }^{24}$ Samoan term for "half-caste".
} 
although situated before the main text and written in prose, it could be considered a part of the sequence as a whole; a prose poem rather than a paratext. This reading is affirmed by the inclusion of a second, lineated "preface" on the following page.

The autobiographical material, however, is less easily defined as narrative. As each poem narrates one or more events, it satisfies Prince's definition; although the challenge in establishing a time sequence reduces narrativity somewhat. Moreover, it can be difficult, and possibly undesirable, to turn factual material into a coherent plot. The problems inherent in any work of autobiography, verse form aside, have been well documented. Fludernik explains that "to write one's own life requires a sustained Augustinian effort to construct from the random succession of remembered scenes (the material of narratives of personal experience) that well-structured tale with teleological shape" (TNN 47). Sidonie Smith and Julia Watson, who have carried out extensive research into autobiography as a genre, argue "[i]t is impossible to construct a single unchanging self capable of remembering and reciting the totality of the past because each of us lives in time and takes ever-changing perspectives on the moving targets of our pasts" (357). White's question, "Could we ever narrativize without moralising?" (25), is also a relevant consideration for writers of autobiography. Autobiographical composition thus presents structural challenges. Smith and Watson identify particular stories that are commonly used as frames for autobiographies, such as the slave narrative, apprenticeship story, or narrative of political consciousness (357). Stories of self-realisation or self-liberation could be named as further examples. A work based on one of these frames is likely to have an intelligible plot. On the other hand, autobiographical poetry may not be plot-based at all. A collection of lyric poems featuring autobiographical and/or confessional material is familiar territory to any reader or writer of poetry. In terms of narrative, Bloodclot stands somewhere between the two extremes. Because of its recurring characters, and its thematic and formal unifying threads, I consider this text to be a book-length poem, or poem sequence, rather than a collection of separate poems.

How, then, does one approach the issue of plot in Bloodclot? Many of the poems occur in series set in the same time and/or place, but abrupt chronological and geographical shifts, as well as a number of poems with no specific markers of time or place, make it difficult to interpret events as sequential. It is also difficult to ascribe any 
goals or plans to the protagonist. The book ends with the birth of a child, although it is not made explicit that this was the desired final state. Prior to Nafanua's pregnancy, occasional suggestions of her desire for a baby are given. "Nafanua at the Red Sea" depicts Nafanua menstruating or miscarrying, and likens fish to "the souls of lost babies I the mother who missed them" $(76,4-5)$. The expectations of others, particularly family members, are also ostensible. In “Aunty Lapo'a calls Nafanua and talks about her holiday", Nafanua is lectured by her aunt:

What's da use travel travel everywhere an no baby?

\section{A?}

No husband, no baby, no one look after you

you jus fink you smart

even da Palagi dey get marry. $(69,12-16)$

. The final two poems in the book deal with birth, and the arrival of "Alualutoto 2", another bloodclot. This placement suggests that these are redemptive events, and that the narrative has come full circle. Nafanua and her child become one person, just as the two Nafanuas become one person. The penultimate poem is titled "Nafanua is surprised at her birth", suggesting this is both the birth of Nafanua's child, and her own birth; both goddess and human. In this sense the events provide closure. Thus the life of Nafanua from Christchurch could be narrativized by a reader, somewhat simplistically, as the story of a woman's difficult childhood and family life, her travels around the world and search for adventure and love, and her sense of new beginning attained through becoming a mother. However, there is no evidence that this is the author's, or the protagonist's, perspective on the events described. One characteristic of poetry as a vehicle for autobiography is its room for ambiguity. Poetic segmentation both supports and undermines the narrativization of Bloodclot, but is ultimately conducive to narrative in a wider sense. It enables stories to be told, and to be placed alongside each other as a collective whole, whether or not this whole constitutes a plot.

Considered as autobiography, one striking feature of the text is the amount of information that is left out. As well as substituting the name of the goddess for the name of the autobiographical protagonist, which distances the poet from the text, Avia omits 
factual information such as names and dates. Many important events are no doubt left out, while relatively unimportant events - such as talking to a taxi driver - gain in significance by becoming the central subjects of poems. These features lessen the focus on factual authenticity, and allow for more literary readings.

\subsubsection{Units of segmentation and their function in relation to narrativity and narrativization}

Bloodclot is divided into seven sections, which are in turn made up of varying numbers of individual poems. The poems take several forms: some are lineated free verse, while others are prose poems. Lineated poems are at times divided into regular stanzas or couplets, and lines are of variable length. Prose poems are at times divided into paragraphs. None of the poems are organised according to a regular metrical pattern; however, rhythms play an important part. These rhythms are enacted by line-breaks, and also at times by recognisable metrical feet. Repetition is frequently used. Paratexts, including a section of notes, and the jacket copy, also play an important role.

An understanding of the titles of sections in Bloodclot is facilitated by the preface. This tells us Nafanua "arrived in the mortal world armed with four magic battle clubs given to her by her father; the names of the clubs were Ulimasao, Tafesilafa'i, Fa'auliulito and Fa'amategatau" (9). The four main sections are titled according to the names of these clubs, with further elaborations - Fa'amategatau, for instance, is the "victory club", and gives its name to the final section. The first section is intriguingly named "Epilogue", and contains a single poem about the arrival of the goddess Nafanua. This title suggests that the beginning of the book should also be read as the end, and vice versa. In the four poems of the second section, "Susū mai: Welcome, you're all wet", the two Nafanuas emerge as separable entities, providing the groundwork for the material to come. "Pulotu: underworld", the third section, equates Christchurch with the legendary home of the goddess Nafanua. Here it is useful to note that the Nafanua of legend is also a person "living in the borderland between history and mythology" (Hovdhaugen 32). She has clear ties to the mythological realm through her parentage, but has also been involved in historical events considered by some to be factual (32). 
The sections are roughly chronological. They are also roughly geographical, different sections featuring Christchurch, Hawaii, Russia and the Middle East. At times chronology and/or geography are varied or disrupted. Amidst the Christchurch poems is a poem entitled "Nafanua is accused of shoplifting". The notes following the main text explain that this poem is "for Unity Bookshop, Wellington". Although the poem describes Nafanua as a "girl", it is unclear whether this event has occurred during her adolescence or as an adult - although statements in interview suggest the latter (Liang). Other poems, such as "Nafanua reflects on the nature of the human heart" and "Nafanua relates an incident from her childhood" give no indication of time or place. It is unclear whether or not such poems are coterminous with those that precede or succeed them. A reader may justifiably assume these have been ordered according to another framework, such as emotional significance.

The individual poems in Bloodclot usually address a single event. Some represent speech acts, some offer direct reportage of an event, others are less straightforward. As in the texts previously discussed, some poems are more eventful than others. Although the fragmented nature of Bloodclot makes a course of incidents difficult to establish, the existence of culture-specific scripts is implicit in the text. Avia's Nafanua violates these scripts in a number of ways: travelling alone, having sexual adventures with men in Arab countries, delaying childbearing, having many lovers but avoiding marriage. Much of Nafanua's childhood and adolescent experience also breaches canonical scripts, in its violence and abuse (although this is familiar material in autobiography). Perhaps the most significant instances of eventfulness, however, occur when ontological boundaries are crossed.

Most importantly, the division of the text into individual poems allows for fluidity between the two protagonists. This fluidity is further increased by the mingling of the characters within individual poems, facilitated by stanza, line-break and verse paragraph. While the majority of the text could be construed as dealing solely with Christchurch Nafanua, comparisons of the two characters in the opening and final sections, as well as occasional instances elsewhere in the text, invite multiple readings. The early poems "Nafanua is the goddess of war" and "Nafanua is a girl from Aranui" mirror each other in form, and the final six lines of each contain minor variations. This reinforces both the separable and inseparable natures of the two characters. In a later 
poem, "Nafanua and the New World", the two Nafanuas are again placed alongside one another:

Nafanua from nowhere driving out into the world as far away from Aranui as she can go

Nafanua from Pulotu driving out into the world and all the things that make her beautiful spin away like hubcaps.

When her long dead children ask her, Nafanua, mother, what did you do with our lives?

She will answer, Babies, I tucked you away so you would never be lost or hurt or boiled

down for hubcap manufacture. I wrapped each one of you and put you in the sea and you

learned to be red orange blue.

When the old people say to her, Nafanua, daughter, did we hurt you so bad? She will say

I will not bow as I pass, you are dead, your legs are strong enough, go catch the bus. $(42,5-13)$

The final poem, "Alualutoto 2", begins with the narrator in the bath, and continues:

I had to make a noise

When I thought of what I could do

Of how I got here

The ground I grew in

My father riding the waves looking for his brothers and sisters

His big sharp teeth

Their soft soft bodies. . . . (92, 7-13) 
The poem ends with the narrator deciding, in regard to Alualutoto 2, "This goes down the toilet" $(92,23)$. Both Nafanuas are in evidence here. Such comparisons, juxtapositions and fusings between the two characters allow the autobiographical material to be told. Nafanua the goddess shields Nafanua from Christchurch throughout the text, lending the protagonist her name, and also her strength. Every poem in Bloodclot contains emotional material, much of it painful. The incorporation of the legend gives the poet the necessary distance to address difficult subject matter. This distance is further increased by the use of the third person in most of the poems.

As well as using the legend of Nafanua as a background to writing her own life, Avia has used her own story as a vehicle for bringing Nafanua to the surface. In "Waiting for Nafanua", Avia suggests that the goddess has returned to take the place of the Christian God brought to Samoa by missionaries, in the lines:

Take it

Say the words

Pour a little out to her

Forget your God he is no longer with us

He will be made

To walk the streets backwards

And climb the trees upside down. (16, 31-37)

In this context, replacing the Christian God with the warrior goddess is a gesture of hope. In the story-world of Bloodclot, the two Nafanuas depend upon each other: one for strength; the other for renewal. Verse form facilitates the relationship between these two characters: both through the juxtaposition of individual poems, and through the placement of the characters in adjoining stanzas or lines of the same poem.

Avia's use of verse form complements and strengthens the freedom provided by the legend. A number of women poets, including Jane Kenyon, Maxine Kumin and Molly Peacock have claimed that working in inherited forms enables the articulation of difficult and/or emotional subject matter. ${ }^{25}$ While Avia's poems do not use traditional

\footnotetext{
${ }^{25}$ See Barrington 25; Clarke 48; Fay 66; Kenyon 117; Koestenbaum 139; Kollar 141; Kumin 143; Levin 147; Moore 162; Peacock "One Green” 179; Peacock "Gilded Cage” 71; Sanchez 195.
} 
rhyming and/or metrical structures, some of them do approximate to inherited forms, such as the sonnet and the ghazal. Furthermore, most of the poems are relatively short, and exhibit craft in their formal structure. Verse form provides a second layer of protection for the poet writing her own life, by placing controls on the amount of information which may be included, and on the ways in which this information is articulated.

The use of the Nafanua legend as a framing device, and the division of the narrative into poem, stanza and/or verse paragraph, frees the poet to move away from realism in other ways. Bloodclot contains frequent examples of supernatural happenings or references. In "Nafanua gets a pet" the pet is described as "small, black, shiny and has a tail not unlike a devil's" $(32,1)$. Is the pet a black kitten or a mythical creature? "Nafanua does a good thing and gives it to Grandma who is dead but still very kind. I Grandma takes it out of the bag and holds it like a darling" (32, 9-10). Is Grandma merely "dead" in a child's-eye version of the world, or is she a ghost? On what ontological level does the pet exist? In "Nafanua and the devil" the question of whether this is a visitation by Satan or a violent act by a living person remains ambiguous. Again, this ambiguity frees the poet to address difficult material without providing explicit factual detail. In other examples, the poet extends her narrative into myth or fantasy: in "Nafanua goes to Russia and meets some friends from back home" she encounters various Māori gods walking the streets; in "Nafanua meets Rasputin" she has a fantastical love affair with the long-dead historical figure. These instances further unsettle factual representation, reinforcing the strength of the Nafanua legend and the opportunities for multiple readings.

In considering "mythic" and "factual" content within the context of this sequence, it is important to remember that conceptions of fact are plural. Various narrative theorists have noted the truth of myths in relation to the cultures from which they originate (Eliade 6; Leeming 3; Schaeffer 99; Veyne). It is therefore problematic, and undesirable, to try to separate the content of a text such as Bloodclot into "myth" and "fact". The importance of the use of elements outside what is generally accepted as "real" is what they allow the poet to achieve with regard to telling stories. The ambiguity of mythic and factual content is foregrounded by the statement in the first 
preface, with consequences for a reading of the poems to come: "There are many stories about Nafanua. Some are true. Some are not" (9).

While segmentation by poem is the most important unit of formal division in Bloodclot, smaller units, including line, stanza, prose paragraph and in some instances metre, also play significant roles. These roles include the juxtaposition and interpretation of information, the enactment of rhythm, and the highlighting of other aural and syntactic features.

Avia's approach to the poetic line is varied. Her lines range in length from one syllable to prose segments extending beyond the right margin. There are several prose poems, sometimes divided into paragraphs, sometimes segmented by the use of forward slashes. One such example is "Nafanua's sister talks about the family", which begins like a puzzle in need of unravelling:

if anyone asks me i can't explain it/ chuck your washing in/ $i$ was the one in the family who got picked on/ the spoiled one/ the pretty one/ every day i got a custard square chips and a Sally Lunn/ he used to body-slam me into the floor[.]

The phrase "chuck your washing in" is made sense of as the punch-line of a joke about epilepsy; Nafanua's sister is an epileptic. The use of prose and forward slashes rather than free verse lines gives the material a visual density, adding to the cognitive challenges of the puzzle.

Avia's line-breaks do not usually serve syntactic difficulty, nor does she often make use of discovery enjambment. Rather, the key function of the line-break is to render the line as a unit of measure, and to call attention to aural and syntactic devices, including repetition, parallelism, rhythm and rhyme. Avia's first collection of poetry, Wild Dogs Under My Skirt, was performed as a touring solo stage show; Bloodclot has had a less performative career. Not all of the poems strongly suggest an oral rendering, and it would be reductive to describe Avia's poetry as "performance" or "oral" poetry. However, the oral and aural qualities listed above are important to any appreciation of the poems. 
Repetition is frequently used throughout the text. At times, short, repetitive lines function like a chant, for example in "Nafanua talks about her tupuaga o le aiga"26.

po

po

poki your ancestor

kalepe your ancestor

ku'i your ancestor

till

you're

dead

the tupuaga come and live in my head

shark

shark

shark

shark

eel. $(21,21-34)$

Anaphora is also frequently employed, as in the following examples:

Do you want to be purified from sin, she says

Do you want to be purified from suffering

Do you want to be purified through sin, she says

Do you want to be purified through suffering. $(61,25-28)$

or:

like he could subtract

himself

${ }^{26}$ Ancestors and/or descendants 
like he could race in perfect reverse

through the underground

like he could remove his insides

and leave the outline[.] $(63,10-15)$

Calling to mind biblical prose, this type of syntactical parallelism is unlikely to be used to such a great extent in typical modern prose. As such, it can be considered a poetic technique, used to emphasise particular ideas or draw comparisons; it has certainly been a popular technique in free verse since Whitman. Avia's use of parallelism in her comparisons of the two Nafanuas, as mentioned above, lends weight to these.

Rhyme serves a similar function in that it links words or ideas which may at first seem disparate, thus playing a role in reader narrativization. W.K. Wimsatt explains that "[r]hyme is commonly recognised as a binder in verse structure. . . [T] he greater the difference in meaning between rhyme words the more marked and the more appropriate will be the binding effect" (164). Avia's rhymes at times suggest important semantic links, for example:

\author{
Love conquerors \\ of world \\ Exceedingly \\ White \\ she lies face down \\ is what she knows about dogs right? $(37,5-10)$
}

where the rhyme between "white" and "right", combined with the violent scenario in the poem, calls to mind white supremacy. At other times, rhymes lend an absurdity, providing a comic overlay to the primary task of life-narration: "In my knees I have that disease" $(49,1)$; "the one that fits into plane seats with real pain" $(49,8)$; "I'll hand over my visa / and they'll say, Welcome Leeza, we've prepared a place for you" (49, 11-12). 
Here, the chiming sounds and the silliness of "Welcome Leeza" stand in contrast to the negative emotions the narrator experiences in regard to her body.

Metrical lines also occur at times, with effects being more localized to a poem's rhythmic and aural qualities than other levels of formal segmentation. The poem "Waiting for Nafanua" contains a number of lines which are metrically symmetrical or similar, as well as having parallel syntax:

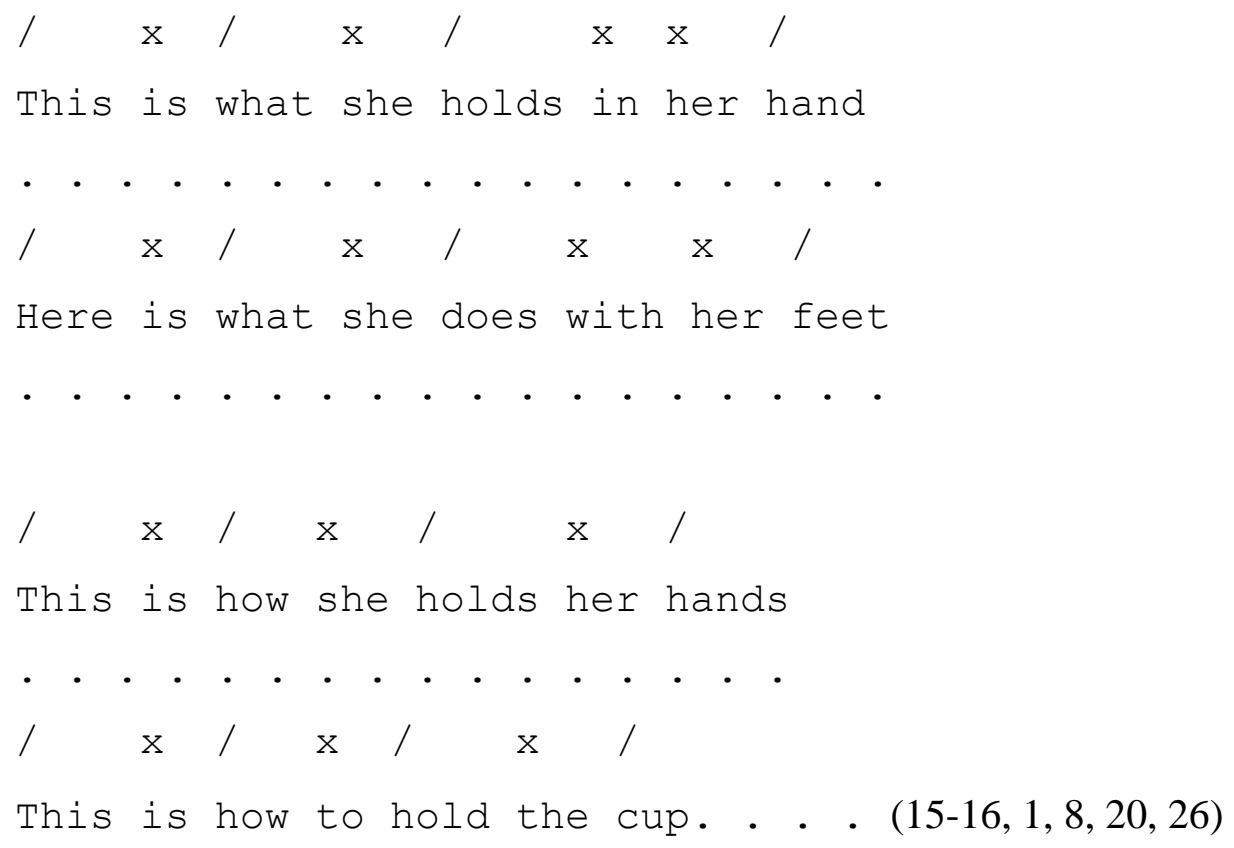

Although the remaining lines do not follow this pattern, these lines give the poem a chant-like, incantatory quality. This reinforces the poem's depiction of the power and the potentially terrifying nature of the goddess. The placement of this poem at the beginning of the sequence means that such aural effects contribute to narrativity by enhancing a particular mood or point of view in regard to Nafanua.

A consideration of the function of paratexts is also important in assessing the role of segmentivity in Bloodclot. A set of notes following the main text plays an important role in narrativizing the poems, providing details such as definitions of Samoan words, and descriptions of places featured in the text. The poem "Nafanua is accused of shoplifting" is ostensibly concerned with Nafanua being accused of stealing a book. Placed within the sequence amongst poems set in Christchurch, the poem takes on an altered meaning when the relevant note "for Unity Bookshop, Wellington" (94) is 
read. The line "and we are called Unity" $(35,24)$ becomes a double entendre signifying the melting-pot notions espoused by proponents of cultural homogeneity, as well as the name of a well-known Wellington bookseller. Another important paratext is the book's jacket copy, which provides coarse detail of the poet's life and work, and also uses the descriptor "automythographical". Without this paratext (and others such as interviews) it would be possible to read Bloodclot purely as a work of fiction, rather than a work containing autobiographical material.

Such an "automythography" as Bloodclot would have been realised differently in the format of conventional prose autobiography. Due to different genre expectations, the dual narrative of goddess and woman might have met with more resistance from readers, requiring a greater degree of linkage, description, summary, explanation and justification. These requirements would have had a bearing on what material was included, and the degree of liberty the writer was able to take in regard to realism. Therefore, poetic segmentation has allowed the dual narratives of Bloodclot to be written, and to be interwoven, meaning that while Bloodclot does not display a clear plot, segmentivity is ultimately conducive to narrativity in this work of poetry. 


\subsection{Bill Sewell's Erebus: A Poem and The Ballad of Fifty-One}

Bill Sewell (1951-2003) wrote two book-length poems, Erebus: A Poem and The Ballad of Fifty-One. The poems examine significant events in New Zealand history: the Air New Zealand Flight TE901 crash into Mount Erebus in 1979, and the 1951 Waterside Workers' Union lockout. Both of these events have remained sources of controversy amongst the wider New Zealand public from the time of their occurrence into the present. In this case study I investigate the narrativity of each of these texts, how particular aspects of the events have been narrativized, how narrativity interacts with lyricality, and how segmentivity through verse form has affected these factors.

\subsubsection{Narrativity and narrativization}

A poet writing about historical subjects faces similar challenges to those faced by any historian. However, verse form provides opportunities to address these in different ways, as well as providing additional challenges of its own. As with other long poems, there are a wide range of options available to the poet, many of these characterised by the degree of fragmentation of a text, and as a result the degree of narrativity, coherence and/or ambiguity. Sewell, who has been described as "arguably, the most polemical New Zealand poet of recent times" (Ricketts "Polemical" 378), has chosen to present his material in a highly fragmented manner. However, clear underlying arguments can be read from each work, both of which are compatible with a unified political perspective.

If the texts are polemical, to what extent are they narrative? In each text, a contrast can be seen between the narrativity of the main text and that of a prose paratext. Sewell includes prefaces in both works, each of which contains a short description of events, along with statements which can be interpreted as guidelines for the reading of the main text. Both of the prefaces fit Prince's definition of narrative, in that they depict chronological sequences of events. Interestingly, they also fit Ryan's definition. A world is constructed in the form of a version of a bygone New Zealand, populated with characters who happen to be identifiable with real people. Changes of state occur - and in relation to Erebus the term "accident" is particularly appropriate - which are both 
non-habitual and not fully predictable. Importantly, Sewell ascribes goals, plans and motivations to particular historical figures, which gives each preface the status of a plot. The plots, while readily assimilable to the interpretations of a large number of leftoriented members of Sewell's generation, must be seen in this context as his own narrativizations. Figures and dates given in the prefaces are compatible with those given in other historical writings (see, for example, Belich 299-307, 391; King 424-425, 456). As will be elucidated further below, some of the opinions suggested within each text are also compatible with these and other sources. However, as with all narrative histories, both the events dealt with are open to alternative narrativizations.

The preface to Erebus states: "Its victims included not only the passengers and crew, and their relatives, but also those involved in the very difficult recovery operation and the protracted investigation" (7). It finishes by describing the Court of Appeal and Privy Council's findings on Justice Peter Mahon's Royal Commission report, explaining: "Their decision led to his resignation from the High Court bench soon after, and, perhaps, to his early death in 1986" (8). Thus Mahon is portrayed as a casualty of a cynical judicial and political climate, which will continue to be painted in dark terms throughout the remainder of the text.

The preface to The Ballad of Fifty-One contains many statements that are inarguably polemical: the Waterfront Lockout is "one of the most shameful episodes in New Zealand history" (7); it "ranks with the Muldoon Government's connivance at the 1981 Springbok Tour as the most cynical adoption of a nationally divisive policy for electoral advantage" (7), but "outranks even the Springbok Tour in the repressiveness with which the Government pursued its ends" (7). The event is placed "[j]ust six years after World War Two, which was after all fought to preserve such freedoms"; accordingly, "[t]hat most of the population was prepared to acquiesce in this policy only compounds the national shame" (7). Quite openly, Sewell states: "These poems make no attempt to be even-handed" (7). While he suggests that the poems do not attempt to offer a "historical account" (7), the preface certainly offers a historical narrative. It also presents an argument which will be referenced frequently in the poems to come.

In contrast to their prefaces, both the main texts are difficult to fit to either Prince's or Ryan's definition of narrativity, for a number of reasons. Firstly, the temporal ordering of the poems is so disrupted that it is difficult to interpret the content 
as a sequence of events. Secondly, many of the poems reflect on events, or upon secondary sources portraying these events, rather than narrating the events themselves. The poems in Erebus are often titled "Frame", suggesting snapshots or vignettes, as well as a pun on the "framing" of pilot Jim Collins by Air New Zealand administration. Thirdly, the difficulty involved in recuperating what happened and in what order makes it difficult to establish causal relations. Fourthly, the lack of a central protagonist in each text means that it is difficult to ascribe goals or plans to any character, and plot is therefore lacking. Erebus in particular displays a lack of closure: as Sewell says of the disaster, "it won't go away" $(58,47)$. As a result, the narrative focus of the text is diverted from the event itself to the roles of political figures, suggesting that the crash functions as an allegory for New Zealand politics of the time. Fifty-One can be considered as having a slightly greater degree of narrativity than Erebus. Closure is suggested by the failure of the Waterside Workers Union to achieve their goals, and the subsequent erasure of the struggle from nationalist mythology: "They left us in an innocence that reeked / of guilt" $(72,1)$, and the dispersion of the union members "Into the blue like everything else" $(74,7)$.

In both texts the presence of a narrator is conspicuous and largely consistent. This narrator is for the most part external to the events related. Many (though not all) of the individual poems appear to be discussing events or addressing characters from the perspective of the narrator at the time of composition, ostensibly the late 1990s/early 2000s. This is indicated in the initial lines of "Knowing better", the first poem in Erebus: "Now that we eat / sundried tomatoes and pesto" $(11,1-2)$ and borne out by later examples, such as "Now, / they'd simply throw glances of farewell / leave the rest to the wind and drift, and go" $(46,12-14)$. It is also evident in Fifty-One: a description of Prime Minister Sidney Holland states “these days / the members wouldn't be seen with him" $(64,9-10)$. At times the narrator anticipates events before they happen; for example, in the poem "Storm warning", the weather forecasts for the day of the Erebus crash are described, with a commentary related to the accident:

\footnotetext{
But cloud is flighty

rarely as reliable as tomorrow:

it mobilises on the horizon
} 
then wipes it out. $(13,9-12)$

Past tense is maintained throughout most of the poems in both texts. At times the narrator refers to the process of research: "They're caught / in those old plates" (B51 15, $1-2)$; or to the process of composition:
And you know it's hard to make
poetry out of the statistics
and regulations, and the newsprint's
corrupting. ... (B51 62, 31-34)

- the latter instance also containing a clever pun on "corrupting". These factors combine to give the impression of a narrator who is at some remove from the events, responsible for their narrativization.

In Erebus, the most significant aspect of narrativization is the inclusion of two political figures: prime ministers Norman Kirk and Robert Muldoon. Kirk was not directly involved in the crash, having died five years prior. Muldoon was prime minister at the time, and was actively involved in discrediting Justice Mahon's report, which had blamed Air New Zealand administration for the crash. Sewell builds on this by presenting Muldoon as a villain, and his government as "Rob's Horror Picture Show" (51). ${ }^{27} \mathrm{Kirk}$, on the other hand, is portrayed as a great "totara" (45), and compared to "a weeping Jesus" $(45,1) .{ }^{28}$ In the poem "The fall of the totara" Kirk's death is depicted as "the end of principle, and the end of hope" $(45,27)$, whereas the election of the Muldoon government the following year is "the start of an era that would be empty of heart" (45, 28, emphases in original). Kirk's death and Muldoon's election are thus linked to the Erebus crash and the judicial climate surrounding the investigation. As indicated in the preface, it is suggested that Justice Mahon's early death resulted from this, which is further indicated by the lines:

\footnotetext{
${ }^{27}$ The title refers to Muldoon's appearance as the narrator in a 1986 stage production of The Rocky Horror Picture Show - which Sewell references in a note.

${ }^{28}$ The phrase "weeping Jesus" was initially used by a friend of Kirk's, Judy Brooker, and gleaned by Sewell from Margaret Hayward's memoir Diary of the Kirk Years (1981).
} 
a late, but by no means the final

casualty of an incident

that occurred at the end of the seventies

in the vicinity of McMurdo station;

and no more detached from it

than a sufferer could be from his cancer. $(55,50-55)$

Mount Erebus itself is used as a symbol of doom, "son of Chaos" $(14,9)$, towards which New Zealand society, like the plane, was inexorably headed: "always on the cards" (14, 13); "always approaching: / a date, an appointment" (14, 15-16). The crash is equated with the death of Kirk, the election of a cynical National government and the underlying shift in public consciousness.

It is important to note that these ideas are, or were, widely held. In Paradise Reforged (2001), James Belich writes that Erebus, like the Tarawera eruption of 1886 and the Napier earthquake of 1931, "was a point where private and public histories intersect, and helps us mark out the advent of a new era" (391). In Belich's view this era is not limited to the Muldoon years; rather, it "happens to include the present" (391). Kirk was, as Sewell explains in his end-notes, described as a "totara" by Māori kaumātua (Grant 7; Hayward 310). It is also a popular belief that had Kirk survived, the New Zealand Labour party would not have lost the 1975 election, and Muldoon would not have been prime minister (Bassett). Broadcaster Paul Holmes argues for Muldoon's central role in perverting the course of justice during the Erebus investigation, casting him as "the diminutive man with the demeanour of a murderous troll" (54).

A similar discrediting of the New Zealand National party can be found in FiftyOne. The preface states this attitude openly. It is also indicated by statements within the poems, such as: "The Herald says as much / in black-and-white / and a rich sort of blue" (47, 10-12). However, a more complicated political picture is painted. Here the New Zealand Labour party, which was in opposition at the time of the lockout, is portrayed as negligibly different from the National party which was in government. In “After the Election, 1949" (a poem drawing on a photograph which is reproduced on the facing page), ousted Labour Prime Minister Peter Fraser is described as "swung to the 
right" $(19,12)$. This is meant in both a literal sense (the way he is sitting in his chair) and a figurative one. The similarities between the two parties are made explicit in "The Red and the Blue", which ends "the same blood ranks them / the same blood dims" (45, 17-18).

The acts of narrativization and related arguments in Fifty-One occur on a more subtle level than the political allegory in Erebus. An aspect of political argument which is not stated in the preface, but is referenced numerous times in the poems, is the portrayal of 1950's New Zealand as subservient to Britain, and largely xenophobic towards migrants of non-British origin. England is referred to (in an ironic sense) as "Home" $(53,21)$; the armed forces who work the wharves in the absence of the lockedout union members are "loyal subjects of His Majesty" (54, 35). A mysterious character named "The Thin Englishman" arrives and takes advantage of local hospitality (17-18), alluding to propaganda using loyalty to England as an argument against the union members' actions. Xenophobia is also suggested in the poem "Home is where the heart is", based on a photograph (also reproduced on the facing page) of the arrival of displaced persons in Wellington in 1950. A boy in the photograph is described as "not entirely happy" $(22,1)$, suggesting that his new "home" will not be as welcoming as might have been hoped. A more understated instance is the inclusion of a poem entitled "The Wreck of the Eunice". Although Sewell does not reference this in the poem or in his notes, the story of the Eunice involves blatant xenophobia. A newspaper account of the time (1917) quotes the court of inquiry:

The court desires to draw the attention of the Minister of Marine to the fact that the master of the scow Eunice, both mates, as well as four members of the crew are by birth foreigners, that the second mate at the helm at the time the vessel struck was unnaturalised. . . no British ship should be allowed to be so officered and manned. ("Wreck")

It appears likely that the reference to this particular shipwreck was made in the knowledge of this report; it is also telling that this poem is positioned immediately before "The Thin Englishman". 
Interestingly, attention is drawn to the act of narrativization in both texts. In "The Valley of Saying" the poet-narrator addresses himself:

\author{
Why, when so many of them \\ have clocked off now, the men \\ who itched and marched and argued, \\ try to re-animate their bones \\ and manipulate the past as you want it? (B51 61, 6-10)
}

At the end of the same poem a rationale is given: "somebody, somewhere, is being cheated" $(62,35)$. "Frame 25: Towards an explanation" questions the significance of the Erebus crash occurring at the end of a decade, which undermines earlier suggestions of the end of an era. Again, the poem ends in an explanation:

And so we can expect

that whatever the day, whatever the month,

Erebus is still irrevocable: it won't go away;

it's part of our history; it's forever. $(58,45-48)$

Both texts also contain strongly lyrical elements. This is in part related to their reduced temporality, and to the meditative nature of many of the poems. It is also effected by the use of lyrical verse forms. It could be construed that the choices to compose and to order the poems lyrically rather than narratively were deliberate avoidances of overt narrativization, and the potential moralising that comes with it. The ways in which narrative-lyric interplay is enacted will be discussed in further detail below.

\title{
2.4.2 Units of segmentation and their function in relation to narrativity and narrativization
}

The units of segmentation in both texts are sections, individual poems (several of which are written in traditional forms or approximations to these), stanzas, lines, and in some 
cases accentual metre. In both texts there are two significant paratexts: a preface and a section titled "Notes" following the main text. All of these units play significant roles in narrativity, lyricality, and narrativization of the texts.

The poems in each text are divided into three untitled sections. Those in Erebus are given epigraphs; the final one, "Something always remains" (43) is taken from Hans Magnus Enzensberger's The Sinking of the Titanic: A Poem (1978), an important model for Erebus. In both texts, sections play a thematic role. The sections of Erebus roughly correspond to the crash itself, the ensuing investigation and reports, and the political aftermath, although there are a number of abrupt shifts within each section. The sections of Fifty-One have been described as "setting the scene for the lockout itself . . clos[ing] in on the period of the lockout ... [and] the aftermath and legacy of that period" (Locke), and similarly as "the setting, the political events of '51, and some consequences" (Wevers). Again, the divisions are not entirely straightforward: Section I leaps forward in time to "Onehunga Wharf, 1971", which logically cannot be the setting for the 1951 dispute. The third section contains four biographical poems, which could easily have been inserted at any point in the text without detriment to meaning.

Segmentation by poem is the most important unit of division in both texts, allowing juxtaposition of information in ways that affect interpretation of that information; the placement of the poems "The Wreck of the Eunice" and "The Thin Englishman" referenced above being an example (albeit one that requires referral to external sources). Such juxtapositions encourage linkage of ideas or events that might not otherwise be perceived as being directly related. Interestingly, segmentation by poem also works against narrative, promoting the importance of gaps and omissions. Despite the informative prefaces, it is difficult to gather a complete picture of what actually happened at Erebus in 1979 or on the wharves in 1951, and in the aftermath of these events, without reference to other sources.

The ordering of the poems is an important factor in the interplay of narrative and lyric. This can be illustrated by a series of poems in Fifty-One, at the end of section II. The poem "Censorship" lists strategies the wharfies could have used, had they not been prevented, and functions as a kind of lament. It is followed by two poems which read as mini-narratives: "The Uninvited Guest" and "Pictorial Parade: A Script". In the former, the guest is described as a "voice amongst you" $(51,1)$, but the source of this voice is 
not identified; possibly, it represents government propaganda via the radio. Regardless, something changes during the course of the poem which affects the family at their table. "Pictorial Parade" describes the troops arriving to work the wharves, loading up cheese for "the hungry people at Home" $(53,21)$, then retiring to "HMNZS Bellona for a wellearned rest" $(54,32)$. Alongside the caustic sarcasm at work in this poem is a straightforward sequence of events. The section finishes with "The Other Side of the Story", a list poem which ends "we have this to say" $(55,25)$, leaving it up to the reader to infer what "this" might have been.

Narrative-lyric interplay may have a bearing on reader response to the poems themselves. Phelan describes how an authorial audience will respond differently to lyric as opposed to narrative by being "less in the position of observer and judge and more in the position of participant" (22). Through participation "we share the speaker's feelings or take on the speaker's thoughts, beliefs, or attitudes" (152). While any poet would hope for at least momentary reader participation, this is of special importance in a reading of political poetry. The poem in Fifty-One which most strikingly invites reader identification with its speaker is "The Enemy Within". Taking its title from a comment of Sidney Holland's, the poem begins by sarcastically describing behaviour that might indicate communist sympathies: the colour of washing, giving away cabbages. In the penultimate stanza the speaker's attention turns inward:

\author{
But perhaps it's you \\ for you could never \\ fully trust yourself: \\ a certain acidity \\ and a burning wind \\ straight from the heart. $(47,13-18)$
}

The final stanza then gives these instructions:
So look into your heart
and consider carefully
what pulses there: 
an irregular beat

a forgotten murmur

a rush of blood to the head. $(47,19-24)$

Here the narrator speaks as a contemporary of the lockout, but the sentiments expressed could equally apply to a present-day reader: political oppression has not magically evaporated post-1950s. The straightforward, emotive language of the poem - the "burning wind", the "rush of blood to the head" - suggests a response that is both emotional and political. The inward turn of this poem is also an example of the work the poetic stanza can do: the shift is facilitated by a stanza-break.

One of the clear advantages resulting from the division into individual poems is the opportunity to use a variety of forms. Inherited forms are of importance in both texts, different forms being used to very different effects which provide additional contrasts between poems, and at times consolidation of content. Sewell uses a number of inherited forms, as well as unrhymed, non-metrical stanzas of regular length, and other forms of free verse. In Fifty-One the ballad form is of central importance, although it is not used throughout. Harry Ricketts points out that Sewell's use of the term "ballad" is akin to James K. Baxter's in "The Ballad of the Junkies and the Fuzz": here, it refers to a story. He explains: "Ballad' places the strikers and their story in a suitably working-class frame but also gives a nod to . . . Brecht and to American protest songs of the early 1960s" ("The Ballad" 26). Two of the poems in Fifty-One do approximate to the traditional 4.3.4.3. metrical pattern, in an accentual metre:

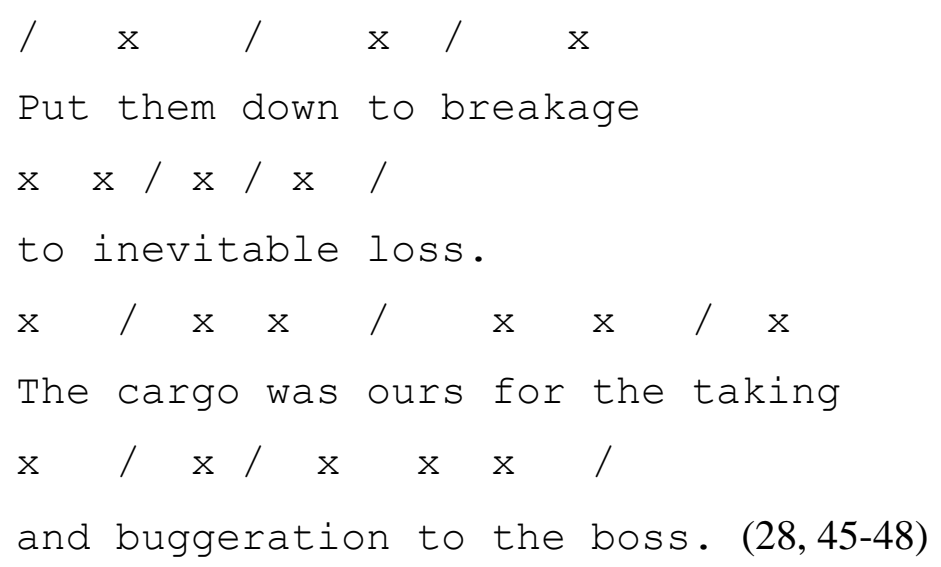


Here the first line is strongly trochaic, whereas the remaining three lines are in rising anapestic and iambic rhythms. All lines have a virtual fourth beat, in contrast to the traditional ballad stanza in which virtual beats fall at the ends of the second and fourth lines. The rhythmical looseness of Sewell's ballads is perhaps due to their composition in an age dominated by free verse, but may also be a deliberate imitation of a working man's style. Lewis Turco differentiates between folk and literary ballads thus: "Folk ballads are written in podic prosody, literary ballads in accentual-syllabics" (95). The use of the ballad form, and the term "ballad" in the title also links to the use of diction which consolidates the working-class frame: "It was a tingling in the balls that told them" $(13,1)$; "the missus in the sack" $(33,8)$; "a square-jawed joker had knocked / the bastard off" $(59,22-23) .{ }^{29}$ The poems "Fintan Patrick Walsh" and "Bull at the Gate" also make use of repeating lines which call to mind the refrain of a ballad.

Another form with significant effects - deriving from aural patterning and association with tradition - is the villanelle. "Fear of flying" is an early poem in Erebus referencing an incident on the morning of the flight, when a woman insisted on leaving the plane and was talked back onto it by Air New Zealand staff. The form is ideally suited to the repetitive thought processes of the phobic. The refrains are varied slightly to draw attention, and give added impetus, to the all-important word "squirm". True rhyme, such as "float/throat"; "burn/churn" is contrasted with off-rhyme or assonance: "float/thought"; "burn/squirm", which enhances the uneasy mood of the poem. "Entropy", the final poem in Fifty-One, is a mostly unrhymed villanelle which preserves the stanza lengths and the use of refrain. The hollowing-out of the form reinforces the dissolution of the union and the erasure of their story from public memory. The repetitive form also draws attention to the cyclical or repetitive nature of history and thus undermines a teleological reading of the poem as a whole. In this context, it is an extremely effective form with which to end.

Other inherited forms used include sestina, haiku and sonnet. Placed in the final section of Erebus, "Sestina on history and the snow" plays a similar role to "Entropy" in highlighting a lack of change. The six end-words - Christmas, nothing, is, left, snow, forgot - form a small poem on their own. Paula Green writes that the sestina form in

${ }^{29}$ The phrase "knocked the bastard off" was famously used by Edmund Hillary after climbing Mt Everest. 
this poem "is a haven for the expression of deep emotion and thought: love, grief, guilt, outrage" ("The Sestina" 68). Its placement near the end of the sequence lends the text emotional weight.

Non-syllabic haiku are used to depict the Japanese casualties in "Frame 18: Postcards to Japan". The haiku make the trademark references to snow and blossoms, and the form is certainly relevant to the culture of the people they depict; however, its use in this context appears less relevant to narrative than some of the other forms present.

A final point in the consideration of segmentation by poem is the use of references from literature or popular culture. These occur in titles: "Fear of flying" references Erica Jong's 1973 novel of the same name; "El Sid" the 1961 film El Cid based on the life of the medieval Castilian hero; "The Red and the Blue" calls to mind Stendhal's The Red and the Black. References are also made within the poems - to Princess Diana, Abba, John Travolta, Luke Skywalker and others. As well as this, some poems take their titles, opening lines or syntactic structure from the work of other poets, including Allen Curnow, Lauris Edmond, Rilke, Gyula Illyés, and Karl Vennberg. These references work together to locate the texts as both literary and "popular". Sewell has said of his work "I aim to make my poems as accessible as possible" ("Bill Sewell"). While this is borne out by the poems in some ways, there are also layers of meaning which would not be obvious to every reader. Furthermore, while forms such as the ballad (as used by Sewell) use simple and familiar rhyme schemes in conjunction with the metrical structure of 'common measure', other forms such as the villanelle ${ }^{30}$ and sestina are less likely to be recognised by a contemporary reader outside of poetry's main readership base.

Stanzaic divisions are not without significance in Sewell's works. Unrhymed non-metrical stanzas of regular length are often used, ranging from couplets through to stanzas of thirteen lines, four- and five-line stanzas being the most common. At times the stanza-break takes on an important role in meaning-making. In "The fall of the

\footnotetext{
${ }^{30}$ Despite its current association with the output of creative writing programmes, within the French tradition the villanelle appears also to have its origins as a working person's form. Julie Kane's 2003 survey of sixteenth- to eighteenth-century French versification manuals finds it portrayed as "a sung lyric composed by uneducated persons" (439). She also finds that the "fixed" form currently in circulation was not prescribed until the late eighteenth century (440).
} 
totara", the stanza-breaks serve a mimetic purpose: "the gaping hiatus of space. // Of course, it cannot rain for every bereavement" (BSE 45, 4-5); "umbrellas bloom to ward off // the excess of light" (8-9) "they almost didn't make // the cemetery in Waimate before nightfall” (12-13).

In "Frame 23: A sense of detachment" a stanza-break negotiates a change in point of view, from second to third person. In "Fintan Patrick Walsh" each five-line stanza begins with the same line, "Two trochees and a single stressed syllable", drawing attention to the spell-like rhythm of the subject's name, as well as the rhythm of the stanzas themselves, which propel the poem forwards just as its repetitions stall it. Many earlier narrative poems - from ballads of the oral tradition to Byron's mock-epic Don Juan (1819-1824) - have a fixed stanzaic form throughout, which may contribute to the movement of the narrative itself by facilitating changes in time, setting or point of view. Contemporary unrhymed stanzas such as those used here may also be taking advantage of this effect.

The division of poems into lines has been particularly useful to Sewell in allowing the insertion of information, particularly quotes, from a variety of sources. He frequently italicises his quotes, indicating to the reader that the phrase has its origin in another source. An interesting example of how the poetic line allows inserted material occurs in Erebus in "Frame 2: The transcript". Here, excerpts from the cockpit voice recorder transcript are interspersed with comments by a narrator who knows the plane is about to crash:

Where's Erebus in relation to us at the moment?

Left do you reckon?

Directly ahead; you can't miss it

Doesn't look very promising does it?

Very hard to tell the difference

between the cloud and the ice

which means they're losing their horizon $(15,9-15)$ 
These insertions create the illusion that the poet-narrator is in conversation with the crew, as well as the reader. A comparison with the actual transcript shows that the excerpts have been considerably re-ordered and in some cases re-worded, perhaps to bring about a more coherent narrative of the moments before the crash. The poem also complicates the act of narrativization through its mixing of diegetic levels. The interspersal of statements by the historical protagonists with the narrator's commentary in hindsight functions as a highly intrusive metalepsis. This heightens the potential for reader awareness that historical material is being consciously manipulated.

As well as allowing insertion of source material, the division of lines allows the poet to merge information in a manner that frustrates reader interpretation. The poem "Frame 9: On impulse" appears to follow a single character, addressed as "you" by the narrator, from his house to the airport to Flight TE901 to his death. However, buried within the poem (which contains no stanza-breaks) are references to First Officer Cassin ("So you left the house / in a hurry" (28, 15-16)), Justice Mahon ("and drafted that report that was a little too / intemperate for its own good" $(28,20-21))$ and Air New Zealand navigation ("typed the number / six instead of four into the programme" (28, 21-22)) as well as the generic passenger who lets the aircraft carry him. The mingling of these separate people reinforces the sense that they died in unison, Mahon included.

Lastly, in each work the inclusion of paratexts alongside the main text is important to a consideration of segmentivity, largely due to the roles these play in assisting narrativization. The very existence of a preface is significant in itself, presupposing that there is information the reader requires prior to reading the main text. Sewell's prefaces serve two distinct purposes: to familiarise the reader with the particulars of events (although, as described above, a degree of local knowledge is assumed), and to introduce the poet-narrator's perspective on the events and agents: for example, "the sinister Fintan Patrick Walsh" (B51 8); Mahon's "early death" (BSE 8); the "shameful" nature of events in Fifty-One (B51 7). In each text, the preface is integral to reader interpretation of the narratives of the main text; "narrativization" in Fludernik's rather than White's sense of the term. The notes following the main text serve a different purpose. Some of these acknowledge literary references or borrowings, although there are many examples within the text that go unacknowledged. Some aid interpretation of particular poems: the note to "The fall of the totara" makes it explicit 
that the tōtara is Norman Kirk. Others give additional facts - how Mt Erebus got its name, what Jock Barnes's nickname was - which are not vital to narrative but contribute to recognition of layers of meaning in the poems to which they refer. Sewell has been selective with the information included: an example being the inclusion of biographical detail on Fintan Patrick Walsh, whereas other figures in the poems such as Peter Fraser, Sidney Holland, Walter Nash and Mabel Howard do not receive this treatment. Again it is likely that the factor under consideration was the contribution to meaning a note would make, as opposed to the relative ease of readers turning to a complementary source or to their own knowledge in order to fill in the blanks. Thus the notes can be seen as additional to the narratives of the main texts, rather than essential to their understanding.

The use of poetry to write about history is fraught with complications, many related to the difficulties involved in shaping a narrative while at the same time maintaining artistic integrity. As this case study has shown, Sewell's works can be read fruitfully for the interactions they display between verse form, narrativity, lyricality and narrativization. Close reading of the texts under consideration suggests that, as with a fictional narrative, segmentivity can be used both with and against narrativity in a historical long poem. While Sewell has chosen not to present a coherent, plot-based narrative within the main poetic component of each text, it is of course possible for another poet to compose a history in poetry as informative and narrative as any prose history.

In Sewell's case, poetic segmentivity makes contributions to the understanding of historical narratives, which would not be available in other literary genres. The interplay of narrative and lyric modes can be considered as being of particular significance in this regard, affecting reader identification with the speaker of a poem, and thus judgment in relation to the events or opinions being portrayed. It also allows for the avoidance of a grand or moralising narrative by resisting narrativization, and incorporates a greater degree of subjectivity than might be present in a conventional prose history. 


\subsection{Anna Jackson's The Gas Leak}

Anna Jackson's The Gas Leak is a book-length poem sequence in three parts, centred on three different characters. Sections one and three feature, respectively, a husband and wife; section two features their teenage daughter. In a note following the main text, Jackson makes explicit that The Gas Leak was written in response to J.M. Coetzee's translation of Dutch poet Gerrit Achterberg's "Ballade van de gasfitter", published in Coetzee's book of essays Doubling the Point. In this case study I examine how segmentivity can contribute to an undermining of narrativity, in conjunction with the use of metafictional and metapoetic devices that push self-reflexivity in the direction of antinarrativity. I also consider the significance of Jackson's model in relation to the two variables of narrativity and segmentivity.

\subsubsection{Narrativity}

In approaching the issue of narrativity in The Gas Leak, it is useful first to consider narrativity in the "Ballade van de gasfitter". Coetzee's translation of Achterberg's poem is the "story" from which The Gas Leak has taken its starting point, and with which it is continually in conversation. Although The Gas Leak stands alone as a poem, a reading of Coetzee's translation provides a clearer picture of Jackson's approach to narrative. Coetzee's essay, subtitled "The Mystery of I and You", begins with a "bald outline" of the poem:

(1) In every house I pass I glimpse You. How can I reach You? Disguised as a gasfitter? (2) Disguised, I am face-to-face with You. But now the disguise cannot be dropped. (3) Shall I gas us both? Imagine the newspapers: "Death of gasfitter and woman. Mysterious letter. Sex motive not suspected.” (4) So I seal the leak in the gasline, and find that You have gone. (5) Ignoring my orders, I resolve to search in the new apartment block. (6) Reconnaissance of the block tells me nothing. (7-8) I fail to find Your name, but am directed upward by a maid. (9) In the elevator I realise what a fool I am. There is no gas here, God is the hole. What am I going to say? (10) The people of the upper floors eject me. 
(11) Back at street level, I realise I have failed. The game is up. (12) The fitter's union calls for a full confession. (13) Years later, we meet the fitter in an old age home, still obsessed with finding the right address. (14) When he dies all the personages of the story, myself included, pay their last respects. (69)

This summary clearly constitutes a temporally ordered sequence of events, and is therefore narrative, according to Prince's definition; despite the mysterious shifts in focalization, and the lack of concrete existents. Similarly, the three sections of The Gas Leak contain sequences of events: in the first, for instance, a couple are married at the registry office; they go driving together; they argue; the husband goes to work as a gasfitter; the couple go house-hunting; the gasfitter visits the house of his wife's sister; a family gathering is held at Christmas. Despite ranking low on the scale of eventfulness, these events constitute a narrative of sorts.

Both The Gas Leak and Achterberg's "Ballade" fare differently when measured against Ryan's three-part definition. Each text initially appears to meet the criteria, but it quickly becomes evident that various elements of narrative are being deliberately undermined. Perhaps the most significant undermining is that of character. Expanding on her first criterion, Ryan states: "Logically speaking, this condition means that the narrative text is based on statements asserting the existence of individuals and on statements ascribing properties to these individuals" ("Modes" 371, emphases mine). Achterberg undermines the existence of the gasfitter in the fourteenth sonnet of his sequence, by having his character (formerly the poet-I) die and be buried, overseen by a replacement poet-I. Coetzee writes: "To kill the fitter, all that is required is that I reassert myself as wordmaster over a domain of words" (86). Following suit, Jackson "kills" her poet-I character, the gasfitter's wife, in the thirteenth sonnet of her third section, entitled "I need not make up stories any more". ${ }^{31}$ This title, and the opening lines "Nothing left to do but print / the sequence out" $(49,1-2)$, suggest the "real poet" is finished with both character and fictional world, further emphasised by the description of the words as "little corpses" $(49,4)$. Furthermore, all three sections of

\footnotetext{
${ }^{31}$ The title is taken from Achterberg's sonnet 11, in which the gasfitter must confess his trespassing to his supervisor.
} 
The Gas Leak contain allusions to the fictionality of characters. The most overt relate to the teenage daughter, for example:

\author{
she wants \\ me three dimensional \\ but you have to be thin \\ as a needle \\ to enter life's vein[.] $(28,10-14)$
}

Pinocchio-like, the daughter in these poems expresses a longing to become a 'real' character, presumably in a more narrative setting: "Life has to have living in mind / for me" $(26,1-2)$, or:

It's like I'm swallowed

by a dream of me,

a dream I'm always

struggling to wake up

out of. . . . (29, 1-5)

or:

we obviously are going

to have to get out of here,

go somewhere where we can

get totally written. $(34,19-22)$

In "The maths lesson solves nothing" Jackson alludes to the triangular diagrams in Coetzee's essay, exploring shifting pronouns:

Like you can just

find the right figure to fill

those empty markers 
$x, y, z$, you, he, whatever,

and it will all

come out right. $(25,5-10)$

These and other examples allude to the dominant theme of much of Achterberg's poetry, of recalling the dead beloved "through the power of the poetic word" (Coetzee 400). They also serve as metafictional comments on the process of constructing a narrative world, and the setbacks involved. The daughter hints at this, and also at the pitfalls of poetry as a narrative genre, in the lines:

\title{
I hate
}

poetry, I'd rather be

a short story writer, getting

bored with a story before

I have written it. . . . (30, 5-9)

The shortcomings of the narrative itself are suggested in section three, sonnet 13 , in the lines:

\author{
What kind of eulogy \\ can I give these corpses, \\ what send-off \\ will make up \\ for such a lousy end? $(49,8-12)$
}

In addition to the fictionality of the characters being highlighted, none of them are characterised to any great degree. The three central characters are either enigmatic, in line with Achterberg, (the gasfitter and his wife) or typical (the daughter). Following Joseph Ewen, Shlomith Rimmon-Kenan suggests three continua or axes along which characters may be positioned: complexity, development, and penetration into the "inner 
life" (41). ${ }^{32}$ Furthermore, she describes the various means by which characterisation occurs: direct definition, action, speech, external appearance, environment, and reinforcement by analogy. The three characters in The Gas Leak could be positioned at the simple end of the complexity continuum, and at the static, undeveloping end of the development continuum. The gas-fitter and his wife lack complexity in that it is difficult to infer much about them; the daughter because she is presented as a typical teenager, whose anecdotes never stray outside the expected. She is what Forster would call a "flat character" (93) and Richard Dyer a "social type" (13). The portrayals of husband and wife focus almost exclusively on their inner lives, in a manner that positions the text firmly within the lyrical tradition. In terms of characterisation, none of the characters has a name; no direct descriptions are given; they carry out only routine or unremarkable actions; the daughter speaks a couple of sentences while the parents do not speak at all; the only aspect of appearance described is the daughter having brown hair; environmental details are minimal. Metaphor becomes all-important in understanding the characters and their emotions: the lift in the wife's workplace which, with its rising and falling, signifies both hope and despair; the mundanity of family life suggested by "the floor / covered in piles of washing" (11, 2-3); the stage on which the daughter acts and its connotations of a constructed, projected persona. In section one, the building of decks forms an analogy for the couple's marriage:

In the weekends he builds her decks -

everywhere she goes,

he builds yellow decks -

she can't sit down

to read a book

without leaving little yellow decks

behind her. $(8,8-14)$

The focus on emotions rather than action or physical attributes (of characters and their surroundings) suggest a degree of experientiality, in Fludernik's terms, in the text.

${ }^{32}$ Ewen's original study was published in Hebrew. 
However, in defining experientiality, Fludernik explains that "the emotional involvement with the experience and its evaluation provide cognitive anchor points for the constitution of narrativity" (TANN 13). As well as there being a lack of a clear portrayal of the experiencers, The Gas Leak remains shadowy about what actual experiences their emotions stem from, and how these experiences are evaluated, making this term difficult to apply. The poems function as something of an emotional residue; clues left behind at the scene of an event or crime that, as with Achterberg, may or may not have taken place.

The story-world of The Gas Leak is further undermined by the reduced importance of its setting. Temporally, we can assume a contemporary setting, although the period covered is uncertain. Geographically, it is located in New Zealand via the use of a single place-name, Ngaruawahia; given this fact, "The streets / that rise and fall" (37, 1-2) imply Wellington. The central character's role as a gasfitter loses the specific relevance it has in Achterberg's poem. The "Ballade" is set in a time and place in which gas lighting and heating are prevalent, but being replaced by electricity in modern apartment blocks. The gasfitter's job is therefore vital; his exploration of the apartment block, in which the climax of the poem is reached, is transgressive. Moreover, Coetzee explains that the original text hinges on the pun on dichten, which has two meanings in Dutch: (1) to seal (a hole); (2) to compose poetry (73). He states: "The gasfitter is a mediator between the vertiginous and fatal powers of pure gas and the needs of man. The craft of the gasfitter is the craft of dichten" (73). The loss of the pun, and the loss of the significance of gas to the poem's setting, could also be seen as a loss of narrativity in The Gas Leak. On the other hand, these factors contribute to a widened scope in Jackson's poem.

Both The Gas Leak and its model could be seen to meet Ryan's second criterion, in that the events described above constitute changes of state. However, the mundane nature of events in The Gas Leak makes clear that, for the characters, nothing changes: the marriage between the gasfitter and his wife continues to stagnate, the daughter continues to act out a typical teenage existence. Ryan's third criterion, relating to an interpretive network of goals, plans, causal relations, and psychological motivations, is also undermined in Jackson's work. While Achterberg's gasfitter has an all-consuming, though indefinite, goal - his metaphysical quest to find You/God - Jackson's characters 
lack direction. The gasfitter hints at feelings for his wife's sister, but does not express any explicit desires; the gasfitter's wife refers to a You (whom Jackson describes in her note as "desiring but, like Achterberg's God, an absence or hole" (51)) to whom she has no specified relationship; the daughter's desire to "get totally written" $(34,22)$ is pure metafiction. Lacking a plot to this extent, the text's emphasis is clearly on its status as self-reflexive or metapoetic poetry, rather than poem-as-narrative. As Coetzee writes of the "Ballade", the post-Romantic poet succeeds in constructing "a poetry that is no more than the process of poetry" (87).

The Gas Leak could therefore be assigned to Ryan's mode of "antinarrativity". Ryan gives several visual metaphors for the antinarrative text, including the "neverfinished picture", linked to a written text thus:

An artist creating a picture may sketch an outline, erase parts, change details, throw the sketch away, and start all over again. The modern text emulates the dynamics of this process by asserting and cancelling information, by building contradictory stories around the same existents, by revising already-narrated episodes, or by exploring the forking paths of possible developments. The purpose of these techniques . . . is to maintain the semantic universe in a state of flux, where represented events never gel into "facts" and never fit into the network of a stable and comprehensive narrative interpretation. ("Modes" 379)

Alternatively, it could be seen as an example of McHale's "weak narrativity": telling stories "in such a way as to evoke narrative coherence while at the same time withholding commitment to it and undermining confidence in it" ("Weak Narrativity" $165)$.

\subsubsection{Units of segmentation and their function in relation to narrativity}

Units of segmentation take varying levels of importance in The Gas Leak. As described above, the book is divided into three sections. Each section is made up of fourteen poems, giving a formal symmetry. The first and third sections, entitled "The gasfitter's marriage" and "The gasfitter's wife" are made up of sonnets in the sense that each has 
fourteen lines, as well as relatively even line-lengths, and in places end-rhymes hint at a traditional rhyme scheme. The second section maintains the line-lengths, but the poems vary in length from 13 to 29 lines; rhyme features at times. Paratexts play an important role in narrativization, particularly the note following the poems, but also the cover artwork which is referred to within the poems.

The three sections allow the juxtaposition of the three central characters. The placement of these characters alongside each other is interesting as much for what it does not tell us about their relationships to one another, as for what it does. We can assume the husband and wife are married to each other, as they narrate some of the same episodes; Jackson also makes this explicit in her note. For the same reasons we can assume that the daughter is their daughter (rather than the daughter of another gasfitter). However, other than this, there are very few concrete details linking the characters to one another. Instead, what links husband and wife is a formal symmetry. Jackson has said of The Gas Leak:

The Gas Leak as a whole is about the gaps in family life. You're all living in the same family, but in a way you're all living in a different family. Everyone in the family has so much that goes on outside of the family. You want to be known as someone who is somewhere else, but within the family that side of you is only present as a kind of ghost of yourself. (Wilkinson)

The term "ghost" seems apt here, as the gaps take greater importance than what goes on "outside", which in the cases of husband and wife is only faintly sketched. The adulterous proceedings hinted at by poems titled "Nothing suggests adulterous proceedings" in each section never come to anything; the husband and wife both have working lives, but nothing eventful takes place in these.

The titles in sections one and three are, for the most part, taken from lines from within Achterberg's poems, which are themselves numbered rather than titled. At times pronouns are changed in order to fit the new context: for example, "As long as I confine myself to this chore" (Coetzee 77) becomes "So long as they confine themselves to this chore" (The Gas Leak 4). Some of these titles are used for poems in both sections one and three: for example, "A master key is easy to procure". Multiple resonances are thus 
set up: firstly between Jackson and Achterberg, secondly between Jackson's husband and wife characters. These resonances are further extended through the use of recurrent metaphors. A prominent example is the metaphor of the ceiling. Achterberg's sonnet 2 contains the line "the ceiling slowly becomes a marble slab" (Coetzee 77, 3). Here, the gasfitter faces You, but making his true identity known would prove fatal. The line also reaches forward to the burial of the gasfitter in sonnet $14 .{ }^{33}$ Jackson uses the line "The ceiling becomes a marble slab" as the title of the third sonnet of her third section. "Ceiling" carries added weight here due to the number of times it appears in section one: "They lie in bed staring at the ceiling" $(3,1)$ is the book's opening line, and is repeated in sonnets 7, 11 and 14 of the first section. This repetition cleverly links the text to its model, and the sections within the text to one another, while at the same time drawing attention to the stagnant state of the marriage, and the uneventful nature of the narrative. The image of the couple staring at the ceiling becomes more repellent with each repetition; the appearance of the "marble slab" in section three equates marriage with death. Then, in section three, sonnet 12, the gasfitter's wife describes "the children grown and buried" $(48,5)$, and, as discussed above, does away with the poet-I in the penultimate sonnet. The marriage has been dead from the outset; all that remains is to kill off the characters and effect poetic closure.

The insertion of the daughter between the parents, rather than contributing to the narrative of their marriage, problematises it further. This is largely due to the abundance of self-reflexive comments in the daughter poems, and to the lack of complexity of her character, as discussed above. It is as though, by giving space to this character, the poet is drawing attention not only to the fictionality of the narrative, but its lack of eventfulness. The use of a social type as a central (and centring) character also lends weight to the impression that the focus of the sequence is poetry as verbal art rather than story. Fotis Jannidis writes: "In many forms of narrative . . . action is not the organizing principle, but a theme or idea, and the characters in these texts are determined by that theme or idea" (23). This is the case for allegorical or didactic fiction, but also holds true for both Achterberg's "Ballade", and The Gas Leak.

\footnotetext{
${ }^{33}$ Coetzee has used "marble slab" for the sake of rhyme: the original Dutch "zerk" literally translates as the more specific "tombstone".
} 
Consideration of the second section also raises the question of formal variation. Green suggests that the daughter's “open-form poems . . . mimic her teenage rebelliousness" ("Narrative" 32); this does, however, risk associating form with ideology. Furthermore, although unrhymed, non-metrical and of varying length, the daughter poems are relatively tight in terms of lineation, and adhere almost universally to the left margin. The difference in form may be due to other factors: the daughter (being a typical teenage girl) is a more garrulous narrator and, therefore, generally requires a greater number of lines to say her piece; the daughter's poems contain more in the way of actual events; the marriage of the husband and wife calls for a formal symmetry that the daughter is not subject to.

Segmentation by poem, used in support of narrative in several of the texts previously discussed, here contributes to its undermining. The shortness of the sonnets creates an episodic structure. As each episode contains little in the way of events, this suggests a mundane and repetitive existence. In conjunction with segmentation by line, segmentation by poem also allows for the insertion of the self-reflexive comments described above. The sonnet is a short form surrounded by white space when printed, which links to the recurrent theme of an absence or hole. White space triumphs in the final poem, in which the letters are printed on top of one another, the "little corpses" of the previous poem "squashed into the margins / by an Almighty / thumb" (49, 5-7). As the title of the first poem states, "Silence, it means something"; a later poem supports this in the line "Safer perhaps to erase" $(40,14)$.

Jackson's use of the sonnet form raises a number of further points. Achterberg's sonnets employ rhyme schemes approximating to the Italian tradition, the octave rhyming ABBAABBA or variations on this, and the sestet rhyming CDECDE, CCDDEE, or CDEEDC, among other variations. ${ }^{34}$ They are also written in iambic pentameter, with a number of interesting, disruptive enjambments. Coetzee's translations in Doubling the Point have a similar rhyme scheme, with frequent use of off-rhyme, as well as approximating to a decasyllabic line, often iambic. A more recent translation, also by Coetzee, in Landscape with Rowers: Poetry from the Netherlands, is more faithful to the original metre. Jackson's sonnets contain frequent end-rhymes,

\footnotetext{
${ }^{34}$ Sonnet 3, for reasons explained by Coetzee as "failure of dichten . . . a flood of gas, logorrhea" (78) has fifteen lines.
} 
sometimes as couplets: "Instead we go where we're sent / Commencing our descent" (43, 13-14); in some instances separated by unrhymed lines:

photographs, and

the name.

In the pictures, the sisters

look just the same $(10,4-7)$

At times rhymes and off-rhymes group together, as if the poet is hovering around a scheme:

while the wedding party before them

all turned and laughed at him

left behind on the seat

of his pants where the street

had skidded out

from under his feet. $(3,6-11)$

"At last the minor leak is traced and sealed", in section three, is almost entirely rhymed:

I wake up once again to a life

I can only continue

and a family increasingly

unrecognisable,

the children grown and buried

in lives of their own,

my son wearing headphones

to the table, my daughter

not eating, my sister flirting

with the man I married.

I'll leave them to go and feed

the dogs you left 
the last trace of the theft, though nothing I'd quite call a clue. $(48,1-14)$

"Own/headphones" links to the internal rhyme "grown"; "left/theft" and "married/feed" are couplets, the latter reaching five lines back to "buried"; the final line ending in "clue" reaches back twelve lines to "continue". Where end-rhyme is lacking, consonance is substituted: the "s" in "increasingly/unrecognisable" and the " $t$ " in "daughter/flirting." In The Gas Leak, the frequency of rhyme suggests a deliberate drawing of attention to device, and thus poem-as-poem: in Wesling's words, "in every line or two, reminding the reader that poetry is a verbal art" (COR 23). Rather than the double focus of form and narrative in Wearne's rhyming poems, the relative lack of narrativity in Jackson's sonnets shifts the focus more strongly towards form.

While many of the titles are iambic due to their origin in Achterberg's sequence, Jackson does not employ regular metre. Her lines often end in hard enjambment, for example:
Also, we have a ghost! In
the second act, one of
the lighting cues throws up
out of the stippling on the
prompt side of the gauze
the face of a man we
suppose must be Pepe $(23,1-7)$

In an oral rendering, these enjambments produce a stuttering effect. They also display a deliberate use of a ragged rhyme scheme, in which "throws" and "gauze" are offrhymes, and "we/Pepe" suggestive of a couplet.

In his commentary on sonnet 9 of the "Ballade", Coetzee describes the structure of a sonnet as "closed" and likens it to the "coffin-cabin" imagery of the lift in the apartment block (82). Jackson's teenage girl hints at this in referring to a "casket" (26, $19)$ and her mother walking from "coffin to coffin" $(31,11)$, a phrase which the mother repeats $(40,4)$. Abandoning traditional sonnet structure places the poems within a 
contemporary stylistic frame, but again loses some of the potential for pun and metaphor found in the original text. Jackson's sonnets could be read as invoking form while at the same time undermining or eroding it, which mirrors the construction of a narrative that undermines the idea of narrative.

The use of a sonnet sequence has further implications beyond Coetzee's essay and translation of Achterberg, linking to a vast tradition of love poetry, into which the tale of an unhappy marriage or a distant lover fits neatly. The sonnet sequence has also been a popular form in New Zealand for meditative or lyrical material; the best-known examples being Baxter's Jerusalem Sonnets and Autumn Testament. In an essay some twenty years old, Gregory O'Brien wrote: "Since the Jerusalem Sonnets, the locallyproduced sonnet sequence has been constantly revived and reinvented. A history of the post-1972 New Zealand sonnet sequence would have to include - for a start - C.K. Stead, Ian Wedde, Dinah Hawken, Leigh Davis, Robert Sullivan and Michele Leggott" (30). That list would now need to be expanded to include Jackson, among many others.

A consideration of segmentivity also needs to include the role of paratexts. The Gas Leak's most significant paratext is the short section entitled "Notes" (51-52), following the main text. Here, in addition to linking the text to its model, Jackson provides clues as to possible narrativizations of her poem. Stating that she began by writing the sequence "The gas-fitter's wife", Jackson explains: "It occurred to me that shifting the terms around on what Coetzee drew up as a triangle might work as an interesting extension of the more usual feminist project of reversing the terms 'desired' and 'desiring' from a male to female attribution" (51). In addition, she writes:

I went on to write "The gas-fitter's marriage" because in "Ballade van de gasfitter" the gas-fitter comes and goes from a home that barely figures in the poem. I became interested in the domestic scene that gets left out of the triangular arrangement with God and the unknown You. (52)

Taking these statements into account, The Gas Leak can be read as a feminist narrative, responding to Achterberg's embodiment of masculine sexuality in the character of the gasfitter who prowls in search of a desired woman. The inclusion of the two female characters of wife and daughter, the use of the first person for the female speakers and 
the third person for the male, and the focus on domesticity, all support this narrativization. A further paratext, the jacket copy, provides additional information in regard to narrativization: the text "offers a glimpse of the gaps and cracks that can exist between family members in everyday life". Supported by Jackson's own description cited above, the words "glimpse"; "gaps" and "cracks" are particularly suggestive, preparing the reader for a minimal narrative in which absence is as important as, or more important than, presence.

The cover artwork also has a bearing on narrative. Taken from the painting Ablage (2000) by German artist Rosa Loy, the artwork is referenced in the poems. In "Sides of the family" the painting becomes a family portrait:

\author{
His wife's sister looks more like him \\ despite their matching red jerseys, \\ looking like school uniforms \\ over the white collars. \\ The vein swelling in her neck \\ resembles the feeling \\ he should have for her sister. $(5,1-7)$
}

This and other references to the painting suggest that the image may have provided a trigger for some of the material in the poems, in particular the suggestions of the relationship between the two sisters.

In addition to, or in spite of, paratextual clues, a reader may provide his or her own alternative narrativizations. The "Ballade" has at times been read as autobiographical. Rita Barnard, for instance, describes Achterberg as "the brilliant, crazy poet who murdered his landlady and then spent the rest of his life writing poems about murdering his landlady, of which "Ballade van de gasfitter" was one" (86). The Gas Leak could also be seen as containing elements of autobiography, although it seems unlikely this applies to the text as a whole. The poem "Indeed I can quite freely step inside" contains the lines:

I do not have a phone number 
or address but stop

and scan each letterbox

for a name - Jackson

rings a bell. $(37,5-9)$

This locates the poet within the text, but functions more perhaps as a self-reflexive comment on the act of composition than as an autobiographical marker. The references to God in section three imply a possible underlying Christian (as with Achterberg) or other spiritual narrative. There are also, as discussed earlier, strong parallels between The Gas Leak and Coetzee's take on the "Ballade" as "a fiction continually generating itself" (78) and "a poem which ends by swallowing its own tail" (86).

In conclusion, segmentivity through verse form, while in some cases highly supportive of narrative, can also work against it. In The Gas Leak, this is achieved through the use of separate sections to juxtapose three characters, by turns enigmatic and typical, the use of individual poems to create an episodic structure low in eventfulness, the use of divisions by poem and line to insert self-reflexive comments, and the precedence of white space. The use of rhyme calls attention to poetry as verbal art; the erosion of the sonnet form mirrors the erosion of narrative. However, no written text is entirely non-narrative, and many postmodern antinarrative texts contain narrative elements. The Gas Leak is open to multiple narrativizations, and also gains in narrativity through linkage to traditions of the sonnet sequence. 


\subsection{John Kinsella's Divine Comedy: Journeys Through a Regional Geography}

John Kinsella's Divine Comedy: Journeys Through a Regional Geography is a booklength sequence formulated around "distractions" on the fourteenth-century Divina Commedia of Dante Alighieri. In this chapter I explore how the use of a canonical narrative model as the basis for a lyric sequence influences the narrativity of this work, how narrative interacts with other text types including lyric and argument, and the role played by segmentivity in these influences and interactions.

\subsubsection{Narrativity}

As with Jackson's The Gas Leak, it is helpful to consider narrativity in Regional Geography in relation to its model. In contrast to Jackson's sequence, which responds to a mid-twentieth-century, weakly narrative sonnet sequence, Kinsella's is written in response to one of the best-known narrative poems ever written. Dante's Commedia could be defined as narrative according to any criterion. A time sequence - itself of significance - is in evidence throughout; events occur in each of the 100 cantos. These events are certainly, in Ryan's terms, "non-habitual" ("Theoretical" 4). Dante's narrative worlds shift between the three kingdoms of the Christian afterlife and fourteenth-century Florence, all of these places peopled with memorable characters. Dante's journey is driven by clear goals and plans - both his own, and those of a higher power. Canto 33 of Paradiso is perhaps the ultimate instance of closure: the protagonist, having passed through all the levels of hell, purgatory and paradise, comes face to face with God.

In contrast to its primary intertext, Kinsella's Regional Geography is best described as a lyric sequence. The links between segments are generally non-narrative: neither temporal, causal, nor teleological, they foreground other modes of thinking. Like the Commedia, Regional Geography is made up of three sections or canticles, which Kinsella calls "distractions" (JRG 3). However, neither the sections themselves, nor the poems within them, are organised according to a time sequence, or a recognisable plot. Smaller narratives exist within these poems, some of which could be described in 
themselves as eventful - a boy being struck by lightning, a farmer's leg being torn off in a machine. Others are narratives of everyday occurrences or observations, such as the poet hunting for insects with his son, or watering trees in summer. The narratives within the poems are at times fictional, often allegorical, and at times documentary, reporting on a range of topics from daily walks around Kinsella's property, to discussions of political issues and current affairs. As a whole, however, they lack the goals, plans and closure associated with plot; in fact, elsewhere the poet has expressed a view of the search for closure as "sadly misguided" (Disclosed Poetics (DP) 124). Although Kinsella asserts that "there is a subtextual narrative at work" (JRG 267), this is difficult to pinpoint, and the work as a whole does not constitute a fully realised narrative.

The title Journeys Through a Regional Geography is itself significant, particularly in consideration of the journey undertaken in the Commedia. In a wellknown essay, Osip Mandelstam describes journeying as a central motif of the Commedia. For Mandelstam, a key point of interest is the way Dante's terza rima represents movement, glorifying "the human gait, the measure and rhythm of walking, the footstep and its form" (400). In contrast to Dante's goal-oriented travels through Inferno, Purgatorio and Paradiso, Kinsella's “journeys" display a lack of linear progression. Formal differences, particularly in regard to the stanza, will be discussed further in the second half of this chapter.

In Kinsella's text, the many seemingly uneventful poems exploring everyday observations and concerns give the work diaristic qualities. In a similar vein to Baxter in his Jerusalem Sonnets, Kinsella mixes his observations of daily life with meditations on spiritual and political subjects. The minute details - bees drinking from a clay bowl, parasitic wasps building their nests, a glimpse of a legless lizard - matter because of what they signify to the poet-observer. Each one of the many animals and plants observed in Regional Geography takes on something of a totemic role. Where the central force of Dante's poem is a heaven-dwelling God, Kinsella's is the natural environment. The meditative qualities, as well as the lack of importance placed on time or action, characterise many of the poems as primarily lyrical.

In the preface to his first canticle, Purgatorio: Up Close (the significance of changing the order of the canticles will be discussed below), Kinsella states: "I had always wanted to write a work over a period of time about one small section of land" 
(JRG 3). Having chosen as his focus the five-and-a-half acre block where his family resides near York, Western Australia, Kinsella wrote the work on a day-by-day basis over the period of a year. More than the other two canticles, Purgatorio displays a tension between the desire to remain structurally faithful to its model, using various motifs and references to map itself against the original, and the day-by-day writing process, evident from the everyday observations throughout many of the poems, and also from the sheer number of cantos included: 87 in total. Read together, the three canticles, all focussing for the most part on the same small physical area, can also be seen as a map in poetry. A useful analogy is a four-dimensional map as might be produced by a Geographic Information Systems program: while the sequence as a whole is not ordered temporally, the poems are not purely descriptive or lyrical, and the occurrence of events gives the poems a temporal dimension. The map is at times "zoomed-in" on, as the subtitle "Up Close" suggests; at other times, it is "zoomed-out", displaying data on a national or international scale. Kinsella's description of the canticle Inferno: Leisure Centre as "a psychogeography of Inferno" (JRG 266) points to further, multi-layered mappings: the mapping of this work against Dante's, the mapping of the poet's personal concepts of "hell" and other aspects of spirituality, and the mental mapping of the persona behind the poems. Although not every poem features an explicit lyrical "I", this unified persona is observable throughout, and (again in contrast to Dante's protagonist), remains largely unchanged from beginning to end. The persistence of this persona adds to the sense of a political manifesto or argument as another significant part of the work. Alongside lyric, argument can be seen as a key text type recurrent in Regional Geography.

The poems and prefaces of Regional Geography, along with Kinsella's other writings, regularly identify the author as vegan, anarchist and pacifist. All three categories place him outside of a mainstream Western worldview, and certainly against the grain of white middle Australia. Although in the prefaces and in other critical writings Kinsella expresses sympathy with, or at least tolerance of, other ways of thinking (DP 34; JRG 266), the poems themselves regularly display uncompromising qualities. Farmers, neighbours, the townsfolk of York, are portrayed in a negative light: “Closed off on their properties, satisfied / they've deleted language of prior ownerships, / they listen to the Queen's Christmas broadcast" (126, 1-3). A neighbour who sprays 
weeds and lays poisoned oats for rabbits features in the poem "Canto of the Invisible Terraces: Between Pride and Envy . . .", with the epigraph "Those thinking they're doing the right thing but . .." The "sinners" dealt with most harshly in Kinsella's work are those who use and abuse animals. In "Canto of Tangential Movement", written from the viewpoint of a kangaroo, hunters run an animal down: "I hear their beer-disjointed contemplations paralleling / my anus, vulva, pouch, with sex rites // they'd commit if they could get away with it" $(149,17-19)$. Hunters are also cast as violent sexual deviants in "Canto of a Pouch for the Violent Towards Animals (Seventh Circle, sub subcircle, 11/12)" in which an older "professional"

will watch, goading

as his wiry boys fuck soft girls; will even

shine the spotlight on them for a laugh:

dirty old bastard. (314, 13-16)

This particular poem is linked via its title to cantos 11 and 12 of Dante's Inferno, in which Dante and Virgil descend to the seventh circle of hell, where the violent are immersed in a river of boiling blood. Here Kinsella superimposes his vegan ethics upon Dante's biblically derived condemnation of violence, creating his own "sub subcircle" for the killers of the kangaroo, and other animal abusers. Importantly, all of Kinsella's poems take place in the "real world": the hunters create hell on earth for themselves (and others), rather than being sent there in the afterlife. "Canto of Boiling Blood (Seventh Circle, first subcircle, 12)" also links to the same part of Dante's Inferno, only here the blood is literal boiling blood, in a local tannery where horses are rendered down in vats. Other poems reference Kinsella's anarchism: "nationless on five acres" (47, 43); "war-time profiteering . . . a market for their golden grain" (102, 19-21); still others consider environmental issues or indigenous land rights. Statements, references and pieces of allegory work together throughout the text to give an impression of clear arguments for particular political viewpoints. Kinsella's work has often been described by himself and others as "anti-pastoral" (DP 34; McCooey 167; Pingping and Phillips; Reed). Kinsella explains: "Writing the pastoral now, here, one must be ironic, and 
(consequently) political" ("The pastoral" 37). The "anti-pastoral” in his poetry attempts "to tackle the contradictions and uncertainties, with an ecologically inclined politics, but also an eye to "how it is"' (DP 34).

\subsubsection{Units of segmentation and their function in relation to narrativity}

If narrativity must be considered against the model in Regional Geography, this is the case even more so with a consideration of segmentivity. Structurally, the sequence (up to a point) mirrors its model, and it is this mirroring which allows references to the original narrative to be made and to be recognised by a reader. It is fair to say that Regional Geography would suffer from not being read in conjunction with, or without a sound knowledge of, Dante's Commedia. In this sense it is a scholarly text, requiring painstaking effort on the part of the reader to piece together even a fraction of the myriad intertextual references.

Segmentivity works both with and against narrativity in Regional Geography. Describing his use of poetic sequences, Kinsella suggests that the relations between segments are of importance; however, these relations are not necessarily narrative:

I often use sequences: within the sequence a textual dialogue is created. Even the narrative destabilises itself through alternative relationships being set up between different sections, chapter, occasions, events. Numbered, asterisks, roman numerals: different languages. Annotations work in a similar way: dialogues within texts, within the frame of the page, across frames, between different surfaces. All poems are part of a larger project. A greater sequence of language usage. Nothing exists as a thing-in-itself. Efforts to disconnect create new connections. (DP 49)

The "larger project" and the poem not existing as a "thing in itself" point to the role of the text as part of a wider corpus of work with recurrent concerns, particularly in terms of political analysis.

Units of segmentation of significance in Regional Geography are the section or "distracted" canticle, the individual poem (here almost always titled "Canto"), stanza, 
and line. Paratexts also play a role in narrativization, particularly the relatively lengthy prose prefaces to each canticle. The relations of segments to the model contain various significances - political, spiritual, and lyrical, if not narrative. In many cases it is the departure from the model which is of interest.

The first observation any reader must make coming to Kinsella's work is that he has re-ordered the canticles, beginning with Purgatorio: Up Close, progressing to Paradiso: Rupture, and finishing with Inferno: Leisure Centre. In the preface to his first canticle, Kinsella suggests that:

In a much-damaged space, where poison and over-clearing are a daily fact of unlife, it seems to me that we have made our own purgatory and have to unmake it to survive. We simply have to move towards a Paradise - one can't countenance Inferno, which is why I've started where I have. (JRG 5-6)

However, while casting light on the poet's spiritual views, this does not fully explain the significance of his re-ordering. Putting Inferno last signals a departure from the original narrative, and its teleological qualities, making Kinsella's work a kind of antiCommedia. Dante came to the end of his journey a changed man, having bathed in the Lethe and the Eunoe, and having been guided to the Empyrean by Beatrice. In contrast, Kinsella's poetic persona does not undergo any ostensible transformation. The mounting sense of relief in Dante's progression out of hell through purgatory and into paradise is replaced in Kinsella's work by a sense of despair or flatness. While all three canticles contain references to blissful experience and to destruction, the poems in Inferno: Leisure Centre are certainly darker, on average, in comparison to the other two canticles. This may be taken as a reflection of an environmentalist theology: that hell, rather than paradise, is where the earth is headed if we continue on our current path.

It is mentioned more than once within the main text, and in its prefaces, that the realms of the afterlife are being considered as part of the earth in the here-and-now, and part of each other. This is highlighted by the final lines: "below the starlit mountain / where earth, hell and paradise // grow inseparable" (408, 26-28). It can therefore be considered that the re-ordering reflects a post-Christian spirituality in which neither God nor the afterlife are a given, and good and evil are not easily delineated. It has also been 
argued that the spiral themes of the Commedia are the "spatial analogues of the terza rima forward motion which recapitulates the beginning in the end" (Freccero 263), suggesting that although it does contain a linear narrative, Dante's poem can be seen as cyclical in this way - a quality which Kinsella may have sought to emulate.

Another way in which Kinsella has departed from the original is through the number of cantos in each canticle. For Dante, numerological harmony was important: reflecting the Trinity and certain passages of the Bible, ${ }^{35}$ the number three "held sacred significance ... as it did for most Christians in the Middle Ages" (Hurley 322). Dante's three cantiche are each divided into 33 cantos (Inferno has 34: this is sometimes considered as a reflection of the disharmony of Satan, in other cases canto 1 is seen as a prologue to the whole). Each canto is composed in terza rima, a form Dante invented, ostensibly as a reflection of the importance of the number three. Composed in hendecasyllabics, each line contains eleven syllables, making each tercet 33 syllables long, a formal structure which "suggests a certain homology between the versification and the formal divisions of the poem" (Freccero 262-263). ${ }^{36}$ This creates a numerical harmony between Dante's levels of segmentation which is further borne out by multifarious narrative links. While Kinsella retains the three sections, and has composed in three-line free verse stanzas, the number of poems in each canticle is variable: Purgatorio: Up Close contains 87, Paradiso: Rupture 57, and Inferno: Leisure Centre 77. This reduces the numerological significance, and also affects the mapping of the work against the Commedia: rather than having a single poem respond to a single canto, Kinsella sometimes has a suite of responses to one canto, at other times cantos (or even entire levels of hell/purgatory/paradise) are unrepresented, and at others different information is worked in. Not adhering to the number 33 could be seen as a reflection of the disordered state of the contemporary world, as presented in the poems. It is also worth noting that Kinsella's poems are generally shorter than Dante's cantos, making the overall work a similar length.

\footnotetext{
${ }^{35}$ For example, Wisdom 11:20: "thou hast ordered all things by measure and number and weight" (New English Bible). Hurley cites this incorrectly as Wisdom 11.21 (322).

${ }^{36}$ This is not universally the case. Pound points out, citing an unnamed source, that "the 'eleven syllable' line was composed of various different syllable-groups, totalling roughly eleven syllables, and not running, so far as I can remember, to more than seventeen" (204).
} 
The beginnings and ends of Kinsella's canticles are another important factor in a consideration of this level of segmentation. Purgatorio: Up Close begins with a canto about the beach. Obviously, this links to Dante's Purgatorio, in which Dante and Virgil watch souls arriving on the beach of the island Mt. Purgatory. It takes on added political significance in Kinsella's work. Kinsella's mountain of purgatory/earthly delight is his local Walwalinj, or in the coloniser's language Mt. Bakewell: a landlocked, bush-clad mountain in a sea of wheatfields. The beach we arrive on in the first poem, "Dream Canto: Egotistical Sublime",37 and observe further in the second, "Canto of the Beach" is the beach longed for by the land-locked farmers, the focal point of white Australian culture, and "the place where the colonisation begins" (DP 36). In "Dream Canto: Egotistical Sublime" the farmers' admission that "yes, yes . . our paddocks were saltwater and krill" $(7,15)$ also references the environmental problem of salination due to clearing of native vegetation for agriculture. Starting with the beach is therefore important to a work which will address issues of indigenous land struggles and environmental desecration.

Kinsella's Purgatorio ends with a reference to "the stars" $(157,34)$, as does each of Dante's three cantiche. Although the other two canticles do not continue this linkage, their endings are significant in themselves: the final lines of Inferno cited above, and the ending of Paradiso which points to "a future" of unknown quality $(260,30)$.

The division of the text into individual poems influences narrativity in a number of ways. The first, and most significant of these is the achronological ordering of the poems. Seasons are sometimes mentioned; however, these references do not occur in a recognisable sequence. Furthermore, poem-to-poem transitions are at times abrupt, changing between subjects, settings, or points of view. While Dante's cantos logically follow on from one another, almost in the manner of a serialised narrative, Kinsella's poems deliberately employ disjointedness and fragmentation. The juxtaposition of material out of a time sequence and without consistent connections is one of the main points of evidence for considering this a lyric rather than a narrative sequence.

Another effect of the division into poems is the manner in which it allows Kinsella to map his work against the Commedia. This casts a light on the political

\footnotetext{
${ }^{37}$ The reason for the reference to Keats's famous description of Wordsworth is unclear.
} 
arguments present in the work, as well as its spiritual concerns. Many of the titles contain explicit links to particular Dantean cantos; other poems reference particular recognisable episodes, not necessarily in the order or magnitude of the original. Although Kinsella describes his work as "allegorical" in a similar manner to Dante's $(J R G 5)$, he often translates figurative detail into literal object or occurrence. A striking example of this is a pair of poems relating to the eagle of Paradiso. While Dante's eagle is composed of the myriad souls of just and temperate rulers, Kinsella's is a native wedge-tailed eagle, uncannily seen in the same place on the same day two years in a row. Kinsella extrapolates on the eagle motif in "Canto of Divine Justice (19: Jupiter)", in which the divine eagle becomes a galah. A reverse movement from literal back to figurative then occurs, when the galah speaks to the poet:

I ask the galah why its grace doesn't shine down between skyscrapers, in houses of government, inside the heads of the military. I am we,

it replies cryptically, as if quarrelling with itself. (193, 13-17)

As an anarchist, Kinsella cannot reconcile himself to the idea of "just and temperate rulers" on earth. The use of the wedge-tailed eagle and the galah in place of the eagle of divine justice positions nature above human concerns, affirming an earth-centred spirituality.

Angels also become "real" objects: "An angel / is an advertising dirigible or a banner towed // over the lipid sea" $(8,5-7)$; or in "Canto of the Moths": "In dull / green light they are tiny angels / without entries or exits" $(9,8-10)$. In the latter example a three-way metaphor is constructed between the moths, the angels, and "spent nuclear fuel" $(9,25)$. Earthworms stand in for angels in "Canto of the Angelic Orders". Likewise, tomatoes are "red planets" $(177,12)$ and Christ is replaced (or represented) by sharks in "Canto of Polyhymnia (23, Fixed Stars)". Dante's four stars representing 
the four cardinal virtues become the four points of the Southern Cross, of which it is said "we can see them down here all year round" $(8,1-2)$.

Snakes feature often, and display a symbolic shift from the Christian association with Satan, to the power of nature. Killing a snake is portrayed as a $\sin$ in "Re-echoing Canto of the Snake Being Run Over". The poem echoes D.H. Lawrence's “The Snake", as well as an Australian bush ballad entitled "The Dukite Snake: A Western Australian Bushman's story” by John Boyle O'Reilly, which Kinsella quotes from as an epigraph to another snake poem, "Canto of Serpents and Theft (Eighth Circle, seventh bolgia, 24/25)". Several poems reference canto 8 of Dante's Purgatorio, in which two angels chase away a serpent: in "Ante Canto 4" two birds fight over a snake; in "Canto of the Stratus of Acacia Leaves" a character named "John" is described as "the angel lunging to ward off pretenders // to his first crop of figs". (40, 30-31)

The division of the text into individual poems also facilitates insertion of allegory amidst documentary poetry. As in the galah poem, "real world" observations often shift into allegorical interpretations. A prominent example of this is "Ante Canto 4". The birds begin to speak as they fight for the snake, ventriloquising through a jam tree and a boulder of granite, in the voices of local body politicians:

I ran for town council and proposed

an abattoir, a lease of life for the Shire,

I am a visionary ... opposed on the basis

that there's more to life than balance sheets ...

that it would downgrade the district ...

I farmed out where the creeks begin

and resisted the soil going saline ... (24, 15-21, ellipses in original)

The birds end in repetitive squabbling: "the snake would be better off with me" $(25,25)$. The comparison here is obvious. 
Departing from the model, the individual poems are expressively titled. The titles alone create enough interest for the table of contents to be viewed as a poem in its own right. These range from the descriptive: "Canto of Listening to Birds in the Tree", to the mysterious: "Canto of Tripping Off the Edge of Earthly Paradise", to the blunt: "Canto of Shit", to the highly detailed, and also humorous: "Canto of the Soothsayers: as they blithely played The Kinks' 'Lola' on the Juke Box (Eighth Circle, fourth bolgia, $20) "$

The stanza is a significant unit of segmentation in this work in that it confirms the text as a response to the Commedia, and provides a point of departure from the model. Kinsella has chosen to use three-line stanzas, which, because they do not display a regular metrical pattern, can be described as free verse stanzas. Occasionally a poem ends in a four-line stanza or an isolated line. Although, as in the majority of free verse, internal and occasional end-rhyme occurs, Dante's interlocking rhyme scheme has also been abandoned. This has had a profound effect on the way the poems have been composed. Repeating rhyme schemes have been shown to exert an effect on the articulation of a narrative (Kinney; Addison "Little Boxes", "Heritage"), pointing the poem in the direction of particular words or groups of words, and thus particular occurrences. Without the rhyme scheme, the poet is free to wander as he chooses, albeit without rhyme's subtextual "guidance". In losing Dante's rhyme scheme, Kinsella's poems also lose the likeness to walking or journeying described by Mandelstam.

In order to contextualise and to further understand Kinsella's use of free verse in Regional Geography, it is useful to consider the ways in which the Commedia has been translated into English. Some translations, such as Laurence Binyon's, Dorothy Sayers and Barbara Reynolds's, and Michael Palma's, attempt to replicate the terza rima form. Others, such as John Ciardi's, use a modified rhyme scheme: in Ciardi's case, couplets with an unrhymed line between each, ghosting the original form. Many are composed in blank verse, including those by Longfellow, Allen Mandelbaum, Mark Musa, Robin Kirkpatrick, and Robert and Jean Hollander. C.H. Sisson's uses lines of between nine and thirteen syllables, without a regular metre. Still others, such as John D. Sinclair's and Robert Durling's, are written in prose. Without attempting a discussion of the relative merits of each approach, it is worth noting that many translations do not contain typographical stanzaic divisions. Dante's original manuscripts are no longer in 
existence; however, early surviving manuscripts, such as those copied by Boccaccio, suggest that the text was written in columns without space between tercets. Because the rhymed, metrical unit of terza rima is an aural unit, there is no need for visual divisions. When a poem is composed in free verse, divisions are not aurally recognisable and must be visually articulated. What effect, if any, does this have on interpretation of a poem? Another poet who frequently used such a form was William Carlos Williams. In a discussion of Williams's three-line free verse stanzas, Cushman writes:

What we can say is that lineation enforces a tripartite division of the conceptual movement within each triad. Lineation gives each triad its epigraphic quality. Even if there is no inherent three-part movement in thematic content, visual format makes each triad a three-part inscription. Where we might not recognize tripartiteness if the triads were printed as prose, we are now forced to see it. In choosing the triad, Williams landscapes an utterance with a beginning, a middle, and an end. The symmetric format inscribes balanced parts within the whole.

Cushman's descriptions of balance and beginning, middle and end could certainly be argued against. The frequent use of free verse stanzas of regular length by many twentieth- and twenty-first-century poets make this an important consideration, and one that does not lead to immediately satisfying conclusions. Dana Gioia, for instance, describes such an approach to form as "pseudo-formal", arguing that "the lines have no auditory integrity. ... Their integrity is merely visual - in a gross and uninteresting sense" (171). What can be observed in light of Kinsella's stanza is that it allows for a degree of syntactic difficulty. Linguistically complex sentences stretch at times over five or more stanzas, and the pacing afforded by the relatively even line- and stanzabreaks make these easier to process cognitively than they would be, had they been formatted as prose.

Lines display a similar length throughout the entire work, which contributes to a sense of balance and regularity. As with Williams's poetry, there is no observable system for line-breaks, and although many fall at aural or syntactic junctures, they would not necessarily be evident to a listener. As part of a largely visual stanzaic unit, 
Kinsella's lines are also primarily visual. Elsewhere, he describes the measure of the poem as "the word, not the line" (DP 93), and also states that "Form is not about line, it is about shape" (DP 58). He unsettles his own analysis later in the same text, writing that "the line is not the measure of the poem; not even the word is. The moment before articulation, the suggestion is the measure of the poem. It is biological, it is chemical" (DP 130). This suggests that, as with Charles Olson, the poet's reasoning in terms of measure is relevant to the situation at hand, and varies across his body of work. In any case the line in Regional Geography is of secondary importance in relation to other units of segmentation. The main reason for this is that on other levels, form reflects the text's model, but the line does not continue this association.

As with other texts in this study, the use of paratexts is of importance in relation to narrativity in Regional Geography. Each canticle begins with a lengthy preface, which provides insights into the composition of the poems. These prefaces are similar in format to personal essays, linking the poet's readings of Dante and his responses through his poems to his own life and conditions. They include statements on spirituality: "Hell is where we are, where we've been, and where we're going" (267); "Celestial bliss is not an option: we've got responsibilities to the land" (164), alongside political statements - the city of Perth is described as "Internecine, greedy, boom-andbust cowboy frontierism" (268) - and anecdotes about the poet and his family. Some parts of the prefaces work to explain particular poems or motifs, such as the recurrence of $\mathrm{Mr}$ and Mrs Potato Head in several poems in Inferno: Leisure Centre.

The use of prefaces has an effect on the interpretation of the work as a journey or map of a "regional geography". Hurley points out that the common inclusion of prefaces by modern translators of Dante "creates a buffer between the reader and the poem" (323). The preface provides the reader with direction, while Dante himself "has no compass or map on his journey; he is led by a guide, and the poem itself, quite deliberately, only reveals its vision step-by-step, rhyme-by-rhyme" (323). Kinsella occasionally refers to a "guide", who is sometimes a figurative guide, often his partner Tracy ("She's a Virgil and a Beatrice rolled into one" (5)), and sometimes his dog Shep. While Kinsella's prefaces certainly affect a reading of the poems by highlighting particular pieces of information, the poems themselves can be seen as the "guide" in this 
work, as mentioned earlier "mapping" the geography they traverse, both physical and internal.

The use of a canonical narrative model has a wide range of effects on both narrativity and segmentivity in Regional Geography. Both adherence to, or reference to, the model, and departure from it, are of importance in the recognition of this work as a lyric sequence incorporating a range of text types, including narrative, lyric, and argument. Segmentivity is of great importance in establishing these features of the text, and its links with the original. Segmentation allows for non-narrative ordering, and inclusion of other text types. It also facilitates intricate and multi-levelled references to Dante's text, making this a truly intertextual work. 


\section{Part 3: Conclusion and Bridging essay}

\subsection{Conclusion to the Critical Component}

In Part 1 of this thesis a review of the literature on narrative in poetry showed a lack of sustained research into the relationship between the narrative and formal components of poems. This study has sought to address this gap by investigating the relationship between an aspect of narrative: narrativity, and an aspect of verse form: segmentivity.

The central research question at the beginning of the critical component asked: what possibilities are offered by verse form that distinguish poetry from other literary narrative genres? The case studies were designed to investigate how segmentivity through verse form may support and/or undermine narrativity in long poems or poem sequences, with the assumption, based on DuPlessis's theory, that segmentivity is a key underlying characteristic of poetry as a genre. Close reading and analysis of the case study texts by six stylistically different poets have pointed to a number of findings in relation to narrativity and segmentivity in the contemporary long poem.

The case studies support the idea that there is no specific direct or inverse relationship between narrativity and segmentivity. Segmenting a poem to a greater degree does not automatically reduce or increase its narrativity or its potential for narrativization. Instead, the effects and interactions of these variables depend upon a variety of factors, including the choices the poet makes in regard to temporal ordering, whether or not a plot is present, the eventfulness of the material, and the ways in which different levels of segmentation work together. On the whole, segmentation through verse form can be shown to work with narrativity or against it, with a number of possibilities in between. This supports the idea that segmentivity through verse form is a distinguishing feature of poetry as opposed to other literary genres. While other genres and narrative media employ various forms of segmentation, poetry can be seen as particularly conducive to various levels of division. These divisions allow numerous methods of juxtaposing information, thus creating a wide variety of possible approaches to narrative. In the case studies these range from the continuous, plot-based verse novels of Porter, through the braided narrative of Wearne, to Avia's and Sewell's loosely 
narrative sequences incorporating factual material, to Jackson's antinarrative sequence and Kinsella's lyrically ordered work. For each of these texts, corresponding examples could be analysed which would demonstrate similar approaches.

The various possibilities offered by verse form, demonstrated by a comparison of strongly narrative with less narrative, antinarrative and lyrical texts, also have a bearing on the concept of narrativity itself. The importance of temporality is shown in that chronologically ordered sequences are much easier to process as narratives, whereas in sequences where chronology is either irrelevant or difficult to retrieve, narrativity is reduced. The importance of consistency and development of character is demonstrated, most obviously through the lack of characterisation in The Gas Leak and subsequent reduction of narrativity, but also by the ways in which characters are presented in the three verse novels under consideration. The importance of goals, plans and motivations is indicated by their clear presence in these verse novels, and by their absence or lack of clarity in other texts, particularly in Kinsella's largely personal and lyrical work. Eventfulness and tellability are related to these factors, and the texts under consideration show great variation in this area. The lack of eventfulness in The Gas Leak highlights its importance to narrativity; however, even in Porter's verse novels, relatively uneventful episodes are shown to be of importance to the plot as a whole. Rather than a consistent level of eventfulness, a variable approach is probably more conducive to narrativity: few readers could sustain interest in a text which continually presented border-crossings or breaches of canonical scripts. On the other hand, the spareness of language brought about by verse form, and the influence of the lyric tradition, particularly its tendency to emotional subjectivity, means that narratives in verse are likely to present a higher proportion of eventful material, both in a narrative and a lyric sense, than prose narratives.

Importantly, it has been shown that different levels of segmentation have different effects on narrativity, some levels playing a structural role, others having more localised effects. The various levels of segmentation clearly distinguish poetry from other narrative genres and media, as the larger levels (book and section) are not entirely analogous to other forms of division such as the prose chapter, and the smaller levels (the poem, stanza, line and metre) are mostly unique to poetry. 
The division of a longer text into books, as in The Lovemakers, aids composition of the text, and its accessibility to readers. It also allows for structural conceits such as the mirroring of beginnings and ends. The division of a text into sections serves a similar purpose. In some cases, such as Porter's novels and Sewell's works, it plays a thematic role. In other cases, such as The Lovemakers and The Gas Leak, sections are based around characters or narrators. Sections can be chronologically ordered, as in The Monkey's Mask or Bloodclot, in an approximate sense. Their juxtaposition may contribute to the undermining of narrative, as in The Gas Leak. The different roles played by sections suggest different methods of composition by the poets concerned. Wearne and Porter are likely to have planned out the sections to some degree prior to writing: Porter around the movement of the plot, and in What a Piece of Work the alchemical conceits, Wearne around the "dramatis personae" of each section. Kinsella obviously began with a Dantean structure, which he chose in advance to subvert by reordering the canticles. Jackson, by her own description, began with her final section in response to Achterberg's sequence, then added the others as a development of this. Sewell and Avia may have worked from the level of the poem to begin with, then organised these into either chronological or thematic groupings.

In all the texts under consideration, the division into individual poems is the most important unit of segmentation, for a variety of reasons. This division has the greatest bearing on whether or not a sequence will be interpreted as narrative. This is largely a matter of temporality: a series of poems with clear markers indicating a time sequence is more likely to be processed as narrative. It is also a matter of consistency: the presentation of the same existents in successive poems is conducive to the development of narrative; whereas inconsistent or erratic references to existents has the opposite effect. In a plot-driven work such as The Monkey's Mask, the ordering of the poems contributes strongly to the making of inferences which affect a reader's interpretation of the plot. Interestingly, this points to poetry as an ideal medium for detective fiction, a genre Porter re-visited in her 2007 verse novel El Dorado.

While in fictional works the division into poems allows for narrativization by the reader, as in Fludernik's terminology, in works containing factual material it also allows for narrativization by the writer, in White's sense of the term. Placing poems alongside each other suggests to a reader that they are somehow connected. The ability 
to draw inferences from these juxtapositions requires varying amounts of effort by the reader, in some cases necessitating reference to external sources.

Segmentation by poem also allows for the juxtaposition of primarily lyric poems with those more easily recognisable as narrative, thus allowing narrative-lyric interplay. In some cases the shift in text types occurs between narrative and argument, as Sewell's and Kinsella's works show. These shifts may also occur within individual poems. In Wearne's case, it could be argued that some of the poems are closer to the dramatic text type, displaying clear qualities of performativity.

One of the reasons why segmentation by poem is so important in contemporary long poems or poem sequences is that the stanzaic structures used in long poems of earlier periods - such as The Faerie Queene, Eugene Onegin and Don Juan - are no longer in common use, although there are more recent examples such as Seth's The Golden Gate, or Rubinstein's Solstice. The division of a text into relatively short poems serves a similar function to the stanzaic divisions in earlier narrative poems; the reduction of narrativity in many contemporary long poems perhaps influenced by the potentially abrupt transitions between individual poems, as opposed to stanzaic divisions which can more easily accommodate both logical flow and digression. The division of a long poem into books without regular stanzaic divisions, as in Paradise Lost (1667-74), Robert Browning's The Ring and the Book (1898-9) or Elizabeth Barrett Browning's Aurora Leigh (1856), also seems to have fallen out of favour although again there are exceptions, such as Frederick Turner's The New World (1985). This structure is perhaps closer to the prose chapter than a section made up of relatively short poems; it is also less conducive to digression than a stanzaic poem or a poem sequence. Parts of The Lovemakers, notably the lengthy monologues by Kevin and Stubbs, could certainly be likened to the dramatic monologues of The Ring and the Book, although the remainder of the novel is structurally dissimilar.

Another reason for the importance of segmentation by poem is that contemporary readers of poetry are familiar with the format of a collection of short lyric poems. Contemporary poets writing long poems or sequences play on, or respond to, these expectations, whether subconsciously or consciously. All of the texts studied here could be considered as descending from the lyric collection; all the poets had published collections before publishing book-length sequences or verse novels. Rather than being 
the direct descendants of the narrative poems of Byron or the Brownings (Wearne's monologues being an exception), these works trace a clear lineage to twentieth-century collections of lyric poetry. Again, other examples stand in contrast: Byron's Don Juan (itself a descendant of the works of Boccaccio, Ariosto and others) has its literary descendants in Kenneth Koch's Ko: or, A Season on Earth (1959) ${ }^{38}$ and Anthony Burgess's Byrne (1995).

Inherited formal patterning is one of the major resources available to poetry which distinguishes it from other written genres. The use of inherited forms in contemporary poem sequences has an important bearing on reader interpretation and appreciation of the work. Inherited forms bring the various associations of the tradition to which they belong - such as the sonnet sequence, ottava rima stanzas, limericks or villanelles. In some cases, as in Wearne's novel, inherited forms are useful in portraying diverse characters. In others, such as Sewell's works, inherited forms provide an additional layer to meaning. In The Gas Leak and the poem "Entropy" in The Ballad of Fifty-One, erosion of an inherited form has significant effects: in Jackson's case mirroring the subversion of narrative, in Sewell's, underscoring a sense of dissolution and loss in the book's final poem.

The use of stanzaic divisions varies in importance between poems and between texts. In poems such as Wearne's "Non in spatia sed in muneribus capitus", an inherited stanza creates opportunities for intertextuality and for digressions and metalepses. In free verse poems, it is evident that the stanza is primarily a visual unit. Stanza-breaks can be used productively to support meaning in a poem, as shown by Sewell in "The fall of the totara". They may also allow for reader processing of linguistic denseness, as in some of Kinsella's poems. More attention to the cognitive processes of reading would be needed to assess fully the significance of the stanza-break. The possibility that free verse stanza- and line-breaks are relatively insignificant to reading must not be discounted. Readers of contemporary poetry are generally trained to see significance in such breaks, and poets may be capitalising on this.

Interestingly, despite the amount of critical attention by poets and academics to the free verse line, it is not as important a division as one might be led to think. Of all

\footnotetext{
${ }^{38}$ Koch directly names Don Juan as the model for his work (248).
} 
the case study texts here, Porter's works appear to place the greatest importance on the line: it is often used to draw attention to information with a bearing on plot, or to recurrent themes or motifs. In general, segmentation by line tends to have localised effects, which are less significant than those of segmentation by poem. Again, cognitive studies might be useful. Furthermore, although controversial, the possibility that the poetic line is over-theorised must be taken into account. Comparisons between metrical and non-metrical poems would add to understanding of the aural and visual functions of the line; it can be seen from existing studies that in a work such as Paradise Lost, the iambic pentameter line, with its enjambments and metrical variations, has a bearing on meaning (see, for example, Fussell 49-51, Hollander 91-116; Kinney; Ricks). Interesting comparisons could also be made between prose poem sequences and free verse sequences: the differences in interpretation may well be slighter than critics of contemporary poetry might expect.

Metre is only of occasional significance in the case study texts: where inherited forms are used, and where a poet incorporates a regular stress pattern into groups of lines, as demonstrated by Avia. My focus on contemporary poetry, which is largely non-metrical, has unfortunately lessened the extent to which I have been able to investigate the role of metre. In considering its importance, it would be interesting to compare free verse sequences to texts in inherited forms such as The Golden Gate, or to earlier narrative poems such as Don Juan or Aurora Leigh. Conceptions of rhythm made by theorists of free verse are often difficult to apply in practice, and such an investigation might shed light on this common point of confusion.

As identified by Wesling, rhyme occurs frequently in free verse. It has a variety of effects, including promoting semantic links between words, as in Porter's novels, humour, as in Wearne and Avia, or the suggestion of an inherited form, as in Jackson. Rhyme is of particular importance in inherited forms, such as those used by Sewell and Wearne. In Wearne's case in particular, the double focus of rhyme-scheme and narrative affects reader interpretation of, and engagement with, the text.

While paratexts are not a unique feature of poetry, the relationship between a poetic text and its paratexts has implications for the relationship between narrativity and segmentivity. In general, as texts become less narrative, paratexts gain in importance in relation to narrativity. They are also of greater significance in works based on factual 
material than in fictional works. Paratexts are of minor significance to plot interpretation in Porter's and Wearne's novels. Prefaces and end-notes are important to narrativization in the works of Avia and Sewell; an end note also serves to make sense of The Gas Leak. In Kinsella's work the prefaces are lengthy and seek to explain the work as a whole. While they aid the understanding of the poem's composition, and justify particular formal and narrative choices, Kinsella's prefaces can be seen as a continuation of the material presented in the poems.

The disagreement between McHale and Heiden over the application of DuPlessis's term "segmentivity" centres on the relative degree of coincidence or counterpoint of line and syntax. Heiden in particular may have shaped his argument around DuPlessis's statement that "Poetry is the kind of writing that is articulated in sequenced, gapped lines" (51, emphasis mine). While one can certainly argue, as McHale does in his reply to Heiden, that line-breaks may support or disrupt syntax, their relative importance to narrative does not appear to warrant a sustained argument on this subject. Instead, DuPlessis's observation that "all the meanings poetry makes are constructed by segmented units of a variety of sizes" (51) can be read as the more relevant aspect of her definition of poetry. This study supports this observation, with the further observation arising that the units of varying sizes also vary in their importance to a poetic narrative.

As the field of this thesis is creative writing, this study has implications for creative practice: both my own in the creative component and no doubt in future poetic endeavours, and for the work of other poets with an interest in narrative and verse form. Further to this, I offer the findings of this study as a contribution both to narrative theory and literary criticism of poetry. My investigation of the relationship between narrativity and poetic segmentivity adds to the body of work in transgeneric narrative theory, elucidating some of the features which distinguish poetry from other literary narrative genres. In terms of poetry criticism, the focus on narrativity addresses a gap in the literature, and the focus on different levels of formal segmentation in contemporary poetry sheds light on issues surrounding verse form, in particular free verse. The most important implication in this regard is the relative lack of significance attached to the free verse line-break. 
A greater understanding of the relationship between narrativity and segmentivity would be achieved through comparative studies, as mentioned above. Other branches of narrative theory, such as cognitive narratology, will have more to say about the processes of gap-filling, and could be more thoroughly investigated. Comparisons of segmentation in poetry with that of other media such as film and graphic novels (as with McHale's study of Rowson's The Waste Land) would also likely yield interesting results.

Another point which is outside the scope of this study, but which could shed light on the issues raised by this thesis, is the role of genre expectations. To what extent do writers play to the idea that readers expect poetry to be fragmented, non-narrative or primarily lyrical? Is antinarrativity or weak narrativity more acceptable in long poems than in prose fiction, and does segmentivity contribute to this?

The findings of this study suggest that the investigation of the relationship between narrativity and segmentivity in long poems and poem sequences yields many interesting observations; the most important being that segmentivity through verse form can support or undermine narrativity, or both, and that different levels of segmentation affect narrativity in different ways. These findings also point to a broad range of possible topics meriting further analysis. 


\subsection{Bridging essay to the Creative Component}

The critical component addressed the central research question by assessing segmentation in long poems and poem sequences. The creative component approaches this question from another angle: through creative practice in the composition of a poem sequence.

I began this project with a concept for the creative component which has changed over time. The changes have been brought about by the findings of the critical component, as well as wider reading and creative experimentation. In this essay I link the findings of the critical component to the creative component by considering the relevance of narrativity and segmentivity within the specific context of my own work of poetry based on historical events, with ecological and socio-political themes.

\subsubsection{Narrativity and narrativization}

The creative component consists of a work in three sections, entitled Flow. The original concept was to have several narrative sequences based on stories from the Whanganui river region. The work evolved into a single entity with the river as a focus; it also became less narrative, incorporating elements of lyric and argument.

There are specific and deliberate reasons for the reduction of narrativity in this sequence. One is that it is impossible to tell "the story" of a geographical region and its people: there are many stories relating to this place, and many interpretations of these stories. Importantly, the significance of the relationships between Whanganui iwi and the river cannot be adequately addressed by a Pākehā writer. Although six generations of my family have lived in this region on and off, and although I have a strong personal connection to the river, I felt that a unified narrative was beyond my understanding or capabilities, and a fragmented approach was better suited to the way I wanted to respond to local geography and history.

Another reason for avoidance of continuous narrative is the time-scale of the work. As the critical component demonstrates, temporal organisation, development of characters, and the existence of a plot all contribute to narrativity. The first section, entitled "Catchment," features events which took place between 1864 and the 1980s, 
making it impossible to follow a single protagonist. Moreover, having a protagonist would have required a more limited focus and a greater degree of fictionalisation. A verse novel set in Waimiha could well have been an interesting endeavour, but was not the project I embarked upon.

The three sections of the sequence display different approaches to narrativity. "Catchment" is ordered chronologically and could thus be considered loosely narrative; it depicts the retreat of Waikato iwi into the King Country/ Te Rohe Pōtae following the invasion of the Waikato by colonial troops, the subsequent opening of the King Country as the Main Trunk railway went through, and the boom-and-bust economics of sawmilling which followed. Near the end of the sequence the treetop protests by the Native Forest Action Council point to changing Pākehā attitudes towards the natural environment. A line in the early poem "Plotlines" which states "The greatest stories of all time are geological" $(152,40)$ is intended to reflect the processes of deep time, thus avoiding the privileging of particular human perspectives. It would be foolish to make any claim to objectivity: as an individual I acknowledge strongly held opinions on colonisation and environmental issues, which I have not sought to avoid or down-play in the poems. However, I have attempted to include a variety of perspectives in order to better portray the complexities of the situation. "Catchment" contains six poems (all in free verse) set in 2013-2014, which feature the explorations I made with my family during the composition of the poem. These insertions undermine narrativity by drawing attention to the fictionality of the other poems, and by severely disrupting the chronology. However, they also function as something of a meta-narrative of the process of composition. Furthermore, they provide glimpses of the current state of former sawmilling and mining towns in a now-depopulated landscape.

The middle section, "A body of water", takes its inspiration from the granting of legal personhood status to the Whanganui River in 2012, and the settlement of the Whanganui River Treaty claim in 2014. I chose to order this section geographically rather than chronologically, and to include a larger amount of lyric material, to avoid any attempt at narrativizing a history which is patently not my own. While this section contains narratives of particular historical figures, including Richard Taylor and Suzanne Aubert, it is not in itself a narrative. Recurrent motifs occur in the form of 
short poems about the native fauna of the river; these are intended to have something of a totemic function, but also to highlight the environmental effects of human activities.

The third section is positioned towards the less narrative end of the spectrum, via a lack of either chronological or geographical order. A series of sonnets feature stories and observations from the Whanganui port and town, organised around the conceit of recurring shipwrecks. A narrative, or indeed an argument, could perhaps be extrapolated from this; it is my hope that multiple narrativizations will be possible.

In all three sections, eventfulness is variable. The animal poems contain little in the way of narrative interest; the autobiographical poems largely document the everyday. In other cases poems feature border-crossing events: land wars, acts of violence, protests and accidental deaths. Histories are by nature fragmented, and the significances of various occurrences not always clear. National histories tend to feature events of political importance; however, the personal, domestic and mundane happenings of everyday lives are as much a part of culture and society. A sequence of poems of varying eventfulness and varying narrative focus provides an alternative means of portraying these complexities.

\subsubsection{Segmentivity}

As described above, Flow is divided into three sections: "Catchment" focuses on the catchment area of the river, "A body of water" on the river itself from mountains to sea, and "The moving sand" on the river mouth, port and town of Whanganui. Each section is divided into 33 poems, making a total of 99 poems. As well as being a Dantean conceit, this division reflects the importance of a three-part division to Whanganui iwi, whose main hapū, Hine-ngākau, Tama Ūpoko, and Tūpoho, trace their lineage to three siblings, and whose rohe (tribal districts) comprise three distinct geographical areas. "Te taura whiri a Hine-ngākau" is a local saying referencing "the plaited rope of Hinengākau": when the three strands come together as one. From a craft perspective, three sections seemed both a natural and a writeable structure; 33 poems provided a workable limit in the organisation of diverse and difficult material. The differing methods of temporal and geographical organisation in each section provide contrasts which are consolidated by different approaches to verse form. 
The writing of each section began with a particular form in mind. In "Catchment," the ballad seemed a good fit to colonial narratives. "A body of water" started with the ode: a form traditionally associated with celebration, and which felt appropriate in responding to the subject at hand. "The moving sand" became a sequence of variations on the sonnet, essentially by accident. However, once established, the form proved to be ideal for truncated narratives. Writing (and in some cases re-writing) material in sonnets was a valuable experience in understanding relationships between form and content.

My initial interest in undertaking this thesis stemmed from the experience of writing a book-length sequence, Dear Neil Roberts, addressing the suicide of a young punk anarchist outside the Whanganui Police Computer centre in 1982. Through writing this sequence, I became interested in the ways in which historical narratives are constructed, and how political material might be presented. For reasons which were perhaps arbitrary, I wrote Dear Neil Roberts entirely in free verse quatrains (although irregular end-rhymes, off-rhymes and visual rhymes occur frequently). In early drafts of poems in "Catchment", I continued in this form, but quickly became fatigued by it. The ballad is traditionally based around a four-part structure: four-beat lines (counting the virtual beat in the second and fourth lines which is actualised in a musical rendition) and four-line stanzas. As well as variations on the ballad, "Catchment" includes a number of other four-line forms: fourteeners, sapphics, the Kyrielle, the "In Memoriam" stanza, Rubaiyat stanzas, and other variations on rhyme-schemes and metrical arrangements. One of the issues I encountered with free verse quatrains was a tendency towards the prosaic. The inherited four-line forms force the composition away from prose towards the aural qualities of chant and/or song.

Beginning with the ode in "A body of water", I looked to various models. Thomas Gray's “The Progress of Poesy: A Pindaric Ode" provided the starting point for the forms used in "Seed" and "Kauarapaoa," the important aspect being mixed measures alternating between pentameter, tetrameter and alexandrine lines. "Foundlings" is written in terza rima: most obviously associated with Dante's Commedia, but also used by Shelley in "Ode to the West Wind". Experiments with the Keatsian ode proved unsuccessful, but the poems "Hīnaki" and "Spoonbill" are sestets rhymed CDECDE, a feature of both Italian sonnets and Keats's odes. "Flood" is loosely based on a form 
known as the "Ronsardian ode", although its attribution to Pierre de Ronsard is dubious. Many of the poems in this section use variable metrical structures. The rhythmical shifts seemed a good fit to the shifting currents of a river and of the changing social world around it; I have also used several nonce forms based on varying metre. This focus, along with an interest in repeating forms and interlocking rhyme schemes, led me to model poems on works by Arnaut Daniel and Guido Cavalcanti; particularly as translated by Pound, but with reference to other translations. I have also included a villanelle, a sestina and a triolet.

The sonnet as a basis for the third section arose by accident. In an early, free verse draft of the poem "Blood and sand", I noticed that the final two lines were iambic tetrameters. In re-working the poem, I decided to extend this measure to the remainder. The result was seven couplets linked by off-rhyme or assonance: fourteen lines in total. The other poems in this section include variations on Shakespearean and Petrarchan sonnets, some off-rhymed, some non-metrical, a blues sonnet, a sonnet-sestina crossbreed, some fourteen-line poems in blank verse, and some in couplets. It is my intention that the combination of truncated or subdued narratives with the various formal variations brings about a discordant, polyphonic, achronological and complex portrait of a physical and social environment, which can be likened to a beach strewn with debris after a storm. Some of the objects on this "beach" are identifiable; others are not. At regular intervals are poems about shipwrecks. The bar at the mouth of the Whanganui is dangerous, and in times when coastal transport was more common, ships were wrecked there on a regular basis. The use of a motif helps to tie together otherwise disparate elements; it also serves as a reminder of the conflicts between human endeavour and natural processes: one of the themes of Flow as a whole.

In working with inherited forms, I have greatly extended my own poetic practice. I began publishing poetry ten years ago; my first collection Secret Heart was composed entirely of prose poems. Since then, my published work has been mostly free verse or short fiction. In undertaking the critical component, I learned a great deal about the potential of inherited forms to contribute to meaning. I also located a gap in contemporary poetry, especially within New Zealand. While there have been significant bodies of poetry in inherited forms published in Britain, the United States and Australia over the last thirty years, New Zealand poets appear by-and-large to have avoided such 
an approach. As well as an exploration of craft, I have undertaken something of an artistic risk. Combined with the varying, experimental approaches to narrative and the various levels of segmentation in Flow, this exploration and risk-taking tests and extends the findings of the critical component in regard to narrativity and segmentivity. 
Creative Component: Flow 
He pūkenga wai, he nohoanga tāngata he nohoanga tāngata, he putanga kōrero

Where there is a body of water, people settle and where people settle, legends unfold

Whanganui River proverb 


\section{List of Illustrations}

Fig. 1 Map of Whanganui River Catchment 161

$\begin{array}{ll}\text { Fig. } 2 \text { Map of Whanganui River } & 217\end{array}$

Fig. 3 Map of Whanganui Town 289 


\section{Contents}

$\begin{array}{ll}\text { I Catchment } & 157\end{array}$

Confluence: Taumarunui, 2013

Plotlines: Waimarino, 2013

$\begin{array}{ll}\text { Clear away: Ōrākau, } 1864 & 167\end{array}$

Hat on a map: Te Rohe Pōtae, 1870s 169

Pigs, potatoes: Te Kumi, $1883 \quad 170$

A living sea: Te Nehenehenui, $1884 \quad 172$

First sod of the Main Trunk Line: Pūniu, $1885 \quad 175$

Surveyor's grave: Tāngarākau, $1893 \quad 176$

Into the ground: Kākahi, 1905

$\begin{array}{lr}\text { Sound the Whistle: Manunui, } 1907 & 178\end{array}$

Inroads: Ōhura, $1913 \quad 179$

Roads: Central Volcanic Plateau, $2013 \quad 180$

Tree-oh!: Kākahi, 1914

$\begin{array}{ll}\text { Only dancing: Kākahi,1916 } & 185\end{array}$

$\begin{array}{ll}\text { That winter: Ōngarue, } 1923 & 187\end{array}$

The road out of here: Upper Retaruke, 1927

$\begin{array}{ll}\text { Falling branch: Manunui, } 1928 & 190\end{array}$

$\begin{array}{ll}\text { Out of the ground: Waimiha, 1930s } & 191\end{array}$

Three days: Horokino, 1936

Up to their necks: Tokirima, 1940

$\begin{array}{ll}\text { Eggs for an army: Ōngarue, 1940s } & 194\end{array}$

Forgotten world: State Highway 43, 2014

$\begin{array}{ll}\text { What sport to-night?: Ōngarue, } 1953 & 198\end{array}$

Cutting down King Mahuta: Ōngarue, 1950s 199

Bush Tram: Ōngarue, 1955

$\begin{array}{ll}\text { Parts shed: Pureora, 1950s } & 201\end{array}$

This'll do me: Ōngarue, 1962 
Oil drill: Ōtunui, 1966

Final whistle: Ōngarue, $1966 \quad 205$

Treetops: Pureora, $1978 \quad 206$

$\begin{array}{ll}\text { Buried forest: Pureora, } 1983 & 208\end{array}$

Tributaries: Taumarunui to Piropiro, 2014

Huihui: Taumarunui, 2014

$\begin{array}{ll}\text { II A body of water } & 213\end{array}$

$\begin{array}{ll}\text { Puanga } & 219\end{array}$

Snow 223

$\begin{array}{ll}\text { Seed } & 225\end{array}$

$\begin{array}{ll}\text { Flow } & 227\end{array}$

$\begin{array}{ll}\text { Kākahi } & 228\end{array}$

$\begin{array}{ll}\text { Western Diversion } & 229\end{array}$

$\begin{array}{ll}\text { Whio } & 230\end{array}$

$\begin{array}{ll}\text { Map-making } & 231\end{array}$

$\begin{array}{ll}\text { Shingle beach } & 233\end{array}$

$\begin{array}{ll}\text { Trout } & 234\end{array}$

$\begin{array}{ll}\text { Grayling } & 238\end{array}$

$\begin{array}{ll}\text { Spring - Black, red and white } & 239\end{array}$

$\begin{array}{ll}\text { Kōura } & 243\end{array}$

$\begin{array}{ll}\text { Whirlpool } & 244\end{array}$

$\begin{array}{ll}\text { Dynamite } & 245\end{array}$

$\begin{array}{ll}\text { Fire } & 246\end{array}$

Hīnaki 252

$\begin{array}{ll}\text { Tuna } & 253\end{array}$

$\begin{array}{ll}\text { Foundlings } & 254\end{array}$

$\begin{array}{ll}\text { Lamprey } & 257\end{array}$

$\begin{array}{ll}\text { Moutoa } & 258\end{array}$

$\begin{array}{ll}\text { Summer } & 259\end{array}$ 
$\begin{array}{ll}\text { Girl with baby in a cornfield } & 263\end{array}$

$\begin{array}{ll}\text { Pandora's box } & 264\end{array}$

$\begin{array}{ll}\text { Kauarapaoa } & 265\end{array}$

$\begin{array}{ll}\text { Children in the mud } & 267\end{array}$

$\begin{array}{ll}\text { Wattlebirds } & 269\end{array}$

$\begin{array}{ll}\text { Pākaitore } & 270\end{array}$

$\begin{array}{ll}\text { Flood } & 271\end{array}$

$\begin{array}{ll}\text { Girl with oranges } & 275\end{array}$

$\begin{array}{ll}\text { Spoonbill } & 277\end{array}$

$\begin{array}{ll}\text { Listen } & 278\end{array}$

$\begin{array}{ll}\text { Autumn } & 280\end{array}$

$\begin{array}{ll}\text { III The moving sand } & 285\end{array}$

$\begin{array}{ll}\text { Geology } & 291\end{array}$

$\begin{array}{ll}\text { The long wait } & 292\end{array}$

$\begin{array}{ll}\text { Surprise } & 293\end{array}$

$\begin{array}{ll}\text { Beachcombing along the tidal reaches } & 294\end{array}$

Lieutenant 295

$\begin{array}{ll}\text { Open Country } & 296\end{array}$

$\begin{array}{ll}\text { Constable } & 297\end{array}$

$\begin{array}{ll}\text { Eunice } & 298\end{array}$

$\begin{array}{ll}\text { PechaKucha } & 299\end{array}$

$\begin{array}{ll}\text { Mrs Field } & 300\end{array}$

$\begin{array}{ll}\text { Shifting sand } & 301\end{array}$

The jail house $\quad 302$

Holiday Park 303

$\begin{array}{ll}\text { Stormbird } & 304\end{array}$

$\begin{array}{ll}\text { Bluffs } & 305\end{array}$

Heads Road 306

$\begin{array}{ll}\text { Blood and sand } & 307\end{array}$ 
Gathering the berries of the Pimelea turakina 308

$\begin{array}{ll}\text { Meat workers } & 309\end{array}$

$\begin{array}{ll}\text { Port Bowen } & 310\end{array}$

$\begin{array}{ll}\text { Glow in the dark } & 311\end{array}$

$\begin{array}{ll}\text { Longshore drift } & 312\end{array}$

$\begin{array}{ll}\text { The sandhill } & 313\end{array}$

$\begin{array}{ll}\text { Observatory } & 314\end{array}$

$\begin{array}{ll}\text { Dead port } & 315\end{array}$

$\begin{array}{ll}\text { Cyrena } & 316\end{array}$

$\begin{array}{ll}\text { Control } & 317\end{array}$

$\begin{array}{ll}\text { Walking the dog } & 318\end{array}$

$\begin{array}{ll}\text { The long wait II } & 319\end{array}$

South Beach Café $\quad 320$

$\begin{array}{ll}\text { Grace Dent } & 321\end{array}$

$\begin{array}{ll}\text { Pour } & 322\end{array}$

$\begin{array}{ll}\text { North Mole } & 323\end{array}$ 
I

Catchment 
Well may these plundered and insulted kings,

Stripped of their robes, despoiled, uncloaked, discrowned

Draw down the clouds with white enfolding wings

William Pember Reeves, 'The Passing of the Forest'

Did you hear the Bush a-calling, when your heart was young and bold 'I'm the Mother-Bush that nursed you! Come to me when you are old?'

Henry Lawson, 'On the Night Train' 
Fig. 1 Map of Whanganui River Catchment

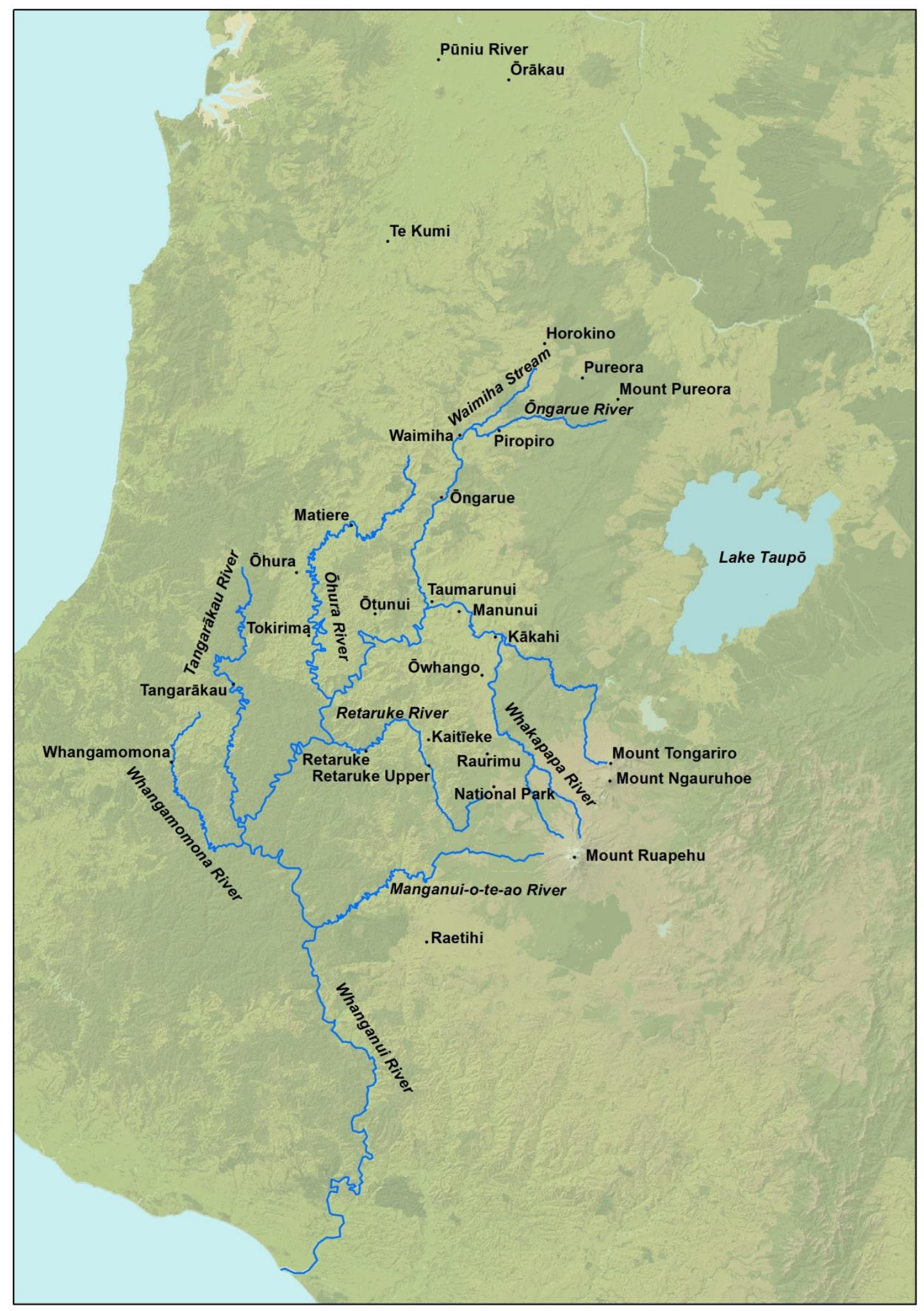




\section{Confluence}

\section{Taumarunui, 2013}

Two rivers meet, at an acute angle,

hold a point of ground in their fork.

Although this place is called Cherry Grove, there are only a few cherries,

and not the edible type. Looking down Whanganui, one bank grows willows and Japanese walnuts; the other, corn and half a tōtara, unbranched by the wind. It's the end of a dry summer;

wine connoisseurs have been rubbing hands together, anyone with grass has been downcast. Ōngarue is clean-looking; deep, dark brown of tannins, slight scent of algae,

thistledown drifting on its surface.

'Most rivers are clean this time of year,' says Joe, my brother, 'because the only water going in them is ground water; there's no run-off.'

Standing at the confluence, you can see the join in the rivers; either side a different colour and speed.

Like standing at Cape Reinga watching two oceans

seam together.

'The Whangaehu, though,' says Joe, 'the Whangaehu is never clean. I don't know why.' We sit on the spit, watch Joe flick his line, the rod bend 
almost immediately. It's a big one, and must be played.

Joe tells the line and the line tells the fish, leap there, and it's ashore. Joe's netless since he dropped it in the Mohaka, has taken to braining trout with a rock,

rather than knifing between the eyes, like he taught me. People will do all kinds of things to come down to earth. The trout have been eating caddis-fly pupae, algae, stones. 'I found a dragonfly in one once,' Joe says, 'it was still alive.'

Joe's misplaced the tray from the smoker, so he builds one of willow, and we eat the trout a few metres from where he caught it, with bread, and wild greens harvested from New World.

I rock the baby to sleep along the bank, among the disposable nappies, circles of bourbon bottles. Tea from a thermos, talk of our grandparents. I've bought Joe a kilo of frozen peas, to take a fish north.

'You know how people say, Oh, the good old days,' Joe says, 'I think I'll remember these as the good old days.' We leave him there, parked up. He'll sleep in the car, drift off to the sound of water, the poplar leaves slapping. 


\section{Plotlines}

Waimarino, 2013

Driving into Raetihi, you're greeted by the graveyard.

The town is on side-roads, the main street has a frontier look,

with the kind of useless false-fronts Laura Ingalls hated

in Little Town on the Prairie. Though it's not tumbleweeds

blowing down this street, but mountain air, and a clarity

that comes with coldness, a light distilled.

Buildings on the point of collapse, an empty theatre.

I imagine Friday night in the 'fifties, feet sounding

in and out of doors, plotlines of the real unfolding

in the back seats, or down the road a way.

In the charity shop, an impromptu coffee-group is underway.

I look through racks of ripped jackets, holed pants.

'I stuffed up my interview. They asked me

"What are the three Ps of the Treaty of Waitangi?"

And I said Um . . . People ...'

I am tempted to join in their conversation,

but get a sense it's better if I'm barely here.

'Most people wouldn't know that. I don't even know that. What are the three P's?'

'Partnership, participation, protection.'

Or maybe it's the sense that I shouldn't be here,

that I have accidentally stumbled into the set

of someone's life, not even an extra in the script.

'They asked me that in my interview too, and I didn't know.

So I just said People, peace, and . . . pineapples!' 
I keep sifting, nothing's leaping out. Good books can hide among the shirtless rugby players of years gone by. You can't argue with the view from here.

I've never seen Ruapehu looking so bare.

According to the National Institute for Water and Atmospheric Research, we can expect, by the year 2099, a 2.2 degree average increase in temperature, shortened duration of seasonal snow, rise in snowline ...

My son always wants a story. Tell me a story about a T-rex who was far away. Tell me a story about a spider who was lonely. And if the plotline doesn't develop: 'That wasn't a story! I want a proper story!'

Obstacle, obstacle, obstacle, solution.

Even a three-year-old knows the basic devices.

Obstacle, obstacle, obstacle, attempted solution, failure.

The greatest stories of all time are geological. 


\section{Clear away}

Ōrākau, 1864

\section{Orchard:}

They carved their bullets from my wood, the peach too soft to be much good, but apple, solid, worked all right.

No use in wasting lead at night.

\section{Field:}

The British dug their ugly sap, then soldiers swarmed into the gap. I heard the cannons sound their knell, I shook with every booming shell.

Fence:

The soldier's body was still warm.

Blood ran from where his uniform was torn. The chief passed, while he bled.

'Do not cut out his heart,' he said.

Hill:

No water left, their throats were dry, food hard to swallow. 'We will die,' warned Rewi, 'if we wait a day.'

They shouldered axes, guns. They'd stay.

Palisade:

Surrounded, Rewi ordered: 'Fire!'

Major Mair brought word: 'Ceasefire.

Surrender now.' The answer: 'Never.

My friend, we'll fight forever and ever.' 
Fern:

But time came to retreat. As one,

they broke their cover, were fired upon.

Some of the wounded, women. They

were bayoneted where they lay.

Pūniu River:

They swam across me, found a track.

The Pākehā were falling back.

South of here, they journeyed on.

Clear away. Then they were gone. 


\section{Hat on a map}

Te Rohe Pōtae, 1870s

One million acres gone,

Waikato journey in.

Across the river's boundary,

Maniapoto country.

Down here, the trees hold sway.

No wide and cloudless sky, no gentle rolling dales, these gorges and these hills.

Tāwhiao's white bell-topper lands on the map's wide paper.

The border of its brim

holds each range and stream.

No Pākehā. No surveys.

No land court, and no railways.

No liquor, and no Crown.

The rivers spine on spine.

Somewhere, Te Kooti shelters

from the colonial soldiers.

The countless pathways mingle in this wet and silent jungle. 


\section{Pigs, potatoes}

\section{Te Kumi, 1883}

They name two pigs for us, to kill, and cook, and feast upon. We hear them chant outside the small slab hut where we are kept, hands tied by manacle and chain. 'No one will look

for us out here,' sighs Newsham. And he's right, how many miles we are from any track. I feel a knot of bruise upon my back, where I was struck by stirrup iron that night,

two days ago, or one? It's hard to tell.

In cold and smoke I feel my bare skin shrink.

Our bowl of water isn't fit to drink, being soured with blood. That maddening smell:

our porcine namesakes roasting on the fire.

They've thrown us pigs' potatoes, green and raw, but they've rolled from our reach. The earthen floor is hard beneath my bones as I retire,

attempting sleep. The chiefs have been talked round, but it would seem not everyone's disposed towards this railway. And so the survey's nosed a little further, only to be found

out by Tekau-mā-rua. Now here we are. 'My pipe was in my coat,' my cellmate cries, hands jerking uselessly. They must despise me most of all, since that time at the pā 
at Parihaka, where I was the one

who placed the survey pegs, which they removed.

I work at freeing a hand. By day, it's proved

successful. Then the light reveals a gun

poked round the door. A man walks in.

'It is I, it is I, my children,' comes his voice.

It is Te Kooti. All of us rejoice.

I greet him choked with tears as thick as sin. 


\section{A living sea}

\section{Te Nehenehenui, 1884}

Up at Te Kumi there's a gallows built

to hang the Native Minister, if he

should venture there. But I have travelled lands

of ill repute before, and have no fear.

My sole intention being to advance

the scientific interests of this land,

I'll not let any obstacle impede

my course, save force. 'If you should meet ...

with Mahuki,' we're told, 'you may be chained

like Hursthouse was, or get a bullet through

your head.' We leave the pack horse and my gun.

Te Wheu takes us to where the forest starts.

With so much open country hitherto,

the leafy scenery seems a welcome change.

But pathless woods can lose their pleasure fast:

dark trunks, sly vines that coil round neck and feet.

The ground as slippery as if it were glass,

our two remaining horses crouch and slide.

The muddy creeks so terrify the beasts

we have to flog them over, every time.

They leap on fallen trees, jump down like dogs.

And now we notice we are bearing down

into the valley of the Whanganui.

The night comes fast, we make camp in a swamp. 
The ground so rooted-up it seems to me to be some kind of pig-Elysium.

We make our beds of nikau fronds. The rain pours down from branches, slicks around our necks.

Leaving this 'Dismal Swamp,' at dawn, we pray we never come upon this place again.

Not long into our walk the forest breaks, a valley parts, a bright clear river strung through it - the Manganui-o-te-ao. We hear a voice shout Pākehā! Then out from hiding, people circle us. They send a messenger to fetch their chief, who comes

gun shouldered, hand in easy trigger's reach.

'What brings you through the forest?' we are asked.

'We're travelling for pleasure,' we explain.

And all burst into laughter, even the dogs.

'Their horses look like rats,' an old man cries.

'These Pākehās,' he adds, 'have singular ways.'

But then the oldest woman rises up and calls us in with strange and wailing sounds.

Her words appear to have a magic charm: the horses cared for, feasting is prepared. Potatoes, apples, pork rendered in fat. My stomach curls with pleasure at the smell.

The morning comes. Our journey far from over, we take our leave, farewell our new-found friends. 
'If Manganui don't land you here again,'

the chief says, 'you may have to eat your nags.' 
First sod of the Main Trunk Line

Pūniu, 1885

There was a boy who shook and shook his hat, but I stood still, no matter how the heat annoyed me, how the lace cut at my throat, how my head hurt. Giving my back a pat,

my father looked away into the green.

There were these painted men, each with a crown of feathers, on the barrow. Dark red skin.

They didn't look like any men I'd seen.

It seemed like hours and hours and hours I stood.

My father spoke, as plainly as he could.

Then the Premier did, and the crowd

all cheered as Wahanui cut the sod. 


\section{Surveyor's grave}

Tāngarākau, 1893

A road to map, we worked the chain

Lay me down, lay me down

We worked in sun, we worked in rain

O lay me down on the moss.

But deep, far deep, in dip and hill

Lay me down, lay me down

While we were camping, I took ill

O lay me down on the moss.

My belly tight with stabbing pain

Lay me down, lay me down

I'll never know my home again

O lay me down on the moss.

Send for the doctor, walk the track

Lay me down, lay me down

But I'll be done before you're back

O lay me down on the moss.

See that the farm goes to my wife

Lay me down, lay me down

And wish my child a prosperous life

O lay me down on the moss. 


\section{Into the ground}

\section{Kākahi, 1905}

Our 'hotel' is a canvas tent, and every brew we sell is made from - if you'd like a glass, it's best if I don't tell. What we don't know won't kill us, the navvies usually say. They turn up in a crowd at dusk, to drink the night away.

And when they've spent their pay on booze, with no relief in sight, they think there's nothing left to do but get into a fight.

The reverends are at home in bed, beside their rigid wives. The Holy City has the coppers fearing for their lives.

I'm with a fellow lying in the shadow of the wall when by the bar a scuffle forms, and swells into a brawl. A lantern is knocked over, then a flagon of potcheen and soon the flames are licking all around the whole shebeen.

Jane shrieks like there's a knife in her, the man beside me stands and offers his assistance, holding out his navvy hands. But I'm a faster runner. I know how to work that floor. I claw my way past drunken men and sprint out through the door.

I look back over my shoulder, and the whole town is alight, bright orange like a ship's flare in the black and silent night. I see women in their nightgowns, their hair all loose and wild, under one arm a bundle, and the other a screaming child.

We shelter in the railway cuttings, safe within the stone. Jane cries into my mantle, but I've no tears of my own. The Holy City's up in smoke. I shudder at the sound, but mostly I am pleased to see it go into the ground. 


\section{Sound the whistle}

Manunui, 1907

Down the tight line the lokey shakes and veers

its train of logs. The nervous brakey peers

around the gap. We'll be the first across

Burnand's new bridge. I've worked here, now, two years

as driver, like to think I'm my own boss, free to move on, and it would be no loss

to me. The load smells damp, the wet tracks glow, sun flashes where the bridge's railings cross;

entering it, I let the whistle crow.

A scream so loud it's like the sound could go halfway around the world. And then we meet the other bank, the smokestack's steady flow,

the whine of saws comes tearing through the heat of early afternoon. This is our feat:

the first logs over the Punga. Manunui!

We swing into the yards on Totara Street. 


\section{Inroads}

Ōhura, 1913

Sunrise lights the valley's pipe,

spits polish on the camera lens.

I pack my notebook and my pens,

and give my muddy shoes a wipe.

A pointless task. The horses climb, the buggy teeters, overfull, its wheels sink deeper every pull.

We could have walked in half the time.

A farmer whistles to his dogs,

a tide of sheep weaves through the stumps.

The roadworkers are laying lumps

of greyish clay on piles of logs

and stuffing smaller logs between.

'It's papa rock. We bake it there,

for metalling roads. No shingle here.'

'The strangest thing I've ever seen,'

I say. I think of Homer, how

he told the way a funeral pyre

was built. The kindling catches fire,

the logs flare up, then char, then glow

the while we stand there, looking on.

'Well, I suppose you have a lot

of wood round here.' But there is not

a grove left standing - all is gone. 


\section{Roads}

Central Volcanic Plateau, 2013

At National Park, the railway station café

is playing nu-jazz, selling Wellingtonesque food.

No ladies' rest, no tearooms. Time-travel

is becoming increasingly difficult. Where

is my indestructible teacup? Where is my pink lamington?

We eat lunch at Whakapapa Village,

rain gushing all over the mountain.

Sit in a public shelter, strewn with possum scat.

No tables to coax the kids to. They crawl and run.

A happy-looking couple walk through to the toilets;

thumping ensues. Some kind of a bet, I guess.

Leave your jacket on, hon; it's freezing here.

They climb back in their car as quickly as they came.

In the info centre I feel for the teacher

instructing with questions, getting grunts

for answers. My sons try to muscle their way

through the forest of legs to the table

with a plaster model of the mountains,

buttons that make little red lights glow.

Volcanoes! Volcanoes! From the Age of the Dinosaurs!

Displays must be examined, then climbed.

The AV feature tells stories it has told for years, which, it has recently emerged, aren't entirely factual.

The word 'gift' something of a misnomer 
given some of the land in the park was taken.

There was an occupation at Taurewa, a few years back; a couple of caravans, and waving flags, but the tussocklands as we pass them now, are empty of all but tussocks.

I want to find the Whanganui intake, but drive in squares through blocks of licheny pines. I find, instead, a hump of grass like a wave about to break over the car, and climb it to see sodden fishermen in oilskins, dipping lines in a lake.

The rain stops just before Turangi. Under the bridge at dusk, we find more anglers to watch. Lukas fishes with a twig, catches willow leaves. All along the river, the pools are staked out, lines flicker.

In the morning, Highway 41, over the Punga.

This road was built, in part, by Rene Beautrais II and III (Beautrais and Son). In Taumarunui we walk every row of the old cemetery,

looking for Rene Beautrais I, and Elizabeth.

How we link to France, and Ireland.

Wet leaves lie everywhere, fly-agarics bloom.

'Fliegenpils! Fliegenpils!' chants Lukas, fan of fungi.

I find the grave, scratch lichen from the headstone.

It stains my fingernails, dark brown.

It was a fiery family. And anyone

who might have been inclined to tend

these cracking slabs is dead.

If I come here again, I'll bring a brush, 
and clean it properly,

at least so the names can be read. 


\section{Tree-oh!}

\section{Kākahi, 1914}

The whistle-boy pulls on the line, lets out a rush of steam.

Stoke the hauler full of wood and hear that piping scream.

Tree-oh!

Hear that piping scream.

The swing of arms into the axe, the crosscut's symmetry.

The sound of thunder in the ground when bushmen drop a tree.

Tree-oh!

The bushmen drop the tree.

The strain is great, the hauler groans, the rope-man walks the bush.

Uneven ground before a log, it takes charge with a rush!

Tree-oh!

It takes charge with a rush.

The brakey works his wooden blocks The train shakes down the tracks.

Hack a hold into a log and hold onto your axe!

Tree-oh!

Hold onto your axe. 
The trucks are brought down to the mill two hundred feet below.

A smoking of the wooden brakes, she moves in nice and slow.

Tree-oh!

She moves in nice and slow.

The log is sawn, the lunch bell's gone

go home and raise your cup,

while sitting at the giant teeth

saw doctor sharpens up.

Tree-oh!

Saw doctor sharpens up.

Mill No. 2 is all cut out, two years for No. 1 .

There'll be a strange peace settles here with all the bushmen gone.

Tree oh!

With all the bushmen gone. 


\section{Only dancing}

Kākahi, 1916

I wish you'd found me Tuesday night

down at the station, Dave.

I could have faced you man to man

and heard you rant and rave.

Instead you stayed at home three days, the devil in your head.

You made your hut a pit of death,

a bath of blood your bed.

They say that Bulltown got its name from wild beasts clashing there.

If we had fought it out like that I'm sorry Dave, I swear.

Sure, there were rumours going round I'd got myself in strife.

There may have been a grain of truth but nothing with your wife.

Sure, she's a lovely lady, the best dancer of them all.

How smooth her dress beneath my hand at the Military Ball.

But dancing - that was all it was!

It always made you sore.

'I'm leaving town,' I said to her, 'come twirl with me once more.' 
You knew the way the talk had turned, the rancour and the rot. You said she mustn't look at me; she didn't see why not.

You'd stayed at home, you weren't to see, but gossip spreads like flu, and twisted tales soon found their way around the town to you.

Pea-rifle pressed against her head, you fired. Then, one by one, you went to each of your six kids and beat them with the gun.

What words could I have said to you?

What words had turned your brain?

You're with your children in the ground; we'll never speak again.

The mill closed down not long ago, you'd joined a roading crew.

To read it like this in the Truthand how they've mangled you!

My music was your music, mate: the saws, the axe's thud. I'll never be back to Bulltown now come fire or come flood. 


\section{That winter}

\section{Ōngarue, 1923}

That winter, light went sooner from the hill. I walked my boundary fence same way I had for twenty years, and watched the boulders spill onto the line. This spot was always bad;

I'd told them time and time again to make a deviation, take my corner field. But every time, deaf ears. What was at stake was more than I would risk. Something would yield,

these weeks and weeks of rain. And then it did one icy morning, keeping to the clock, the Auckland-Wellington express train slid around the bend, and met the latest rock.

The feeble headlight no match for the night, the gas-line carbide-blocked, the engine hit before the brakes were touched. The ugly light of dawn lit up the wreckage, sleepers split

to kindling, rails ripped up, the boiler smashed.

Two carriages had telescoped to one, and on the back of that, a third had crashed. The living staunchly did what could be done.

Inquiry found the railways not to blame, they couldn't have foreseen it. Strike me dumb! Whatever they said, the dead remained the same. I grasped my black umbrella, and kept mum. 


\section{The road out of here}

\section{Upper Retaruke, 1927}

My granddad Hursthouse told these tales, the wildest I had heard of being tied up, and almost cooked. I hung on every word.

When I came back from fighting in the war with Germany what other place but King Country?

The King Country for me!

I got five hundred acres with a soldier's rehab loan.

Till my heart strained, I worked the land I hoped I'd someday own.

I chopped the bush, then came the slump to smack me in the eye.

I watched the wool price plummeting

I watched my prospects die.

I needed land. I made a deal: I'll chop, you buy the seed.

The government man was willing and he readily agreed.

But when I'd done, the deal fell through - they wouldn't spare a cent.

I'd rather deal with Lucifer

than with the government.

So I set to and burned the bush, burned all the valleys bare.

They'll have to sow it now, I thought, they'll have to make it square.

How wrong I was, left broke and sick, no fodder for my sheep.

How do they get away with it?

How do those scoundrels sleep?

The Commissioner for Farmers came, could not believe his eyes.

That soldier-settlers have been had, a fool could realise.

He said the land was mine for free, but didn't twist my arm.

I can't take one more week of this

I can't take any farm. 
A glance around the second growth, you'd never know a man

had wasted five years here. Well, now I'm doing the last I can:

a few clothes and a blanket roll, two ponies and their gear,

I'll walk the road down Retaruke,

the long road out of here. 


\section{Falling branch}

\section{Manunui, 1928}

How strange the sky went sudden bright

when something struck me back of head.

Leaves sticking to my skull I lay

still as the dead.

Warm-handled axe still folded in

a ponga lying where it fell.

I'd knocked a heavy branch, as far

as I could tell.

They scooped their hands beneath my back,

they loaded me onto the train.

The sky kept going bright, then pale

then bright again.

The hospital so vast and bare

that every whisper seemed a shout.

I stared the brightness in the eye

till it went out. 


\section{Out of the ground}

Waimiha, 1930s

They brought the bird in. My heart fairly sank.

Their father had been felling, and had found

it in the bush. 'We'll use the empty tank

by the back door.' He'd dragged it from the ground,

and under it were these two eggs. No chance

that they would hatch - the children's pets all died.

Dazed by the light, it did its wingless dance,

searched for a hole to roll its eggs inside. 


\section{Three days}

\section{Horokino, 1936}

She sat there three days on the line.

Her cloak was soaking with the rain.

The tracks were wet, the earth was brown.

She sat three days.

Down at the mill the work was slow, because the loco couldn't go.

The boss fumed, but what could he do down at the mill?

They tried in vain to talk to her but didn't dare to touch a hair, and so she kept on sitting there; they tried in vain.

They heard her say that they were cursed: she cursed their bridges all to dust; she hoped their tracks would bend and rust, they heard her say.

And when she finally walked out she said, 'Now here's another thought, I'll see you fellows all in court.'

Then she walked out. 


\section{Up to their necks}

Tokirima, 1940

The rising water's three feet deep

inside the church. The banks all seep,

the roadway is as thick as glue.

O Lord, have mercy on our crew.

The rivers tear apart the guts

of towns, rip bridges from their struts, the streets are travelled by canoe.

O Lord, have mercy on our crew.

To every road the flood's unmade they've sent us out. What good's a spade, compared to what the rain can do?

O Lord, have mercy on our crew.

We've been inside this hut all day, and now the ground is giving way we're buried if we don't get through. O Lord, have mercy on our crew. 


\section{Eggs for an army}

\section{Ōngarue, 1940s}

Lucky winter weather! The line is blocked up with another slip, and the train is filled with soldiers! Here we come in our dancing dresses, rushing to greet them.

One by one, the houses light up like flowers, doors thrown open. Usher them in, to sleep on sofas, hearthrugs. And in the morning, all our eggs in their pockets. 


\section{Forgotten world}

State Highway 43, 2014

The Whangamomona hotel smells

like my grandma's house. Dust, grease,

newspapers. Rugby photos deck the walls,

men leaning in on shields. Hog's heads,

antlers, dry and spiderwebby. We drink tea,

eat toasted sandwiches. At the next table

an Australian family, kids almost grown.

'I just love these country pubs,' says the mother,

'they've got so much character.' A pub crawl drives up,

drunk at midday. Middle years,

in coloured wigs. To-and-from the bathroom.

'Someone's been shavin' 'er minge in the sink,'

bawls a man, delightedly. Kitted out

in their cute cardigans, my sons are set

to trash everything, bouncing off walls.

'I just love those hand-knitted clothes,'

says the Australian mum. She's going to make some

for a baby on the way.

Out in the sun, two farmers down a jug,

rurally handsome. A lurking dog

scares the kids. 'It's a friendly dog,'

I reassure them. 'You just missed

the friendly goat,' says a farmer,

pointing to where an animal's pissed, 
right by his seat. 'It's not every day

you sit down for a beer and a goat pisses

next to you,' I laugh, but maybe, for them, it is.

That strange pang of wanting

to drink with locals, but we drive on.

Past Tāngarākau, 'Ghost Town.'

The hills look like they have undercuts,

the sides shorn close, trees left on top,

where it's too steep to fell. Roads unsealed,

dirty and skiddy. We reach Ōhura,

nestled in a circle of hills. Check in

at the former prison, chickens

and sheep wandering the grounds.

Any jailbreaker would have taken

a long time to escape to anywhere.

My mother's friends lived in the town a year.

'The only socialising was Tupperware parties,

and, as a teacher's wife, Sophie was expected

to spend up large.' At the museum

there's a lot of china. The Raurimu spiral

on a teacup. Long white christening gowns.

A stuffed ferret, a kiwi spitting larval droppings:

something has been eating it from within.

Rusty dental pliers, hardened saddles,

a slab hut brought in from the hills.

How did a family live there, five kids, 
one tiny sackcloth bed? At the prison

we sleep in the old Programmes building.

Corrections signage everywhere,

shelves with staff mug spots still named.

Why is the most disturbing place

the kitchen? Rosters still chalked up:

who was on dishes,

who was on brush and shovel.

The lounge is stacked with books

kids must have leafed through, on visits.

Over and over, we read Blueberries for Sal.

When we go to look at the jail cells,

Felix thinks we might find blueberries there.

Or little bears. 


\section{What sport to-night?}

\section{Ōngarue, 1953}

My borrowed lipstick has a stale fat scent.

We're the boys of the Ongarue team

When we're on the field we look so grand

Black kohl and turquoise eye-shadow, that's good.

Kingdoms are clay. And that's true, around here:

the rugby clubroom always reeks of earth

and booted grass, and all the punters have

that smell, like they were cut just yesterday

by God from naked soil. I hear a call

'Where's Cleopatty?' 'She's, or he's, out back,

having a fag.' I stub the butt, and smoothen

out my bra. I could get used to this.

There's not a minute of our lives should stretch

without some pleasure now. Boys will be girls,

and that's Shakespearean, or so they say.

There's not a script, as such. We know a bit

by heart, but all the punters want is laughs.

I lie prone on the couch, gaze longingly

while Antony, with false nose, strokes his chin.

All through the hall, the women shriek, their jars

of coins keep filling, and the mugs flow over.

Most of our fortunes shall be-drunk to bed.

The rugby club could use a bob or two.

They laugh so hard they don't see how it ends. 


\section{Cutting down King Mahuta}

Ōngarue, 1950s

The slap of hand on bark a kind of prayer.

The groan of heartwood as the rimu leans

and falls. 'King Mahuta,' boss says, to air.

We're quiet, know exactly what he means. 


\section{Bush Tram}

Ōngarue, 1955

Mary, Martha, Matilda - the locos all have

female pronouns, even the 'Climax' warrants

'she.' The smell of tea-tree reminds me I am

dying to light up.

'Smokers please be careful,' the pamphlet tells us.

Bending over, all of the men are pointing

cameras. Now and then, they compare equipment,

peer in the workings.

How my husband turns to a boy, round steam trains!

'Absolutely no souvenirs,' I tell him.

'Hands in pockets, love, or you might be tempted.'

He doesn't listen.

'Monday,' says the driver, 'we start on lifting

all the track from here to the clearing.' Passing

through, we see the last of the branch line. Martha

ending her toiling.

Just to please a man, you will gladly travel

deep in darkest bushwhacker country, smiling

while he prattles. Climax, that loving woman

silently smoking. 


\section{Parts shed}

Pureora, 1950s

The guy in charge of stores was a right prick

and so was I. We came down for a check

at Pureora. Took us a whole week.

I can't complain; I love this sort of work.

There was no end to all the things they had, and they were beautiful, American made, from Caterpillar tracks right down to bits of carburettor; all these fine new parts.

It was a working forest; native trees, not like at Kaingaroa, those millions of pines. There was no need for foresters, with degrees: the work all done by powerful machines.

The whole thing was extremely powerful.

What the government had done was really good.

Me, I'm just happy dreaming of that shed

and all the parts I would have liked to steal. 


\section{This'll do me}

Ōngarue, 1962

Keys are often kept in trouser pockets, and this is where I find them, in the dark cloth shape slung over a chair. In double bed the postman and his wife breathe, out of time.

Their bedroom has a human smell; of sheets and scalps. I'd rather rob an empty house you feel the silence welcome you, almost, when first the window gives, and you ease in.

I always clean up afterwards, leave thanks by way of note. Most of the year a bach is shelter going to waste. The master's key, hello, hello, fits nicely in the safe.

Three hundred pounds. Why thank you, now I'll go. I tiptoe out, exhale into the night.

A short way down the road, a van is parked outside the store - delivery, looks like.

This'll do me. The engine thrums, the road rolls underneath. Like everything, it's fun, just for a while. The days, or weeks, I'm out. Time blurs. The roadblock takes me by surprise:

soldiers and cops. Their bullets whizz and ping off panel and roof. I reckon I can run faster than them, again. It's fit-and-lean they drag me from the bush, back to the world 
in back of Black Maria. Now there's spies

at large in Wellington, and music plays:

'Mister George Wilder, oh won't you come home.'

Oh, Howard Morrison, keep up your song. 


\section{Oil drill}

Ōtunui, 1966

They're building rigs to drill for oil

the auger creeps down through the soil

and every kettle's on the boil

in Ōtunui, in Ōtunui.

We'll all be mighty stinking rich

when black gold gushes from that ditch

we feel our fingers start to twitch

in Ōtunui, in Ōtunui.

But - shit a brick, the rock is struck

it's typical of local luck

no boom has come, and we're still stuck

in Ōtunui, in Ōtunui.

Protestant popes and flying pigs

will come and dance around our digs

when oil is pouring from the rigs

in Ōtunui, in Ōtunui. 


\section{Final whistle}

Ōngarue, 1966

Now it's happened, even the sound is startling

like a braking train, or a morepork hunting.

All of us are here in the bulging cookhouse,

laughing and eating.

When we started here, I was told the men would need a bit of mothering. Sure, they did, but it was like a family. Well, I don't know why I am crying,

thinking of the bush and its eerie sadness, rain collapsing all of the things we made here.

Still, I know they've sawn every dip and ridge, left nothing of value. 


\section{Treetops}

Pureora, 1978

I stood there, in the clearfell.

I heard the chainsaw's grinding speech

and over that, a kākā's screech.

At the same time, there came a swell

of song. It was a haunting sound, as if the kōkako could weep

for all that came beneath the sweep

of dozers as they bared the ground.

I knew what we would have to do.

We gathered eighty friends or so, and brought them down, so they would know the threat first-hand. But no one knew

what we had planned. When they'd gone back, we made our next move, went and got a camping permit. There was not one law being broken. Near the track,

but not too close, we chose our trees. My brother made a whistling noise. We'd climbed a lot of trees as boys, but never ones as big as these.

First up, we threw a bit of string to pull a rope, and then we tried climbing the rātā vines. Inside the canopy, we felt its swing, 
we breathed its must, ancient and green.

The TV filmed us sitting there, they had the District Ranger swear

on every household's telly screen,

'We've searched the bush - it's all a hoax.'

We'd simply hid too cleverly.

The Forest Service spoke to me

through media message, tried to coax

me down and out, but I stayed put, possession being nine-tenths of law.

A fight was not what we came for.

But here's what hit them in the gut:

one day my brother, keeping still

saw loggers come through, marking wood.

They scarfed the tree next door. He stood

his ground. A trunk's impact could kill,

depending on the way it dropped.

It hit the earth, and he was thrown

around. He made his presence known.

It shook them up. The logging stopped

soon after that. But it was plain

the fight went on - the hardest push

was working to restore the bush,

to stitch these fragments up again. 


\section{Buried forest}

\section{Pureora, 1983}

And there it was. While trying to drain the swamp, they hit the logs. 'It looks like they've been buried a while,' we're told. Two thousand years, almost. So bulldozing was paused, the book of time

looked into. What we found was really strange: the soil this wood had grown on had been poor. Over the trees the blasts of pumice fell, and new bush grew, the type that loves rich soil.

And if the trees are left to do their thing, the soil will slowly lose its wealth again. Then, no doubt, that caldera will erupt and put another layer of bounty down. 


\section{Tributaries}

\section{Taumarunui to Piropiro, 2014}

With a blunt stick my father cleans the lichen

from around his great grandparents' names.

It's grown back since last year.

My mother joins in, scraping moss from the slab.

On each side a long, thin cross. The fliegenpils

have popped up from the same mycorrhizal groove,

but Lukas is collecting acorns, stuffing them

in rear pockets. 'It will feel funny when you sit down,' I tell him.

Hazelnuts and Japanese walnuts

drop their fruit all around the graves. One hazel

springs up from where a young mother

was buried with her baby.

There's a Burnand monument, names wearing away, rows of soldiers' crosses, and a neighbourhood of headstones, days apart, for the 1918 flu epidemic. This cemetery is as far back as we know our Beautrais whakapapa.

The road becomes Ōngarue Back road, becomes a dirt road, ends up in the quiet village.

On the grass verge a group of curly-haired cyclists, smiling and covered with mud.

'Trev used to come here a lot,' says my dad.

We keep following the Ōngarue, as it narrows and grows cleaner, up Ōngarue Stream Road through hills dark with untended pines. 
At Piropiro campsite an apple tree, hung with lichen, moss, and ripe apples. Is it a tree from the old days? Is it a heritage variety? 'Tastes like a gala to me,' says Dad. At the forest's edge a group of Germans cook dinner.

Their voices carry in the still, cold air. Felix on my back, Lukas on his father's shoulders, we walk the gravel track towards the Timber Trail. Here and there various conifers are spotted, remnants of the Forest Service experiments.

'They vindictively clearfelled, then replanted with pines, Douglas Fir, or whatever they felt like,' says Dad.

'Whaddaya mean, vindictively?' asks my mum.

'Every time we said "why don't we protect this bit?"

they went in and logged it.' 'Who sat up the trees?'

I ask them. 'Oh, Stephen, Bernard . . '

'Sam ...' The twilight

comes in, all soupy and violet. The forest

gives off its night perfume. We walk until dark.

It feels like the bush will swallow us up.

A robin follows us out, hiding in the mānuka, reappearing, disappearing, returning. 


\section{Huihui}

\section{Taumarunui 2014}

'Well kids, I'm going fishing.' Out of the car and straight to the confluence, goes Joe in his camo' waders. A jet boat is launching at the ramp into the Ōngarue,

a sound that wipes out all other sound, then blares into the distance.

Another dry summer has ended with weeks of rain.

Ōngarue is opaque, mud-and-shit coloured. Poplar leaves float on its surface; big, round and yellow, like fantastical coins. Joe steps into Whanganui,

the other prong of the fork. The water answers yes to all of Mountain Safety's unsafe-to-cross criteria: it is moving faster than you can walk; it is above your knees; you can't see the bottom.

Three women glide past in kayaks, stern-faced, intent on something. Another jet boat. It is all we can do to stop the children plunging in, boots and all. Under a bandage

on Felix's arm are grazes, and a puncture through to the fat, from a chance encounter with a hungry kunekune. Arm up to the elbow swallowed into that hot, earthy maw. 
As we spread our picnic on the stones,

a wasp stings Lukas under his lip:

with every wail it swells a little more.

We drive out past the sports club: Home of the Eels,

Ngapuwaiwaha marae,

Ngahuihuinga community gardens,

the old name for Cherry Grove.

Huihui: to gather. Like water does. 
II

A body of water 
Wherever I live, let me come home to you As you are, as I am, where you

Meet me and walk with me to the river.

Marilyn Hacker, 'Going Back to the River'

Among the murk I will find things to worship ...

John Kinsella, The New Arcadia 
Fig. 2 Map of Whanganui River

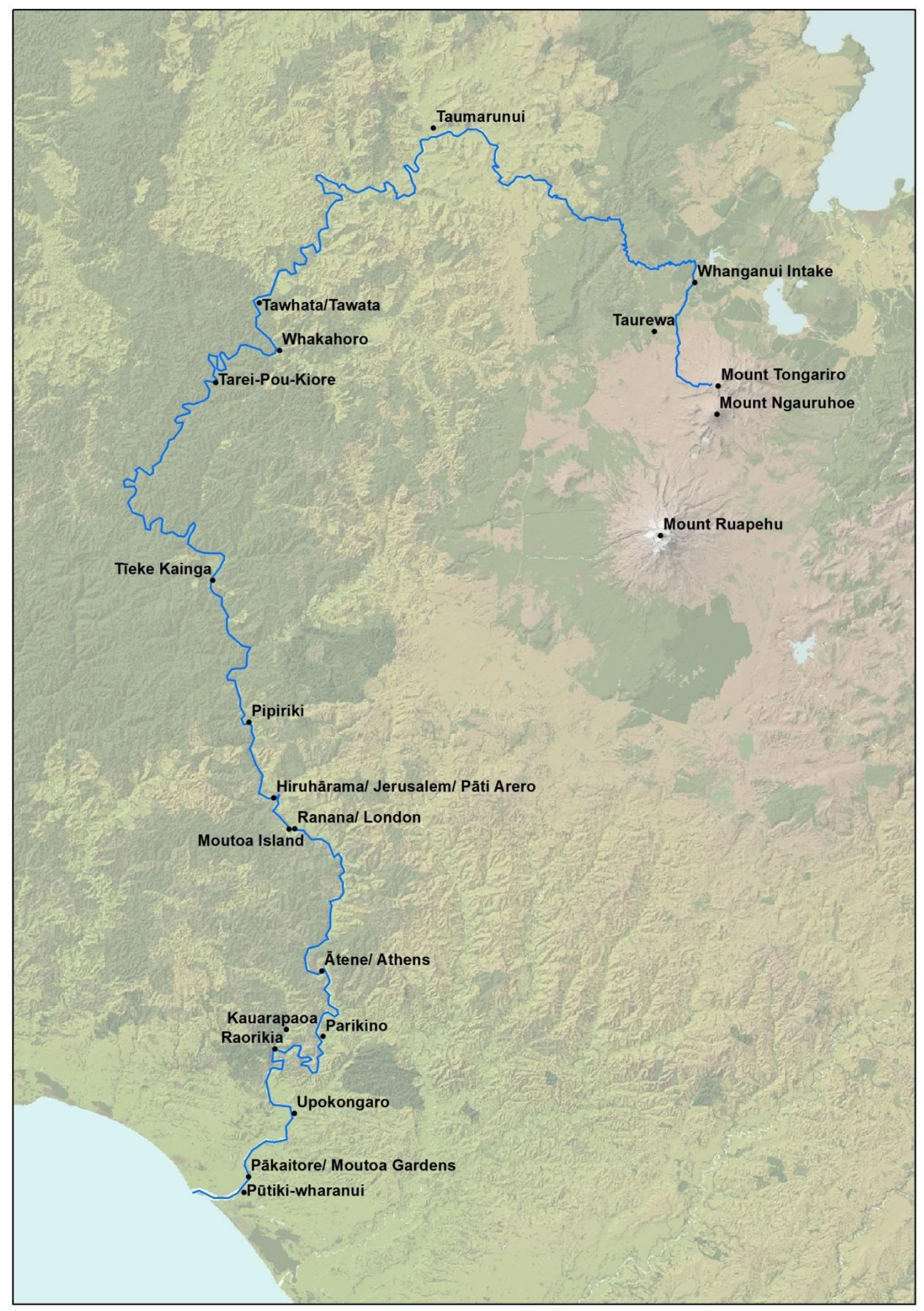




\section{Puanga}

The children are making the river.

They have sand and pumice. They have ferns.

A teacher unrolls masking tape,

presses a map to the wall.

There are birds that sing when squeezed.

Wild-eyed, a girl clings to a tūî.

There are little whare, into which

the birds can be inserted.

A boy carries the kōkako

around all morning.

$*$

Over the radio, silence.

Then the swish of piupiu,

tread of feet,

pat of plastic poi.

Stillness. Silence moves

across the airwaves.

A drum, a guitar strum

breaks it. Girls open their throats. 
The sound of lungs filling.

The loosing of tongues.

$*$

This is Puanga, or Rigel.

The laser pointer circles the gleam.

Children's heads silhouetted

by the projector,

continually in movement.

This is Matariki, or the Pleiades,

or Subaru.

But in Whanganui,

Puanga is the star

we look for in the new year.

The children have made star biscuits.

They have harakeke. They are weaving stars.

Milo in the star-cave,

telescopes searching cloud.

They have playdough the colour

of night sky, filled with glitter.

Dressing gowns, gumboots, woolly hats.

A brazier in the sandpit. 
The smell of damp air.

The smell of burning sugar.

It is a time for planting.

A child chooses a pine

with blue-grey needles.

It will bear nuts in forty years.

A time for gathering.

Pink yam fingers poke from the soil.

A time to prepare new ground.

Bared black of loam.

Where can we plant this tree?

Where will it cast its shadow?

From here, Puanga.

From here, Rigel.

In the sky a hunter stands

on his hands,

both feet upwards.

In a tank a real eel.

The silver of īnanga. 
The stones are lined up,

the birds are positioned.

The children are making the river. 


\section{Snow}

Huka mātahi - the first snowfall

The first snow falls

like sugar, sown

breath-thin

on each blank mountain's face.

The rock

pricked

apart by needling ice

like shattered bone

bears

down, and wears

down to fine scree.

Melt water sucks

below,

and percolates

through every crevice, laced

by weave of gravity,

a plaited rope to tether.

Now leisure calls,

now move the stone,

begin

to smoothen every space,

the shock

slicked,

each surface swept nice.

Fresh powder blown

glares

white, the chairs

ascending lee. 
The rumbling trucks

let go

their loaded weights

in oblong waste-piles, placed

for regularity,

to meet the winter weather.

The cold enthralls,

the crowds are known

to win

their pleasure on this place.

The flock

flicked

to sloping paradise,

the glowing cone

shares

itself, wares

spread out to see.

From spills and shucks

a floe

of waste awaits

the greater thaw, the traced

maps of a century

beneath white flake and feather.

Through zips and ducks

of snow,

through bends and straits,

each tiny move encased

in cold complexity.

Blind cells knock together. 


\section{Seed}

You are in the wildness, wild with song and honey.

You are in the beak and tongue and claw.

You are in the rock face, weathered by the freeze-thaw,

in the summit sulphurous and stony.

Red grain of wood, wet oozing sap,

domatia where the tiny leaf-mites sleep,

ripe pulpy humus dropped and mashed

by rotting rain, the orange berries flushed

on twigs of foetid plants, the swoop

of water black with tannins in the deep-

cut stream. All live things spill your smell,

all death exudes your taste, and in your fist fits all.

You are in a handle, frothing full of amber,

you are in the barmaid's splashy bosom.

You are in the bar-room talk, its raucous timbre,

currency of towns that die and blossom.

Faux-Swiss hotels of varnished pine,

sloshed maenads arm in arm beneath the moon,

and in the morning on the pale

snow, tourists shouting Das ist total geil!

Fluorescent shoes with unspoiled treads,

ovine erotica of clothing ads,

fresh shit of dogs in bread-bags scooped

from foot-tracks gravelled neat and strong, precisely mapped.

Ghost in everything that moves,

shape and map of all that lives,

in your ways of keeping time

lie the marks that ours is come: 
what perishes, what thrives.

Here the cork bursts from the bottle,

here are skeletons to rattle.

Wall of sound and thralling silence,

cryptic means to unknown ends,

tremor of a shifting valence,

knife that cuts and tie that binds.

No tale we tell entails your quiet work,

no fight we sweat unveils a major plan

that pins you down from chaos in the dark

or clearly charts the ways that you have been

above, below us flung, around us sown.

Each small thing comes to you in ritual of its own. 
Flow

To the stone, to the hill, to the heap, to the seep, to the drip, to the weep, to the rock, to the rill, to the fell, to the wash, to the splash, to the rush, to the bush, to the creep, to the hush;

to the down, to the plain, to the green, to the drift, to the rift, to the graft, to the shift, to the break, to the shake, to the lift, to the fall, to the wall, to the heft, to the cleft, to the call;

to the bend, to the wend, to the wind, to the run, to the roam, to the rend, to the seam, to the foam, to the scum, to the moss, to the mist, to the grist, to the grind, to the grain, to the dust;

to the core, to the gorge, to the grove, to the cave, to the dive, to the shore, to the grave, to the give, to the leave, to the oar, to the spring, to the tongue, to the ring, to the roar, to the song;

to the surge, to the flood, to the blood, to the urge to the rage, to the rod, to the rood, to the vein, to the chain, to the town, to the side, to the slide, to the breadth, to the depth, to the tide;

to the neap, to the deep, to the drag, to the fog, to the stick, to the slick, to the sweep, to the twig, to the roll, to the tug, to the roil, to the shell, to the swell, to the ebb, to the well, to the sea. 


\section{Kākahi}

Freshwater mussel/ Echyridella spp.

The water low,

the run-off thick,

the host-fish sparse,

the shells sealed shut.

Feel with my feet,

probe in the bed,

measure each length,

pencil it down.

Twenty-two sites,

only one fit

to harvest from.

An empty sack. 


\section{Western Diversion}

Hills must be levelled, the pumice-stone crushed to span across valleys, ninety-five tonnes of machine scrapes at the fracturing rock.

Heads of gigantic proportion working the earth in their mandibles, thudding of glistening shaft, pumping through layers of soil.

Deeper and cooler each day the tunnellers travel through darkness, over each entrance a shrine, holding a candlelit saint.

Flowering breasts adorning the ceilings of single men's bunkers, workshop a splaying of legs, pink and invertebrate form.

Muscle of men in the showers, soap to the ropings of tension, face to the sun-hardened towel, shirt to the crick in the back.

Click of the pool cue, sending out sparks over green felted valleys, clock of the graveyard shift, bell a rock breaking like sleep.

Fingers of pipework channelling down to the site of the powerhouse, stroking the clay-bellied hill, poking in ditches of murk.

Working the long job of gouging a channel through desolate swampland, block by block set in its place, the cuboid symmetrical dam.

Pipe flushing water, a spuming of high-pressured whiteness down the rectangular race, wetting the cameraman's lens.

Lichen grows over the culvert, the burgeoning language of fungus, cylinder sucking its load, passing obscured into scrub.

What is this twist in the chest, at this dull insignificant concrete? If unaware what it took, one wouldn't think to react.

Shoulder whatever you carry, return to the places you plug in, no way to cipher this loss, only a socket for void. 


\section{Whio}

\section{Blue duck/Hymenolaimus malacorhynchos}

The low guttural groan,

the whistle. How they hone

it, in clear water, pair

judiciously. They wear

a monetary hue.

Hard to come by, that blue. 


\section{Map-making}

The chain clanking, the clouds closing we waded through wetness. Waste is the word for it.

Feeling each footfall, scenting the foetid slurry of shrubbery sliced with the slasher. The fog had a freshness I felt through the flannel cloth of my shirt: it clung to me, clammy. These places appeared perpetually sodden, smelled of a swampy eternal sameness. The air had a taste of toi-toi, tea tree. The ground was bogging, a break in my boot-heel let in a leak. I was losing composure. My throat thirsting, I thought of tea, slung off my haversack. Head down, I heard my companion calling, clutching his chest. I'd never learned the local language, wondered at what he was warning us of. The rainclouds opened, a roll of thunder struck my ears, the start of a storm.

I looked to where the lad was pointing, the drab lagoon lying below us. Above the surface a shape had assembled: fierce, gargantuan, galloping at us.

I felt a hotness heap in my heart-valves, a jerk, a jump searing my jugular.

No time to think of a reasonable theory explaining its presence, I picked up my gear and fled through the flax. My fellows flung out in different directions. I dropped the theodolite; stumbling to save it, the slasher sliced my shin to the bone. The beast behind me, 
I crawled to shelter, shredded my shirt and tied a tourniquet tight on the wound. My gear gone, I lay there, gibbering, crawled for camp, my cut still oozing. Two of the trio had traipsed in before me. All night we opened our eyes at each noise.

At dawn we searched in a deep dread of finding our friend flensed and dismembered.

We found him, at length laid in the swamp, covered in cuts, knocked out cold.

He couldn't, or wouldn't recall his capture but cleft in his skin were the marks of claws.

To this day I don't dare to test my doubts, retrace the trail or recover my tools.

Call me a coward I'll meet your contempt, I marked a marshland on the map I made. Certain places surveys must circumvent, most of our maps leave minutiae omitted. 


\section{Shingle beach}

Kink in the path

fork of a branch

slub in the cloth

spoonful of salt

knot in the grain

fleck in the skin

grist in the mill

grind in the mix.

To even out

to open space

the stone removed

its roundness cracked.

A straighter course

a blotted mark

a metalled road

a deeper hole. 


\section{Trout}

Oncorhynchus mykiss

\section{Salmo trutta}

$H_{\text {e with his flexing }}$

ray-fins at the ready

she scrapes her redd

in the bed

of fine gravel

where water will travel

in riffle soft-peaking.

Now he moves, sexing

the roe lying steady

spills his milt, spread

to the head

at a level

to let it unravel

and meet what it's seeking.

Yellow sac'd alevin clustered in hiding

colliding

together, translucent, light-bending

freckled and blending

to stone-colour, matching

each roll to the current's tug, latching, unlatching.

Bug-eyed and bulbous, their yolk-spots subsiding, backsliding

they break from their cracks to the wending

of current, fast-tending 
to gulping and snatching

grown in the flicker of seek-and-dispatching.

Fingerlings flashing

$$
\text { in blurring reactions }
$$

swift in their shifting,

$$
\text { gulp-sifting }
$$

and feeding

on scoops of fresh seeding

on small fry, on all things.

Rising and splashing

$$
\text { to grasp dark refractions }
$$

of drowned insects drifting

$$
\text { bob-lifting }
$$

$$
\text { black-beading }
$$

the surface. A weeding

$$
\text { of weakness, of small things. }
$$

There was the water, as though it were waiting creating

an emptiness, ripe for the taking.

Sport in the making,

$$
\text { come fry in a swilling }
$$

of barrel by cartload. The rivers are filling.

Flies for the flicking, and hooks for the baiting fixating

in hunger, slow stares without breaking.

No easy slaking 
the line gathers weight, and the buckets are spilling.

There is a beauty

in marking a cluster

each to his stone

wet to bone

in the pooling

where the wide-spooling

hook shimmers, dangling.

We have a duty

to strengthen and muster

keep what's our own

what we've grown,

overruling

anything spoiling

the pleasures of angling.

That which was here first is caught in the jawing,

The gnawing

of newness works to uncover.

Seek to recover

then fall to a culling:

newcomers spread and their numbers keep swelling.

The small and the slimy are fit for ignoring

The roaring

of rapid calls to the rover.

All the world over

tales in the telling 
Keep travellers coming, each one of them calling,

Saying: Come, fish, break from your hollow

Be rose-moled, be of sufficient weight

to meet your fate

on the thin line you follow.

Gulp, swallow

this darting lure, its yearning.

Come to my hook, fish, and keep returning. 


\section{Grayling}

Prototroctes oxyrhynchus/ Upokororo

Small, insignificant fish.

Even your name is formless.

Null, extinct, extinguished.

Even your form is homeless. 


\section{Spring - Black, red and white}

The soil, awaiting spade.

Fingerprints of fire.

Light through the walls

of the womb. Capillary. Breath.

Heke - A rib cage.

Maihi - Arms outstretched.

Nights shorten,

the air quickens.

The wind, livid

lifting flags.

*

Poplars bud,

tītoki splits arils.

A black bird

with a russet saddle.

Heavy and bristling, a sow gives birth.

Piglet upon piglet upon piglet.

Rise, fall, rise, fall, rise.

The water breathing. 
Are the lamprey still running?

Against the current.

$*$

Hunter from hill,

forest-fed meat.

Mist - osmosis,

transpiration.

The droplets disperse.

The paper's space.

Fibre of pine.

Ink runs, then

tears.

Wai ora.

Volcanic clay,

rubbed with pebbles.

Rust of a kākā

folding its wings.

Fountain pen, printing press.

The glyphs of raupatu.

Things that bleed

when you cut them up. 
Mā pango, mā whero

ka oti te mahi.

$*$

Every tributary.

The wide-mouthed estuary.

A pattern of veins

in brain or breast.

The taut threads

of a plaited rope.

The river

is a person.

It draws

its own maps.

$*$

Serpentine stone

in an unlit room.

A kōauau

starts up

when no one's around.

Dim linoleum,

faulty electricals. 
Museum doors

banging

in the wind. 
Kōura

Freshwater crayfish/ Paranephrops planifrons

Berried with eggs, damp-coloured, decked with spines, its tail pulled off, still hides between the stones. 


\section{Whirlpool}

\section{Tarei-pou-kiore}

When the river floods the water squeezes

through a cleft between a massive cliff-face

and a mass of boulders, swift and yellow.

At its base a pool too deep to measure,

gaping, sucking, roaring from its gullet

like a hungry monster, caged and pacing

round its walled enclosure, bent on killing.

Past the cliff the twelve-foot waves come rushing.

'Don't go through in high flood,' say the bosses,

'turn or tie up, wait for it to quieten.'

On the other hand, there's pride in running

services exactly to a schedule.

Cross the beast by charging at its centre;

get a full steam up and make for safety;

keep within arm's reach the only lifebuoy

we possess, in case the skipper fumbles.

Engine flooding, vessel heeling madly,

clinging to the boat's the only option;

though it might go under, no use jumping -

diving in would only kill you quicker.

But then the boat is righted, and flung free

as though the whirlpool spits it in distaste.

Dog-like, it shakes the water from its decks. 


\section{Dynamite}

Make it wider, make it deep,

blast it away!

Where shingle shifts, where cliffs fall steep,

make it wider, make it deep.

The channel must be smooth as sleep,

let no obstruction stay.

Make it wider, make it deep.

Blast it away! 
Fire

God cut a clump of reddish clay

breathed moist on it and made a man.

This truth fits neatly with native knowledge:

they will take to heart what Taylor teaches.

Scores of souls must be swiftly saved.

With sons, three cows, two calves and a mare

he sails from Sydney by the ship Nimrod,

those dear having done their best to dissuade him.

But a headier call was heard by him

to leave his enviable English existence

and go South as sure as the compass spins

to the worst country the world owns.

His wife follows with waxing daughters.

Columbine carries them. The cruel bar crossed

they berth

to forge a house of good

upon the shaking earth,

and set to buying wood

each tree a blanket's worth.

Taylor's mission takes him tramping

a wet wilderness: along waterways,

sea-coasts, swamps wastes and settlements.

No flood, no forest no river, no fen

prevents his progress: he pushes all ways.

When he's cramped with the cold he's carried by guides.

They make their meals of kākā and mushrooms,

lampreys, potatoes, plain and unsalted.

Tired from travelling he tethers his tent,

sealed against rain with sugar of lead, 
then rises early to rescue the wicked,

baptise the heathen wed breeders of bastards

(fifty-two bonds tied before breakfast),

hands to the dying hope of heaven.

Ever searching for souls to bring

ashore,

he hears a dying chief

call for an end to war

in spite of old belief

and what has gone before.

As he wends his way he writes his works

on botany, minerals, bones of birds

as large as elephants lying in caves.

A broker of peace, he pulls teeth,

lances abscesses, lectures on hygiene,

gives salt to women seeking sorcery

to silence their claims of his seeming stinginess,

frowns on the fierce facial tattoos,

the rotten corn rank and reeking.

And near to his home gives new names:

Hiona, Ātene, Hiruhārama

Raorikia, Ramahiku

Karatia, Ranana: Christian cities

made malleable for Māori speakers.

In time

the old names surface less,

the church bells sound their chime

to summon and to bless

the work of the sublime.

Peace cannot prevail all times and places 
and like a lash of Catholic lightning comes Father Lampila the fiery Frenchman who girds hills green and grows grapes, who feeds his flock and filches souls, whose Hine Roimata holding her hands out weeps tears of sap and speaks in whispers. Who challenges Taylor: Let truth be chosen by trial of fire: who's freed from the flames is God's true missionary given His grace to prove His power and serve His purpose. The fire alight, the sparks leaping, Taylor refuses and takes to the track.

Lampila's friends pull him free of the flames, in spite of his vices crown him the victor, a thousand Catholics swiftly converted.

The loss will never be returned and now upon the cross the Priest who would have burned hangs his unseemly dross.

Bishop Selwyn heads south from Auckland travelling on foot through hidden territory. To meet with him, Taylor makes for the mountains.

They camp in rain with the rivers rising; to ford the surge they must strip to the skin and cross with their clothes carried on their heads. The Bishop wades the wild waters, Taylor is carried, Mr Cotton floats aboard the Bishop's inflatable bed. Nihil tries to ford but is swept off his feet. They camp after crossing and catch a wild cat, 
the meat they crave being duly cooked.

The following day it's tūī and fern-root, weka with rice and wild potatoes.

Procuring a pig, Taylor fries some pork.

His heart is happy but his head is aching.

In the morning he presses for Pipiriki,

no one

to keep him company.

The Bishop's work is done;

he paddles for the sea

along the river run.

The wilderness years wearing on him,

he breaks for business back in England

taking Chief Hoani Wiremu Hipango

to gift her Majesty cloaks and mere.

Winds back round the world on the Lancashire Witch.

When stopped on the island of Saint Helena

for water and stores, a weeping willow

is sighted growing on the grave of Napoleon.

He plucks off a sprig, puts it in his pocket.

Mrs Taylor keeps it with care in her cabin,

on bright days brought out in its medicine bottle.

Planted at Pūtiki, it becomes the parent

of weeping willows way up Whanganui.

Wherever he travels, he takes a few twigs,

sets them to root in the river silt.

They grow

a beacon of smoke-green

so travellers might know

where Taylor's feet have been

wading into the flow. 
At Christmas the church at Pūtiki is crowded

with Christian Māori come to the call

while over the river the rush to the races

keeps the Pākehā apart from his preacher.

Settlers seek his assistance, but seldom support him,

and progress is slow, necromancy persistent.

Locals cling to old customs like working unclothed.

One day old Ake is digging his garden

when Taylor commands him to put on a mat.

In the struggle to shove the man out of sight,

his coat is ruined with the ripe red clay

that Ake has spread all over his skin,

to shade

it from the heat of day,

his sacredness displayed.

A man cut out of clay

just as his God had made.

His years waning, Taylor carries on writing,

filling his journals with figures and sketches.

His second son succeeds him as Reverend,

leaves him at leisure to learn his sciences,

continue collecting his native curios.

The cluster of conflict becomes a town,

the roads fill, the fold increases,

the settler's graveyard gathers its citizens.

And when in kindness God calls him close

he is laid to rest in a sandy rise

a place that looks over to Pūtiki-wharanui.

From there

his living friends can hold 
Te Teira in their care

the stories he has told

still moving in the air. 


\section{Hīnaki}

Open $\mathrm{O}$ each end of the ovoid net,

funnelled, bent back, dark with tannin stain,

hung in a glass case over a model weir,

though where the poles remain the traps are set,

your cup will never hold an eel again.

Amidst your star-weave, small stones still adhere. 


\section{Tuna}

\section{Longfin eel/Anguilla dieffenbachii}

They taper their heads, enlarge their eyes, and swim downstream

far out to breeding grounds in the Pacific. Where these lie

no one really knows. They spawn and then they die.

The leaf-shaped larvae drift the currents, turn to glass eels once they're home. 


\section{Foundlings}

The doctor was walking the wharves. A cry

sounded in his arms. He handed me one

newborn, nameless boy, knowing that I

would not refuse. We named this first son

Joseph March, saint and month. Our flock expands:

bundles found on steamboats. In Wellington

the harbour is never full. A girl who stands

astride the rocks, at Oriental Bay

carries a swaddled boy. Unbid, my hands

move up to take him. I hear myself say

Tell me your name, and it remains with me.

The boy is baptised Francis, on his way

up country to the hill-bound nursery

at Hiruhārama, the mud and dust

of our farm on the middle Whanganui.

Why should a woman's name be lost for lust?

Mercy and secrecy do well together;

rather than hide and starve, a girl can entrust

her child to good care, and be free to tether

her loose ends from the fray, to show her face

in the world again. In rough or fine weather

Hiruhārama always has more space.

Each foundling is a child of God, the brother 
or sister of Him for whom there was no place

in the inn. Even in the arms of its mother

it has no room. The sisters are its aunts,

myself, Mother Joseph, its grandmother,

and in our quiet mission there's a chance

at a worthy life. Children tend to bees,

cows, horses and the vegetable plants,

and in the orchard the thousand cherries;

making music with a kerosene tin,

the littlies scare the blackbirds from the trees.

Black cherries, sweetheart cherries, stain the chin

of the boy with his packhorse, slow, unsure,

climbing the steep track to bring the milk in.

In the farmhouse kitchen, with its earthen floor

we cook hearth-fire cakes, while the King of Kings

stands in his watching place behind the door.

Our days are given up to humble things,

searching in the bush for leaves, bark, roots, shoots

to make our medicines. In the dark evenings

we often clean and waterproof our boots

with tallow, beeswax, lard and olive oil

warmed on the fire. The candles blown, night mutes

the valley, only the trampling pigs spoil

the depth of silence. At nine, we all sleep. 
Then, rising shy of five, resume our toil.

Most days, there's nothing I can do to keep

our Father Soulas from his morbid bent.

He lives beside that figure come to reap

his share of souls, and all his days are spent

anticipating death, the timbers sawn

for coffins for himself, myself, intent

on little else. Still more babies are born

and brought to us. Our convent is inspected,

but no money given, because we warn

the authorities we can't be expected

to name the childrens' mothers. Still I write

to Parliament, but my pleas are rejected.

All I can do is wander in the night,

and pray Our Lady will fill me with her light. 


\section{Lamprey}

\section{Piharau/ Geotria australis}

Swam up at the side,

a sweet meat clad

in a grey like mud. 


\section{Moutoa}

A minor island.

A rough-shaped diamond.

A node of darkness.

Gorse-blaze and lupin.

Death-candle poplars.

Its shifting outline.

Its peaceful aspect,

low, unobtrusive.

The call at dawn.

The boundary line.

The battle fought

for half an hour.

The fallen men

lain on the shore.

The current swirled

red with their blood.

A statue made in Melbourne,

a complicated purpose.

A life-sized woman weeping,

some of her fingers missing

(her hand, too wide, corrected).

A panelling of spandrills,

a stopped-and-fluted column.

The braille of missing letters. 


\section{Summer}

You must've stunk, musky, skunky hippie

walking up the road to Jerusalem.

Your bare feet pressed the dust,

like it would always be summer.

Heat shimmered over the verges,

ox-eyes shivered in an almost-breeze.

What magnet pulled you?

Love is not a recent thing.

Bees did waggle-dances,

wood beetles sang in the empty house.

The thousand curves in the old bus, the walk through nauseous groves.

But I don't want to see

a blue duck, whines a child.

Youth stretched in the grass, deep in Dickens.

A girl beside him, her head strung with beads. 
Like a bride who wears

her dowry in her hair.

All the life in London:

a wandering piglet.

Dark and lovely

a Greek woman smiles

under the road-sign at Athens.

The convent's florid bedspreads.

Its table under poplars.

My skin's come off,

cries the child in his sleep,

my bones are hanging out.

A girl writes the marae names

in her curly script

on the song sheet.

Ehara i te mea, nō ināianei te aroha.

Hutia te rito o te harakeke

Kei whea te kōmako e kō?

As scones are served

a woman strums and sings 
Someone loves you, honey

Wherever you go.

You used to hold your arms

out, cruciform,

your long hair hung

around your shoulders.

Beard touching your chest.

Guitar slung over your groin.

The sun has written

lyrics in your skin.

You say you paddled here

from Taumarunui, alone.

Everyone who passes

seems to know you, thin traveller.

The spine of the woman

beside you curves,

breast drooping to her child's mouth.

You talk of community,

part ways at the carpark. 
It is Christmas.

Kate is waiting for you.

And Mary has a cake in the oven. 


\section{Girl with baby in a corn field}

\section{Partington 103a}

Turning your head, you stand still, briefly pausing. Corn rears above you, its green flowers droopy.

Baby lolls over your shoulder - she's sleepy, tied up in blanket-cloth, tight to you, dozing, heavy as rock. Then the click of the shutter startles - the camera completing its gazing. Moving away, baby's eyelids are closing, lulled by the grasshopper's rasp, the birds' patter. 


\section{Pandora's box}

Wilkies shell bed

When you come to this cliff,

cleared and cut-back,

roughly risen,

you read in the rock

strangely pertinent

Pliocene prophecies

silent for centuries,

scripted in shells.

Sedimentary facies,

fossil fauna,

cyclostratigraphy,

a testable timescale.

Search this shell-script,

a set of psalms,

a learnable lesson,

limed, calcareous.

Buried bones,

busted banks.

Contours, isobars

cramming closer.

A storm is coming,

we've searched and seen it

in old oysters,

opened to weather. 


\section{Kauarapaoa}

The road climbs up abruptly, here, beneath the cliff the water dark blue glass.

A peacock dives into the grass oh where oh where oh where oh where oh where?

Wet tang of sheep shit, mass of trees releasing plant-scents in the angled sun, those smells of summers been and gone, bruised sap, ripe humus, rising to the nose.

The road bends with the deep-cut stream, leaves fuzz the chasm to its brim, and the stream slinks down towards the river like a lover you'll never get over.

All over, loose exotic scrub: gum, willow, wattle, elder, poplar, broom stitching the hillside like a seam across the rends of slip-soil dull and drab. A man in white bends to his hives below a face of mānuka sprayed dead. Sheep crawl amongst the sticks to feed on threads of green, wherever greenness lives. Across the road, like greying bones lie slash-piles of cut-over pines. And the naked peaks roll on forever like a lover you'll never get over.

A falcon calls above the rise: Kek kek kek kek kek kek kek kek kek kek.

Far over farmland lies a break of ocean, and the pale of western skies. 
The white volcano points out north,

seeming steadfast, despite its restless sleep.

The road skirts, in a gravel loop

a drop so steep it catches in the breath.

The roadside bluffs divulge their shells,

reveal the ocean held these hills.

And water is as much a mover

as soil in softness is a giver.

And what can the land do but take cover?

Like a lover you'll never get over. 


\section{Children in the mud}

Three mothers

I

The pang, the push, the slide,

the stretch, the yawning wide,

your supple form uncurled

into the waiting world

and water was your sage.

You learned it in its rage,

you learned it in its calm.

The bank-mud was your balm,

as back and forth you swam,

and back and forth you swam.

II

I gave you as sacrifice to the sea.

Pregnant, mad, no help for me.

You were four, disobedient, wild.

I said to the flood-tide: hold my child.

They found your body washed ashore

just south. Came knocking at my door.

Took me to die by the hangman's noose.

I pleaded womb: they turned me loose. 
I'll carry you until my death.

The current in my every breath.

III

Down by the marketplace we often walked.

My friend and I stood on the wharf, and talked.

The tide was out, the bed exposed to day.

You leaped the boardwalk into mud, to play.

All four went out light-footed on the beach.

I ran to you; you ran beyond my reach.

I didn't know if you would sink or float.

The tang of panic rising in my throat.

My knee-high boots sank knee-deep in the scum.

I called and called; you laughed, and wouldn't come. 


\section{Wattlebirds}

There were those who'd seen them, moving like ghosts, heard their calls, deeper, deeper in the wastes of scrub, slash, forest. The numbers smaller as time passed, each tale dying with its teller. 


\section{Pākaitore}

They formed a circle, holding hands.

What cop would break such brittle wrists

stretched round this smallest of small lands?

The statue gone, the plinth still stands.

The fig tree squiggles, bends and twists.

Its branches circle, holding hands.

Some years the garden fills with bands.

The vocals roll, the beat insists,

all round this smallest of small lands.

Movers and shakers, firebrands,

rock standing firm, song that resists;

all in that circle, holding hands.

The grassy bank, the river sands, the landing place that still exists beside this smallest of small lands.

The years move on, and time expands the distance, but the tale persists: they formed a circle, holding hands, around this smallest of small lands. 


\section{Flood}

Riverbank mum:

They came and told us clear out. It got late.

We packed enough,

drove to my folks, nothing to do but wait

to check our stuff.

I never dreamed this happening to me.

Like TV or the movies, but to see

our home gone, stings.

My family's things

buried in mud like we were nobody.

Hill country farmer:

You had any damage? How about you?

Our roads are locked,

washed-out, or slipped. Loaders are inching through

each bend that's blocked.

The power's out, the pump is off, that means

no showers. We'll survive on tinned baked beans.

Plenty of wood.

We can make good

out here, till rescue intervenes.

Flood:

Did you imagine I'd go wide as this?

Lap up your streets?

The lumpen stopbanks easy to dismiss,

where water meets

tarmac is where things really start to flow.

I waste whatever's lying low,

rip up your pontoons, wharves, unmoor your boats. 
My ample stomach swiftly bloats

with free and flash,

treasure and trash

whatever I work loose, whatever floats.

Valley dweller:

Ah well that's it for me, we're walking out.

Goodbye, mud-hole.

The missus's had enough. This latest clout

straight to the soul

straw to the camel. All our wordly worth

strewn round this muddy, mangled square of dearth.

Take stock of it,

pile up our shit,

and find another piece of earth.

Kowhai Park Brontosaurus:

My hump is all you'll see above the murk.

An octopus

submerged at last, arches lime-green leg-work.

Enveloped thus,

the grey whale drinks its hollow insides full.

Tongue moulded to the earth, staunch as a bull,

I brace my neck.

The sunken wreck

of playground bears the river's pull.

Flood:

Into your very fabric I will seep.

So let it pour.

Into your halls and offices I'll creep,

breach every door. 
I pop the lids of sewers, make them spume,

I enter every pleasant room

all bitter, spewy, indiscriminate.

Congeal all with my aggregate

of silt and stick,

of faecal slick,

choke up your holes and leave you desperate.

Road-clearing volunteers:

All over, rubberneckers getting stuck.

They'll never learn.

If they want help then they're shit out of luck, no room to turn.

Why don't they help $u s$, bring a shovel down, instead of being a nuisance to the town.

While others hurt, they gawk for sport.

Drowning in mud? Well, let them drown.

Plateau lifestyler:

Peak flow 4.8 kilotonnes per second, time to reflect.

A tenth of that was soil, or so I reckoned.

Where's the respect?

It's bleeding harder than land can sustain.

Truckloads of our best asset down the drain.

Arabs have oil,

but we have soil.

At least, we did. We won't, again.

Flood:

What seemed safe isn't, what you thought stood still 
is fraught with flux.

There is a wilding horse in every hill

that rears and bucks.

You live astride two moving chunks of crust:

fire, wind, earth, water, spark and dust,

this young geology is supple-sewn.

It answers to your blood and bone,

but strip it bare:

you must prepare.

I'll be the worst that you have ever known. 


\section{Girl with oranges}

You stand there, shifting on your feet, you push your hair out of your eye.

Your trestle set beside the street, your gaze set at the lower sky.

You've built your orange-stall beside the river.

You're younger than you look, or are you older?

Well, it's one way to lose a lonely hour.

You seem to shimmer in the heat, a candle or a butterfly.

Your orange letters round and neat your orange dress all flowery.

Although the day is warm you seem to shiver; beneath the spreading trees the air is colder. Is it their big-limbed presence makes you cower?

The customers you shyly greet are few and far between; you sigh. The traffic is an ageing fleet of souped-up cars that rumble by. A different destination for each driver: new tavern-bound, to drink an anger bolder, or to the cemetery, to lay a flower.

Regardless, each moves on upstreet through weather-boarded blocks that lie in cut-out grid, calm and complete in their peculiar symmetry. The smokefree dairy makes as much as ever. The absent landlords leave their flats to moulder. 
The pirate station's fist is raised to power.

In all the kitchens flour is poured, each siever

pausing to inhale the scents, to shoulder

longings. So they stir it, bitter, sour. 


\section{Spoonbill}

\section{Kōtuku ngutupapa/ Platalea regia}

Down by Bullocks' yards, where piles of bark

and boulders, fill and gravel, bide their time

the waders crept, once sewage was removed.

The tidal mud grew sweeter - coffee-dark

of water faded honey-pale. The slime,

thinned out, held feasts, the wide beaks clapped and roved. 


\section{Listen}

Now here we are, treading water through time.

Shoulders set with all the things it's ripe to

take into account. Now we can listen

for the slow push of mud, its murky truth

under the current. Face the round-about

mirror, which is ready to reflect us.

A lapsed lens doodles light, a this-is-us

free calendar, with blocky squares of time.

What does anyone really know about

the strata we're in, sedimented to

the layers below, not in them. The truth

is only sometimes spoken. Still. Listen.

Dead premier drinking your beer, listen.

The river you're in is one that cuts us

through. Rolling in the thick bed, headless, truth

disjoints you. On the bank, tram tracks mark time,

a vintage daydream easy to succumb to,

still, with the sense of things not talked about.

The shock-jockey, jogging, bounces about

like a wild goat. His feet stamp - don't listen.

The dead mayor wakes in the night, hearkens to

leaf music. He shakes with fear: them or us!

The cops are ready. Some wounds even time

has trouble stitching up, some grains of truth

will sit beneath the skin for years. The truth

turns up at odd times, between lines about 
more digestible things. Sound of this time is sound of people talking. To listen through the white noise won't be easy for us.

These dials - what frequencies will they turn to?

The train steams over the bridge; it has to.

The steamboat under it, making a truth of sumptuous smoke. A photograph of us is a photograph of bridges, about to reach respective other sides. Listen, ear to ground, for lightning earthing. Through time.

There's something troubling 'us'. The letters to the editor, the time-worn claims to truth. We've talked about it. Now we should listen. 


\section{Autumn}

The young man is listening to the river.

Headphones on, behind the bookshelves.

Out come the sounds of spent years.

Out come the voices laid down.

Hands holding branches, silver under leaves.

There are some areas we fought for...

The fuzzy scrawl of a spray-can.

The curve of a cop's helmet.

$*$

A man drives past the library, three dogs and two cats in the back.

The shakes in his wrists, the sun on his neck.

Rain comes and the hills resume their seasonal slumping.

Hens stop laying, gullies darken with mud. 
Children squeeze hail in their mittens, yelping.

$*$

Gourds are strung in the slash, green and bulbous.

Warts swell on the French pumpkins, bean pods blacken, kamokamo thicken their skins.

The buns rise best on Sunday because Christ rose again.

If the shearer's cook makes green jelly it means it will rain.

Two thousand years since the last eruption a steady supply of pumice continues.

Broken reeds floating, a flat rugby ball, a gatepost acorn.

Beautifully inked, a man drags a kahawai from the water.

A branch catches in the paddlewheel. A row of seagulls settle. 
The white streaks on the fig tree

look like bat shit, but are bleeds of sap.

Stone by stone

the monument is rebuilt.

Chunks of shellrock sprayed

with fluoro yellow numbers.

Mortar carried up the scaffold

in bright orange buckets.

The standard chain

is wearing into dirt.

Has the moving earth

narrowed its two brass bolts?

*

Anzac wreaths laid

on the colonial lion.

The awa station plays

a song about Rua Kenana:

Told his people not to go to war.

While Calbuco blows up,

Ruapehu is orange, serene. 
The stone soldier's face is calm

as the crane dangles him

above his rock. 


\section{III}

The moving sand 
The real issue, of course, was this: atomically, energetically,

everything was wave function. And a wave continues forever into space,

the wavelength never alters, only the intensity lessens, so

in the worst cosmic way everything is connected by vibrations.

And this, as even a dog would know, is no consolation.

Luke Davies, 'Totem Poem'

$O$ what $O$ what will

Bring us back to

Shore,

the shore

George Oppen, Discrete Series 
Fig. 3 Map of Whanganui Town

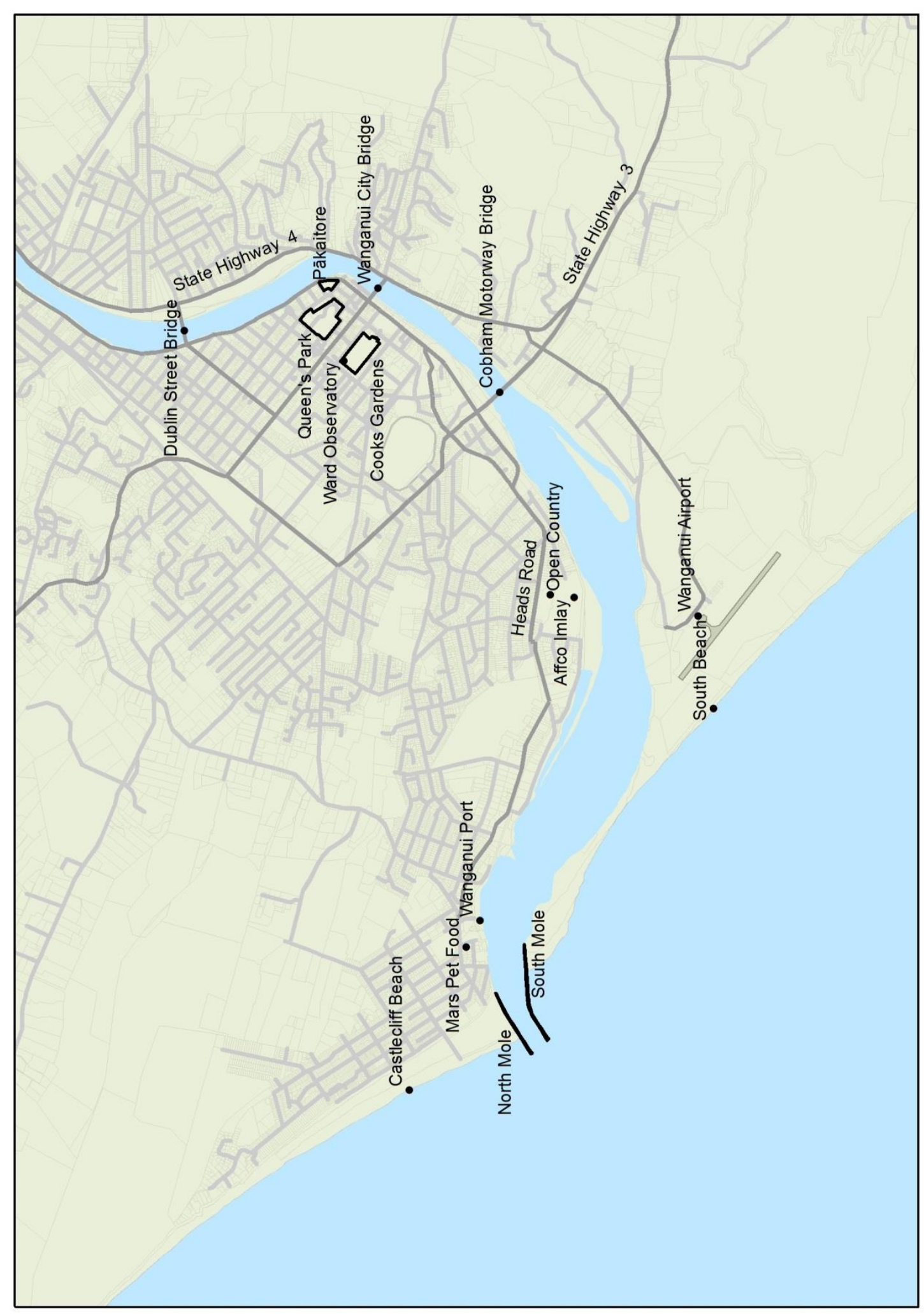




\section{Geology}

Sea nicked the gently-tilted peneplain, deposited a pebbly sand veneer.

Uplift exposed it. Ash-clouds spread their dust; sand dunes advanced across the coastal flats and buried them. When sand stopped, land was planed, coast worn back, valleys shaped. The lines of cliffs were cut by waves, small stones laid at their feet. More uplift, more ash-spreading, rivers worn deep into valleys. And the moving sand rolled in again, was planed, uplifted, cut, and pumice-showers spilled alluvium.

And all this time the wind blew from the north. And all this time the wind blew from the west. And all this time the black sand moved inland. 


\section{The long wait}

Landing here, Kupe said we must eat the wind.

There was so little food to be found.

They followed the river inland

to a turning place, where Arapawa drowned.

Tīeke, kōkako, tīwaiwaka

were the only signs of life.

Keeping an eye out for the waka,

we waited for them, in the sand-chafe,

and it was a long, long wait.

The river opened its mouth wide,

swallowed, spat. No two times the same.

In a dream, I sat there. It was getting late.

Stranded and unstranded by the surging tide.

To make the water safer, we gave it a name. 


\section{Surprise}

I carried in my hold this place's price.

They laid it on the Pākaitore mud.

Jew's harps, umbrellas, muskets, nightcaps, red

wool blankets, pencils, camp-stoves, piece by piece.

Then, homai no homai, in the same space

the locals laid their baskets, a fat breed

of pigs, fresh-killed. My crew were duly fed,

the land thought theirs. My work went on, apace.

I'd sailed the southern strait, sick-making sea

pounding my decks. And here, had crossed the bar

time after time, with all eyes on the break,

the flat deceptive calm. Then one spring day

I passed a notch askew, and keel to spar

was shattered in the foam, a total wreck. 


\section{Beachcombing along the tidal reaches}

Mud laced by snails, tide mark pocked with crab holes.

Bleached bones of last year's bloated cow fanned out.

From over the flat water sounds a phone

from somewhere a persistent rumbling comes.

How slick and still the water's surface is,

how hushed its slopping sounds against the rim

of shattered shellrock, concrete, tyres, laid out

in failed attempt to force the river's shape.

The push of current finds out every pore.

A lark is singing, perching on a thorn.

I walk to where the rotten slipways stand

and look across the estuary, to see

Taranaki set upon a warehouse

like a chunk of dirty polystyrene. 


\section{Lieutenant}

It is a rather pleasant place to live.

The only drawback is the horrid sand,

which blows all day and night with no reprieve,

forced into nook and cranny by the wind.

Even the very weave of my white shirts

is infiltrated with dark grains, like mould.

Any scrupulous person in these parts

must change his linen twice a day. I held

out hopes to grow a garden, for a while.

The black sand swallowed up my every seed.

And though the air is cleansing, I still feel

a proper beach should have white sand, a crowd

of picnickers, an even drift of shells,

rows of striped tents, and girls with parasols. 


\section{Open Country}

White smoke was seeping from a high steel pipe,

milk water blending into sky, on top

of Open Country. At the butcher's shop

fibreglass cattle stood within the swipe

of salt, paint flaking from their rumps. A type

of rotten wind blew over town - the drop

of tonnes of rancid fat had brought a stop

to sewage treatment works. The smell was ripe.

I took a left, drove past the bolted doors

of old wool sheds. I used to call around

there, time to time, break up the dragging day.

They swallowed piles of junk, those sweeping floors,

high roofs. I thought of wheels, thought of the sound

they make when spun, and spinning, roll away. 


\section{Constable}

As we approached the wharves I fired my gun

to tell them law and order had arrived.

I walked to find the magistrate, through fern

and flax - a swamp. The path to where he lived

I might have called a road, if I had been

a pig. I came upon a shabby man

digging his patch, his clothing rough and worn.

I asked 'Old chap, where is your master, then?'

'I have none,' he replied. I stared at him.

He smiled and said 'I'm Samuel King, Esquire.'

He told me I could make his tent my home,

and cook some bacon and potatoes there.

I did as bid. The food was plain, and good.

Already on my knees, I thanked my God. 


\section{Eunice}

There was no set when Eunice met her fate.

The vessel struck the bar, the crew reached shore.

This court's opinion is we can't ignore

the fact the captain, first mate, second mate,

and four more of the crew were foreign-born.

No British ship should be allowed to be

so officered and manned. This travesty

might well have been prevented, and I warn

that in these far from normal times more care

must be employed. There should be a return

stating the number of unnaturalised

seamen engaged in coastal shipping. Where

the causes of this wreck lie, now we learn

steering was at fault. I am not surprised. 


\section{PechaKucha}

I am going to share with you the town I come from.

For years I didn't want to tell anyone. When you drive

in, on the highway there's this sign: Welcome Home.

And I get this sinking feeling, every time I arrive,

that I'll be stuck there forever. Kids have unusual names,

as you can see, reading this slide. My dad's a teacher; it's a list

from a typical class. But we did have some pretty good times:

Durie Hill Tower, Kowhai Park. We used to get pissed

at this lake. This is me on South Beach ... Oh, the hair,

well it was the nineties, hence my tasselled dolphin sarong.

They made us hold hands in circles, dance around the fire,

or the maypole ... I have suppressed these memories for so long.

I wanted to be a surfer, catch every gnarly wave.

I wanted to be a boy named Larry, ordinary, but brave. 


\section{Mrs Field}

I think I would have failed if it were not

for my dear bird, who talked unceasingly,

his cage upon my shoulder. By the sea

were miles of grassy dunes; no shade. The lot

of all our worldly goods my husband got

into a heavy swag; the pots for tea,

our bedding and our clothes. Strapped onto me

my son was bundled like a native tot.

The week-long walk it seemed that every wind

on earth was passing here - a constant threat.

My body sheltered boy and parrot both.

The sand abraded me till I felt skinned

alive. Come evening, we'd make camp, and with

a stick I'd dig up grubs to feed my pet. 


\section{Shifting sand}

Ninety-eight percent of scientists claim an increased incidence of extreme weather events. Carbon emission increases climate change.

Using diesel fuel to move sand to the windward is the ultimate in ignorance and human arrogance. The amount it costs the council - it's strange.

Once a year before Christmas they do a major groom, push huge amounts of sand into the Tasman Sea.

The giant parking lot is empty ninety-nine percent of the time. 'Eco-thrifty' means you invest up-front and save energy, save money and help the environment. What I call win-win-win situations. When you engage in eco-design you just observe how does nature do it. They're spending lots of money to maintain something people don't use. Bad design is expensive, monetarily and carbon-wise. Flood protection is a parallel. When a hundred-year flood becomes a fifty-year flood, stopbanks will fail. 


\section{The jail house}

We built our local jail house at no cost.

When any sawyer erred against the law

I had him fined in timber - first he lost

to us one hundred board feet, and if more

wrongdoing occurred, two hundred. And so on.

Nobody needed jailing, so to keep

it occupied, I bought a dozen ton

of pumpkins, and potatoes. Where I sleep,

I left clear, and my desk - the rest was filled

up to the roof. It had a homely scent.

One day out shooting at the heads - I'd killed

three ducks - I spied the Catherine Johnson, bent

into the western wind. They heard me hail,

brought me on board. We went to see my jail. 


\section{Holiday Park}

Our second day is the first thing I remember.

We all went down to the beach, and it was like

real windy, and it seemed to go forever. Mum and Dad

used to let us roam around the camp and stuff.

The Spittal brothers didn't like my Dad.

There was this one night, I remember

there were six guys, they tried to like stab him and stuff.

We called the cops. The cops came, and they were like

it's lucky they had two knives in each hand, more stuff

would have happened if they'd had one. Dad's

wrist got broken. They hit him with a baseball bat. And like

this other time, there were these people I remember

they like threw bottles at the house. And they had bats and stuff

as well. And I remember crying to Mum, "I'm too young to not have a dad!" 


\section{Stormbird}

She struck the mole bow-on. I heard the cry

'Make for the shore!' The swell tipped Fireman Kyle

out of his bunk. We dressed - Logan and I

were first to make the wall. Waited a while,

five others also leaped, Kyle stayed on board.

'For God's sake, jump!' I yelled, but was ignored.

Miscalculating, Hunter landed short

and drowned. We saw his body float, and thought

the rest of them were lost, but by the light

of a blue flare, we spied them in the sea:

they clung on to the capsized hull all night.

A sweeping wave tore Kyle and Hinchey free;

the others lived. They took us somewhere warm.

The bodies washed up southwards in the storm. 


\section{Bluffs}

Jeez, that Kaimatira pumice, man.

It's fucking huge. It's just, how the fuck

did that happen? It would have gone

all the way up to Auckland. The cutting-back

of the road has exposed these beautiful strata.

It came from Mangakino, would have been

a stupendous eruption. The data

shows there's been quite a few eruptions. The crust is thin

here. And most of the planet is $4.2 \mathrm{k}$ under the sea.

If something fell to earth from space, chances are

it'd land under water, $4.2 \mathrm{k}$ down. In a way

the forces have conspired to make sure

that on a planet covered in water, there's some dry land.

If we weren't in an orogeny . . Well, never mind. 


\section{Heads Road}

While you were working nightshift out at Mars

Petfood, you had a rented house near here.

Your shifts pinned on the wall: these patterned bars

of shocking pink. Something going somewhere

is what I think of, in that part of town.

'Bits are still coming out of me,' you said.

Beside the mantel, flat-packed, facing down

a pram lay in its box. We drank cheap red

wine, and ate nachos. On the tabletop

a singing caterpillar - a coloured row

of different types of music. You pressed ROCK:

Orange orange orange orange. Then pop,

opera, baroque. Each press a double shock:

early for buying, late for letting go. 


\section{Blood and sand}

I spy the boat beached on the shore,

its crew crouched at a smutty fire.

We've hunted half the island for

the captain who is standing there.

Joe Rowe. Down south, we saw his goods.

The moko on our people's heads.

He heard us weep. He stood and laughed.

He heard us beg for them. He scoffed.

Now, here he is. 'What's in your boat?'

I climb inside. He pulls me out.

I meet his eyes, and think of smoke.

I touch the club beneath my cloak.

I watch the veins rise in his neck.

I watch him take his last few breaths. 


\section{Gathering the berries of Pimelea turakina}

You couldn't wield a pair of secateurs

to save yourself. And what use is a man

of unsure grip? But still, that soft hand-span

enters my thoughts, down where the ocean blurs

the land, repeatedly. The hot sand stirs

under our feet; we climb to where the tan

of pīngao, grey of marram holds what can

be held. We're silent, and the wind concurs.

We have no grip on time, we haven't seen

how it can wear us down. And at the turn

of season you are gone. The afternoon

is broken, all the places we have been,

and lying in the sun I only burn.

I think I hear days clicking as they prune. 


\section{Meat workers}

There is a kind of skill in how you cut

the belly of the sheep, and let it spill

its insides, quickly dropping out the gut.

If they don't break our bones, they'll break our will.

My puku not yet sunk from number five

I start my shifts at six, each day a bill

or rent to work for. Somehow I arrive.

If they don't break our bones, they'll break our will.

Then one day I turn up, and we're locked out.

The bosses tell the union, back down, chill,

there's nothing doing kicking shit about.

If they don't break our bones, they'll break our will.

So here we are, out marching in the street.

They've stopped our pay, but they can't stop our feet. 


\section{Port Bowen}

The line went taut. My hand spun on the reel.

No fish, all snag. I waded to the shore.

On board, the wireless rasped about the war.

They had me there by nights, guarding the steel

that they were slowly breaking up. By feel

I took my footsteps through the surf, its raw

cold burning on my skin. One arm's length more

I'd have my jig, my chance to land a meal.

The moon was in the cloud. Her face all pale

and fuzzed, she dimmed and brightened over the hulk.

And as I searched a wave crept up on me,

a sudden smack. I staggered in its bulk,

went under, thrashed my limbs to no avail.

Come into me, I'll have you, said the sea. 


\section{Glow in the dark}

Greet me you red-haired ghost, walking tonight along the riverbank, your mind aflame with all that can be said, and can't. The fight of words was always in you, and your name is said aloud with reverence now. Near here is where you lived, for the short space of time you worked the local paper, where the fear of too much truth, and your unmarried womb with child, spilled out and took your job with it. They whispered behind hands, but they were plumb afraid of all your pluck. Show, blaze and spit! At nightfall things speak, that by day are dumb. The cracked sticks burn to ember, smoke and spark. A small dog's eyes are glowing in the dark. 


\section{Longshore drift}

Sandfly, Imp, Black Warrior, John Penn, Sturt...

The local optimists begin to dream

a future, in the river, for a port.

Prince Alfred, Star of China, Tyne, Midge, Gem . .

Strong walls need to be built, to save the spit

south of the river mouth, also to form

a buffer for the clay bluffs, and divert

the current. From a quarter mile downstream

of the town bridge, they sink the shellrock in,

drive down the posts. And carefully they dredge

ten thousand cubic yards of silt. But soon

the river floods and fills it up again.

North of the wall, along its rubbly edge,

the sand piles up, the dunes come marching down. 


\section{The sandhill}

The sand blew from the sea mile upon mile

The black sand came in waves mile upon mile

And shaped itself into an oval hill.

There was a stockade built there, and a well

A loopholed timber stockade, and a well

That watered all the rough shacks on the hill.

They built a sturdy gallows on the hill

They tied four sturdy nooses on the hill

And hung four captive men till they hung still.

Years later they were digging in the hill

Found four skeletons, buried in the hill

Smashed them with spades and threw them in the fill.

There is a wet place, where thick grass has grown.

The old well oozes up through sand and bone. 


\section{Observatory}

Kids, who wants to look up through the telescope?

This is the largest unmodified refractor telescope in use in New Zealand. Birthday girl, you first. I hope

you'll see a planet up there, with rings. That might come loose

if you fiddle with it, be careful. It looks like smoke?

That would be a cloud. Is that really a planet? Yes.

Nah, I stuck a picture up on the end. That was a joke.

Could an asteroid destroy humanity? Well, I guess

there's a chance. No object we know of threatens us any time soon.

Is there life like ours, out there? Keep looking up, wave a little.

Parents, bring your kids back one Friday night, maybe the moon

will be visible. Who hasn't had a turn yet? Look there, and it'll be right in the middle. Ha, that's what everyone says. You know how they called this planet Saturn? They really should have named it Oh wow. 


\section{Dead port}

Future of the port? Here we go again.

This port is dead. Kaput, lifeless, done.

Never deep enough: it is a river mouth.

It will never bustle like New Plymouth.

Still, now and then, the flim-flam men turn up.

Wake up Council, and Ratepayers, wake up!

You are trying to revive a plesiosaur

by tending to its bones with caviar.

And don't start mouthing off about ironsand

and all its millions. The seabed will be ruined,

and any venture mothballed anyhow.

Just look at Waipipi - what is it now?

We'll have decimated fish stocks once they're gone,

and an injured ecosystem to pass on. 


\section{Cyrena}

Entering port, she stranded on a shoal.

A log had stuck there, by an act of God, and mud had banked up, after a heavy flood.

Her cargo: forty thousand cases of oil brought from the East. That big log ripped her hull;

by midnight she was leaking something bad.

They beached her to the north, and thought they could still float her off. She smashed up in a gale.

And lay there five months, till they blew her up with such a charge that peoples' windows burst and sitting hens went off their eggs. This here's a case of silver spoons I bought, same type as on my ship, but with her name. The last ones left that weren't pinched. They're my souvenirs. 


\section{Control}

Our airport gets a tower. Long live the modern!

I park the car, and stroll around its base.

I love to stand out here and think, my god, in

forty years or so we'll live in space.

I've loved the smell of aeroplane exhaust,

the roar of engines, all my life. The first

plane that I saw ripped through my ears, and coursed

its hydrocarbons through my blood. I'm cursed

to worship kerosene, wherever it burns.

But now, that tower... The problem is the sky.

So wide and pale whoever sees it learns

how small he is, how nothing we might fly

could scratch its skin. The tower, on its own,

so dwarfed, out here you only feel alone. 


\section{Walking the dog}

You know those bunkers, built in World War Two

to guard the town from Japanese attacks,

as if they'd want to take this place. ... The tracks

along the river go past there, where you

might see teenagers huffing paint and glue,

but maybe you'll see something else, that packs

more of a punch. We take it to the max,

and if you like to watch, I dare you to.

That's where I'll be tonight with my big girl -

I should say woman - ordering me round.

She comes down hard on me! And there'll be men

in other cars. Come on, give it a whirl;

whatever floats your boat might just be found.

We go there every Sunday night, round ten. 


\section{The long wait II}

Hau always had to see his vengeance done.

I knew that he'd be wild when I went south

with two men, named for birds. Mouth after mouth

we spanned the rivers, till we came to one

I knew from stories, fast and full, too deep,

too wide to cross. A thousand sparkling eyes

of fish flashed in and out its jaws, the cries

of birds were woven into mine. Come sleep,

said Kiwi, wait until it calms - we'll swim

across it then. You're mad, I said, he'll come

for me and kill us all. And lying prone

upon the sand I listened. Ssh, it's him!

His voice was in the waves, their heavy thrum.

Somewhere he'd find me, turn me into stone. 


\section{South Beach Café}

It used to be like going back in time

flying from here. In sixties dress, I wait;

the lounge unfortunately up-to-date,

sterile and bland. No orange plush, no grime,

no garish carpet squares that seem to chime

a discord with the walls. The tower's fate

sealed up with plywood boards. Proceed to gate.

I'll meet you for a drink tonight, sometime.

But this, too, is the past: the winter light,

the lift-off over dunes, the bumpy ride,

the turbulence so wild I nearly spewed.

Time-travel is the only way I might

get back to you, the wine we drank outside.

And if that's not an option, then we're screwed. 


\section{Grace Dent}

I struck, breached to, became a total wreck.

My bulky cargo quickly made me break, the lightest piece a ton. My shattered deck, my splintered masts, spoke to the clear mistake my captain made, not mindful of the shore, the pilot station's flags. He asked to cross, they signalled How much water do you draw? but no reply. The south wind put a gloss of salt over his glass; the letters blurred. Pounded on the sand, out came a spill of ironbark; the timber sent to gird the railway bridges. Read this how you will: to cross the Tasman sea in heavy gale and reach the destination. Then to fail. 
Pour

Like a twisted tap

like a sinking ship

like a cask of plonk

like a weeping drunk

like a turning tide

like a severed head

like a fatted cow

like those who know

like a steamer stack

like a sudden break

like an after-birth

like the restless earth

let it all pour out.

Let it all pour out. 


\section{North Mole}

We see Kupe climb out of his car

at the North Mole, pull his wetsuit

hood over his head, place foot after foot

on the sharp rocks towards where we are.

Hey man, he says, as he reaches the sand.

He's given up on the gym -

it doesn't motivate him.

He has more of a surfer's mind. And the band?

Yeah, yeah, his music is going well.

He times his movements to the swell;

so many things could lie beyond the roll

of water, out past the end of the mole.

And each wave curling in to the shore

is like the sea saying what are you waiting for? 


\section{Works Cited (Critical Component)}

Abbott, H. Porter. The Cambridge Introduction to Narrative. 2nd ed. Cambridge: Cambridge UP, 2008. Print.

Abrams, M.H. A Glossary of Literary Terms. 8th ed. Boston: Thomson, Wadsworth, 2005. Print.

Ackland, Michael. "Poetry from the 1890s to 1970." Webby 74-104.

Addison, Catherine Anne. "Heritage and Innovation in Byron's Narrative Stanzas." The Byron Journal 32.1 (2004): 9-20. Academic OneFile. Web. 30 May 2013.

---. "Little Boxes: The effects of the stanza on poetic narrative." Style 37.2 (2003): 124143. Expanded Academic. Web. 01 May 2013.

---. “Ottava rima and novelistic discourse.” Journal of Narrative Theory 34.2 (2004): 133-145. Project Muse. Web. 30 Apr. 2013.

---. “The Verse Novel as Genre: Contradiction or Hybrid?” Style 43.4 (2009): 539-562. ProQuest. Web. 11 Mar. 2013.

Anderson, Don. "Chapter And Verse." Bulletin With Newsweek 119.6266 (2001): 89. Australia/New Zealand Reference Centre. Web. 29 Dec. 2015.

Attridge, Derek. Poetic Rhythm: An Introduction. Cambridge: Cambridge UP, 1995. Print.

Avia, Tusiata. Bloodclot. Wellington: Victoria UP, 2009. Print.

---. “Tusiata Avia new book Blood Clot." Online video clip. Youtube. Youtube, 21 May 2009. Web. 14 Oct. 2015.

Bal, Mieke. Narratology: Introduction to the Theory of Narrative. Trans. Christine van Boheemen. Toronto: U of Toronto P, 1985. Print.

Barnard, Rita. “Coetzee In/And Afrikaans.” Journal of Literary Studies 25.4 (2009): 84105. Taylor and Francis. Web. 07 Jan. 2016.

Barrington, Judith. "Scaffolding." Finch 25-26.

Barthes, Roland. "Introduction to the Structural Analysis of Narratives." New Literary History 6.2 (1975): 237-272. Print.

Bassett, Michael. “'Kirk, Norman Eric', From the Dictionary of New Zealand 
Biography." Te Ara: The Encyclopedia of New Zealand. Te Ara, 30 Oct. 2013. Web. 01 Jan. 2016.

Bates, Milton J. "Stevens and Modernist Narrative.” Wallace Stevens Journal 35.2 (2011): 160-173. Project Muse. Web. 2 May 2013.

Bedient, Calvin. He Do the Police in Different Voices: The Waste Land and Its

Protagonist. Chicago: U of Chicago P, 1986. Print.

Belich, James. Paradise Reforged: A History of the New Zealanders From the 1880s to the Year 2000. Auckland: Penguin, 2001. Print.

Bennett, Andrew J. “'Devious feet': Wordsworth and the Scandal of Narrative Form.” ELH 59.1 (1992): 145-173. JSTOR. Web. 07 Jan. 2016.

Bernstein, Michael Andre. The Tale of the Tribe: Ezra Pound and the Modern Verse Epic. Princeton: Princeton UP, 1980. Print.

Berry, Eleanor. “The Free Verse Spectrum.” College English 59.8 (1997): 873-897. JSTOR. Web. 6 Nov. 2013.

Bialostosky, Don. Making Tales: The Poetics of Wordsworth's Narrative Experiments. Chicago: U of Chicago P, 1984. Print.

"Bill Sewell: Biography.” NZEPC. NZEPC, n.d. Web. 1 Jan. 2016.

Blasing, Mutlu Konuk. Lyric Poetry: The Pain and the Pleasure of Words. Princeton: Princeton UP, 2007. Print.

Bremond, Claude. "The Logic of Narrative Possibilities." Trans. Elaine D. Cancalon. New Literary History 11.3 (1980): 387-411. JSTOR. Web. 07 Jan. 2016.

Brogan, T.V.F. “Line.” Preminger et al. 694-697.

Brooks, Cleanth. Modern Poetry and the Tradition. London: Poetry London, 1948. Print.

Brooks, Peter. Reading For the Plot: Design and Intention in Narrative. Oxford: Clarendon, 1984. Print.

Bruner, Jerome. "The Narrative Construction of Reality." Critical Inquiry 18.1 (1991): 1-21. JSTOR. Web. 07 Jan. 2016.

Cameron, Sharon. Lyric Time: Dickinson and the Limits of Genre. Baltimore: Johns Hopkins UP, 1979. Print.

Chatman, Seymour. Coming to Terms: The Rhetoric of Narrative in Fiction and Film. Ithaca: Cornell UP, 1990. Print. 
---. Story and Discourse: Narrative Structure in Fiction and Film. Ithaca: Cornell UP, 1978. Print.

Childs, John Steven. Modernist Form: Pound's Style in the Early Cantos. London: Associated UP, 1986. Print.

Clarke, Cheryl. "Thoughts on Form and Formalism and My Uses of Them....” Finch 48-50.

Coetzee, J.M. Doubling the Point: Essays and Interviews. Ed. David Atwell. Cambridge: Harvard UP, 1992. Print.

Conte, Joseph. Unending Design: The Forms of Postmodern Poetry. Ithaca: Cornell UP, 1991. Print.

Creaser, John. "Prosodic Style and Conceptions of Liberty in Milton and Marvell." Milton Quarterly 34.1 (2000): 1-13. Project Muse. Web. 07 Jan. 2016.

Culler, Jonathan. Structuralist Poetics: Structuralism, Linguistics and the Study of Literature. London: Routledge, 1975. Print.

---. “Why Lyric?” PMLA 123:1 (2008): 201-206. JSTOR. Web. 07 Jan. 2016.

Delmaire, Dominique. "The Subject and his Stories: Lyricality in the Narrative Poetry of George Mackay Brown.” Temporel (2012): 1-25. Web. 9 May 2013.

Dickie, Margaret. On the Modernist Long Poem. Iowa City: U of Iowa P, 1986. Print.

Dobrez, Livio. “Australian Poetry.” Roberts 281-292.

Dubrow, Heather. "The Interplay of Narrative and Lyric: Competition, Co operation and the Case of the Anticipatory Amalgam." Narrative 14.3 (2006): 254-271. Project Muse. Web. 29 Jan. 2014.

DuPlessis, Rachel Blau. "Manifests.” Diacritics 26.3/4 (1996): 31-53. Project Muse. Web. 5 Apr. 2013.

Dyer, Richard. The Matter of Images: Essays on Representation. London: Routledge, 1993. Print.

Eliade, Mircea. Myth and Reality. London: Allen and Unwin, 1964. Print.

Eliot, T.S. Selected Prose. Ed. John Hayward. Harmondsworth: Penguin, 1953. Print.

Fallon, Kathleen Mary. "Ham-Fists in those "Male-size Golf Gloves." Southerly 55.3 (1995): 191-197. Informit. Web. 07 Jan. 2016. 
Fay, Julie. “A Kind of Survival.” Finch 66-69.

Finch, Annie, ed. A Formal Feeling Comes: Poems in Form by Contemporary Women. Brownsville: Story Line, 1994. Print.

---. The Ghost of Meter: Culture and Prosody in American Free Verse. Ann Arbor: U of Michigan P, 1993. Print.

Fischer, Hermann. Romantic Verse Narrative: The History of a Genre. Trans. Sue Bollans. Cambridge: Cambridge UP, 1991. Print.

Fludernik, Monika. “Conversational Narration/ Oral Narration.” Hühn et al. 63-73. Print.

---. "Genres, Text Types, Or Discourse Modes? Narrative Modalities and Generic Categorization." Style 34.2 (2000): 274-92. ProQuest. Web. 18 Sep. 2013.

---. Towards a Natural Narratology. London: Routledge, 1996. Print.

Forster, E.M. Aspects of the Novel. London: Arnold, 1927. Print.

Frank, Robert, and Henry Sayre, eds. The Line in Postmodern Poetry. Urbana: U of Illinois P, 1988. Print.

Freccero, John. Dante: The Poetics of Conversion. Cambridge: Harvard UP, 1986. Print.

Friedman, Susan Stanford. "Craving Stories: Narrative and Lyric in Contemporary Theory and Women's Long Poems.” Feminist Measures: Soundings in Poetry and Theory. Ed. Lynn Keller and Cristianne Miller. Ann Arbor: U of Michigan P, 1995. 15-42. Print.

Frye, Northrop. Anatomy of Criticism: Four Essays. Princeton: Princeton UP, 1971. Print.

---. “Approaching the Lyric.” Lyric Poetry: Beyond New Criticism. Ed. Chaviva Hošek and Patricia Parker. Ithaca: Cornell UP, 1985. Print.

Fussell, Paul. Poetic Meter and Poetic Form. New York: Random House, 1965. Print.

Genette, Gérard. Narrative Discourse: An Essay in Method. Trans. Jane E. Lewin. Ithaca: Cornell UP, 1980. Print.

---. Paratexts : Thresholds Of Interpretation. Cambridge: Cambridge UP, 1997. eBook Collection (EBSCOhost). Web. 29 Dec. 2015.

Genette, Gérard, Nitsa Ben-Ari, and Brian McHale. "Fictional narrative, factual narrative." Poetics Today 11.4 (1990): 755-774. JSTOR. Web. 14 Mar. 2013. 
Gioia, Dana. "Notes on the New Formalism." Expansive Poetry: Essays on the New Narrative and the New Formalism. Ed. Frederick Feirstein. Santa Cruz: Story Line, 1989. 158-175. Print.

Glatt, Carra. “The Maker's Rage: Narrative in Stevens' Poetry. Wallace Stevens Journal 37.1 (2013): 12-23. Project Muse. Web. 07 Jan. 2016.

Graves, Robert. "Harp, Anvil, Oar.” The Structure of Verse. Ed. Harvey Gross. New York: Ecco, 1979. 21-39. Print.

Grant, David. The Mighty Totara: The Life and Times of Norman Kirk. Auckland: Random House, 2014. Print.

Green, Paula. "The Fifties, Sixties and Seventies." Green and Ricketts 147-164.

---. “Narrative Poems and Prose Poems.” Green and Ricketts 28-42.

---. "The Sestina." Green and Ricketts 64-71.

Green, Paula, and Harry Ricketts. 99 Ways Into New Zealand Poetry. Auckland: Random House, 2010. Print.

Hartman, Charles O. Free Verse: An Essay on Prosody. Princeton: Princeton UP, 1980. Print.

Hayward, Margaret. Diary of the Kirk Years. Auckland: Reed, 1981. Print.

Heiden, Bruce. "Narrative in Poetry: A Problem of Narrative Theory." Narrative 22.2 (2014): 269-283. Project Muse. Web. 19 Jun. 2015.

Herman, David. Story Logic: Problems and Possibilities of Narrative. Lincoln: U of Nebraska P, 2002. Print.

Herman, David, Manfred Jahn, and Marie-Laure Ryan, eds. Routledge Encyclopedia of Narrative Theory. London: Routledge, 2005.

Hollander, John. Vision and Resonance: Two Senses of Poetic Form. 2nd ed. New Haven: Yale UP, 1985. Print.

Holmes, Paul. Daughters of Erebus. Auckland: Hachette, 2011. Print.

Hovdhaugen, Even. From the Land of Näfanua: Samoan Oral Texts in Transcription with Translation, Notes and Vocabulary. Oslo: Norwegian UP, 1987. Print.

Hühn, Peter. "Event and Eventfulness.” Hühn et al. 80-97.

---. "Functions and Forms of Eventfulness in Narrative Fiction." Pier and Landa 141163.

---. "Plotting the Lyric: Forms of Narration in Poetry." Müller-Zettelman and Rubik 
147-172.

Hühn, Peter, and Jens Kiefer. The Narratological Analysis of Lyric Poetry: Studies in English Poetry from the 16th to the 20th Century. Trans. Alastair Matthews. Berlin: De Gruyter, 2005. Print.

Hühn, Peter, John Pier, Wolf Schmid, and Jörg Schönert, eds. Handbook of Narratology. Berlin: De Gruyter, 2005. Print.

Hühn, Peter, and Roy Sommer. "Narration in Poetry and Drama." Hühn et al. 228-241. Hurley, Michael D. "Interpreting Dante's Terza Rima." Forum for Modern Language Studies 41.3 (2005): 320-331. EBSCOhost. Web. 14 Dec. 2015.

Jackson, Anna. “Anne Kennedy's The Time of the Giants: Genealogy as Headland.” Floating Worlds: Essays on Contemporary New Zealand Fiction. Ed. Anna Jackson and Jane Stafford. Wellington: Victoria UP, 2009. 108-123, notes 172173. Print.

---. The Gas Leak. Auckland: Auckland UP, 2006. Print.

Jannidis, Fotis. “Character.” Hühn et al. 14-29.

Jarman, Mark. “'The Music of What Happens': A Symposium on Narrative Poetry.”

NER/BLQ 8.1 (1985): 48-51. JSTOR. Web. 30 May 2013.

Johnson, James William. "Lyric.” Preminger et al.713-727.

Kane, Julie. "The Myth of the Fixed-Form Villanelle." MLQ 64.4 (2003): 427-443.

EBSCOhost. Web. 09 Jun. 2016.

Kenyon, Jane. "Shielding." Finch 117-119.

Kindt, Tom, and Hans-Harald Müller, eds. What is Narratology?: Questions and Answers Regarding the Status of a Theory. Berlin: De Gruyter, 2003. Print.

King, Michael. The Penguin History of New Zealand. Auckland: Penguin, 2003. Print. Kinney, Clare Regan. Strategies of Poetic Narrative: Chaucer, Spenser, Milton, Eliot. Cambridge: Cambridge UP, 1992. Print.

Kinsella, John. Disclosed Poetics: Beyond Landscape and Lyricism. Manchester: Manchester UP, 2007. Print.

---. Divine Comedy: Journeys through a Regional Geography. U of Queensland P, 2008. Print.

---. “The pastoral, and the political possibilities of poetry." Southerly 56.3 (1996): 3642. Informit. Web. 07 Jan. 2016. 
Koch, Kenneth. The Collected Poems of Kenneth Koch. New York: Knopf, 2005. Print. Koestenbaum, Phyllis. "Writing Criminally.” Finch 139-140.

Kollar, Sybil. "Calisthenics.” Finch 141-142.

Kumin, Maxine. "Paradoxical Freedom." Finch 143-146.

Labov, William. Language in the Inner City: Studies in the Black English Vernacular. Philadelphia: U of Pennsylvania P, 1972. Print.

Leeming, David. Myth: A Biography of Belief. New York: Oxford UP USA, 2001. Print. Leitch, Thomas. What Stories Are: Narrative Theory and Interpretation. University Park: Pennsylvania State UP, 1986. Print.

Levertov, Denise. New and Selected Essays. New York: New Directions, 1992. Print. Levin, Phyllis. "Embracing Fate.” Finch 147-151.

Liang, Renee. "Cultural Storytellers: Tusiata Avia," The Big Idea: Te Aria Nui, 26 Nov. 2009. Web 14 Oct. 2015.

Litz, A. Walton. "The Waste Land Fifty Years After." Eliot in His Time: Essays on the Occasion of the Fiftieth Anniversary of The Waste Land. Ed. A. Walton Litz. Princeton: Princeton UP, 1973. 3-22. Print.

Locke, Terry. "Bill Sewell, The Ballad of Fifty-One." Hyperpoetics. Hyperpoetics, n.d. Web. 1 Sep. 2015.

Loney, Alan. "The Influence of American Poetry on Contemporary Poetic Practice in New Zealand.” Journal of New Zealand Literature 10 (1992): 92-98. JSTOR. Web. 3 May 2013.

Longenbach, James. The Art of the Poetic Line. St Paul: Graywolf, 2008. Print.

Lotman, Jurij. The Structure of the Artistic Text. Trans. Ronald Vroon. Ann Arbor, U of Michigan P, 1977. Print.

Manhire, Bill. Doubtful Sounds: Essays and Interviews. Wellington: Victoria UP, 2000. Print.

Mandelstam, Osip. “Conversation about Dante.” Trans. Jane Gary Harris. Mandelstam: The Complete Critical Prose and Letters. Ed. Jane Gary Harris. Ann Arbor: Ardis, 1979. 397-451. Print.

Maxwell, Glyn. On Poetry. London: Oberon, 2012. Print.

McCloud, Scott. Understanding Comics. The Invisible Art. New York: HarperPerennial, 1994. Print. 
McCooey, David. "Contemporary Poetry: Across Party Lines.” Webby 158-182.

McHale, Brian. "Beginning to Think about Narrative in Poetry." Narrative 17.1 (2009): 11-30. Project Muse. Web. 14 Mar. 2013.

---. "Narrative in Poetry.” Herman et al. 356-358.

---. "Narrativity and Segmentivity, Or, Poetry in the Gutter." Intermediality and Storytelling. Ed. Marina Grishakova and Marie-Laure Ryan. Berlin: De Gruyter, 2010. 27-48. Print.

---. "Telling Stories Again: On the Replenishment of Narrative in the Postmodern Long Poem." The Yearbook of English Studies 30 (2000): 250-262. JSTOR. Web. 14 Mar. 2013.

---. "Thinking Some More about Narrative in Poetry: A Brief Reply to Bruce Heiden." Narrative 22.2 (2014): 284-287. Project Muse. Web. 19 Jun. 2015.

---. "Weak Narrativity: The Case of Avant-Garde Narrative Poetry." Narrative 9.2 (2001): 161-167. JSTOR. Web. 12 Mar. 2013.

Miller, James. T.S Eliot's Personal Waste Land: Exorcism of the Demons. University Park: Pennsylvania State UP, 1977. Print.

Minter, Peter. "Vale Dorothy Porter." Cordite Poetry Review. Cordite, 10 Dec. 2008.

Web. 25 May 2014.

Moore, Honor. "The Walls of the Room." Finch 161-165.

Moorhead, Finola. “"'She doesn't prove who did it, anyway.” Rev. of the Monkey's Mask by Dorothy Porter.” Southerly 55.1 (1995): 177-92. Informit. Web. 07 Jan. 2016.

Morgan, Monique R. Narrative Means, Lyric Ends: Temporality in the NineteenthCentury British Long Poem. Columbus: Ohio State UP, 2009. Print.

---. "Narrative Means to Lyric Ends in Wordsworth's "Prelude"”. Narrative 16.3 (2008): 298-330. JSTOR. Web. 17 Jun. 2015.

Müller-Zettelmann, Eva, and Margarete Rubik, eds. Theory Into Poetry: New Approaches to the Lyric. New York: Rodopi, 2005. Print.

Murphy, Patrick. "The Verse Novel: A Modern American Poetic Genre.” College English 51.1 (1989): 57-72. JSTOR. Web. 11 Mar. 2013.

Nathan, Leonard. "Narrative Poetry." Preminger et al. 814-818.

The New English Bible. Oxford and Cambridge: Oxford UP/ Cambridge UP, 1970. 
Print.

Nünning, Angsar. "Narratology or Narratologies? Taking Stock of Recent

Developments, Critique and Modest Proposals for Future Usages of the Term."

Kindt and Müller 239-275.

O'Brien, Gregory. After Bathing at Baxter's: Essays and Notebooks. Wellington:

Victoria UP, 2002. Print.

Ochs, Elinor, and Lisa Capps. Living Narrative: Creating Lives in Everyday

Storytelling. Cambridge: Harvard UP, 2001. Print.

Olson, Charles. "Projective Verse." Poetry in Theory: An Anthology 1900-2000. Ed.

John Cook. Oxford: Blackwell, 2004. 288-295. Print.

O’Sullivan, Sean. "Broken on Purpose: Poetry, Serial Television and the Season."

StoryWorlds: A Journal of Narrative Studies 2.1 (2010): 59-77. Project Muse.

Web. 15 Sep. 2013.

Peacock, Molly. "From Gilded Cage to Rib Cage." After New Formalism: Poets on

Form, Narrative and Tradition. Ed. Annie Finch. Ashland: Story Line, 1999.

Print.

---. “One Green, One Blue: One Point About Formal Verse Writing And Another About

Women Writing Formal Verse.” Finch 175-187.

Perloff, Marjorie. "From Image to Action: The Return of Story in Postmodern Poetry."

Contemporary Literature 23.4 (1982): 411-427. JSTOR. Web. 8 May 2013.

---. “The Linear Fallacy.” The Georgia Review 35.4 (1981): 855-869. JSTOR. Web. 9

May 2013.

---. "Revolving in Crystal: The Supreme Fiction and the Impasse of Modernist Lyric."

Wallace Stevens: The Poetics of Modernism. Ed. Albert Gelpi. Cambridge:

Cambridge UP, 1985. 41-64. Print.

Phelan, James. Experiencing Fiction: Judgments, Progressions, and the Rhetorical

Theory of Narrative. Columbus: Ohio State UP, 2007. Print.

Pier, John, and Jose Angel Garcia Landa, eds. Theorizing Narrativity. Berlin: De

Gruyter, 2008. Print.

Pingping, Liu, and Glen Phillips. "Radical Pastoralism: John Kinsella's Great 'Pastoral

Trilogy."' Landscapes 3.1 (2009): n. pag. Web. 01 Jan. 2016.

Plunkett, Felicity. "Daemonic currents in Dorothy Porter's poetry.” Australian Literary 
Studies 25.1 (2010): 19-30. EBSCOhost. Web. 8 Apr. 2013.

Pollack, Frederick. "Rebirth of a Non-tradition.” NER/BLQ 8.1 (1985): 52-61. JSTOR.

Web. 30 May 2013.

Pollnitz, Christopher. “Australian Verse Novels.” Heat 7 (2004): 229-252. Print.

Pound, Ezra. Literary Essays of Ezra Pound. Ed. T.S. Eliot. London: Faber, 1954. Print.

Porter, Dorothy. "Dorothy Porter in Conversation with Rosanna Licari." Stylus Poetry

Journal 26 (2007): n. pag. Web. 25 May 2014.

---. "It's too hard to write good - I'd rather write bad." Australian Humanities Review

17 (2000): n. pag. Web. 8 Apr. 2013.

---. On Passion. Melbourne: Melbourne UP, 2010. Print.

---. The Monkey’s Mask. Sydney: Pan MacMillan, 2000. Print.

---. What a Piece of Work. Sydney: Pan MacMillan, 1999. Print.

Pratt, Mary Louise. Toward a Speech Act Theory of Literary Discourse. Bloomington: Indiana UP, 1977. Print.

Preminger, Alex, and T. V. F. Brogan, co-eds; Frank J. Warnke, O.B. Hardison Jr, and Earl Miner, assoc. eds. The New Princeton Encyclopedia of Poetry and Poetics. Princeton: Princeton UP, 1993. Print.

Prince, Gerald. Dictionary of Narratology. 2nd ed. Lincoln and London: U of Nebraska P, 2003. Print.

---. “Narrativehood, Narrativeness, Narrativity, Narratability.” Pier and Landa. 19-27.

---. Narratology: The Form and Functioning of Narrative. Berlin: Mouton, 1982. Print.

---. “Surveying Narratology.” Kindt and Müller 1-16.

Reed, Marthe. "John Kinsella's Anti-Pastoral: A Western Australian Poetics of Place." Antipodes 24.1 (2010), 91-96. JSTOR. Web. 14 Sep. 2014.

Richardson, Brian. "Recent concepts of narrative and the narratives of narrative theory." Style 34.2 (2000):168-175. JSTOR. Web. 07 Jan. 2016.

Ricketts, Harry. "The Ballad.” Green and Ricketts 20-27.

---. "Polemical Poetry." Green and Ricketts 377-389.

Ricks, Christopher. Milton's Grand Style. Oxford: Clarendon, 1963. Print.

Ricoeur, Paul. Time and Narrative. Vol. 1. Trans. Kathleen McLaughlin and David Pellauer. Chicago: U of Chicago P, 1984. Print.

Rimmon-Kenan, Shlomith. Narrative Fiction: Contemporary Poetics. London: 
Routledge, 1983. Print.

Roberts, Neil, ed. Companion to Twentieth-Century Poetry. Oxford: Blackwell, 2001. Print.

Rosenthal, M.L., and Sally M. Gall. The Modern Poetic Sequence: The Genius of Modern Poetry. New York: Oxford UP, 1983. Print.

Rosko, Emily, and Vander Zee, Anton, eds. A Broken Thing: Poets on the Line. Iowa City: U of Iowa P, 2011. Print.

Rowson, Martin. The Waste Land. Harmondsworth: Penguin, 1990. Print.

Rubik, Margarete. 'In Deep Waters, Or: What's the Difference between Drowning in Poetry and in Prose?” Müller-Zettelmann and Rubik 189-205.

Ryan, Marie-Laure. "The Modes of Narrativity and Their Visual Metaphors." Style 26.3 (1992): 368-387. JSTOR. Web. 28 Dec. 2015.

---. “Narrative.” Herman et al. 344-348.

---. "On the Theoretical Foundations of Transmedial Narratology." Narratology Beyond Literary Criticism: Mediality, Disciplinarity. Ed. Jan Christoph Meister. Berlin: De Gruyter, 2005. 1-23. Print.

---. “Tellability.” Herman et al. 589-591.

Sanchez, Sonia. "Form and Responsibility." Finch 195-200.

Sauerberg, Lars Ole. "Repositioning Narrative: The Late-Twentieth-Century Verse Novels of Vikram Seth, Derek Walcott, Craig Raine, Anthony Burgess, and Bernadine Evaristo." Orbis Litterarum 59 (2004): 439-64. Wiley Online Library. Web. 30 May 2013.

Schaeffer, Jean-Marie. "Fictional vs. Factual Narration.” Hühn et al. 98-114.

Scholes, Robert, and Robert Kellogg. The Nature of Narrative. New York: Oxford UP, 1966. Print.

Schmid, Wolf. "Narrativity and Eventfulness.” Kindt and Müller 17-33.

Schwarz, Daniel R. Narrative and Representation in the Poetry of Wallace Stevens. New York: St. Martin's, 1993. Print.

Sewell, Bill. The Ballad of Fifty-One. Wellington: HeadWorX, 2003. Print.

---. Erebus: A Poem. Christchurch: Hazard, 1999. Print.

Shapcott, Thomas. "History of a Generation.” Island 87 (2001): 130-133. Informit. Web. 30 Dec. 2015. 
Shoptaw, John. "The Music of Construction: Measure and Polyphony in Ashbery and Bernstein." The Tribe of John: Ashbery and Contemporary Poetry. Ed. Susan Schultz. Tuscaloosa: U of Alabama P, 1995. 211-57. Print.

Smith, Barbara Herrnstein. "Narrative Versions, Narrative Theories." Critical Inquiry 7.1 (1980): 213-236. JSTOR. Web. 07 Jan. 2016.

Smith, Sidonie, and Julia Watson. "The Trouble with Autobiography: Cautionary Notes for Narrative Theorists." A Companion to Narrative Theory. Ed. James Phelan and Peter J. Rabinowitz. Malden: Blackwell, 2005. 356-371. Print.

Stanzel, F.K. A Theory of Narrative. Cambridge: Cambridge UP, 1984. Print.

Sternberg, Meir. "Telling in Time (I): Chronology and Narrative Theory." Poetics Today 11.4 (1990): 901-948. JSTOR. Web. 07 Jan. 2016.

Stevick, Philip. The Chapter in Fiction: Theories of Narrative Division. Syracuse: Syracuse UP, 1970. Print.

Sturgess, Philip. Narrativity: Theory and Practice. Oxford: Clarendon, 1992. Print. Sturm, Terry. "New Zealand Poetry.” Roberts 293-303.

Taylor, Carole Anne. A Poetics of Seeing: The Implications of Visual Form in Modern Poetry. New York: Garland, 1985. Print.

Turco, Lewis. The New Book of Forms: A Handbook of Poetics. Hanover: UP of New England, 1984. Print.

Veyne, Paul. Did the Greeks Believe in Their Myths?: An Essay on the Constitutive Imagination. Trans. Paula Wissing. Chicago: U of Chicago P, 1988. Print.

Wearne, Alan. The Lovemakers. Exeter: Shearsman, 2008. Print.

Webby, Elizabeth, ed. The Cambridge Companion to Australian Literature. Cambridge: Cambridge UP, 2000. Print.

Wesling, Donald. The Chances of Rhyme: Device and Modernity. Berkeley: U of California P, 1980. Print.

---. The Scissors of Meter: Grammetrics and Reading. Ann Arbor: U of Michigan P, 1996. Print.

Wesling, Donald, and Enikö Bollobás. "Free Verse." Preminger et al. 425-427. Print.

Weste, Linda. "Productive Interplay: Poetic and Narrative Strategies in the LateTwentieth and Early-Twenty-First Century Verse Novel.” Diss. University of Melbourne, 2012. Print. 
Wevers, Lydia. "In command of his talent." New Zealand Books, n.d., n. pag. New Zealand Books. Web. 01 Sep. 2015.

White, Hayden. The Content of the Form: Narrative Discourse and Historical Representation. Baltimore: Johns Hopkins UP, 1987. Print.

Wilkinson, Jessica. “Jessica Wilkinson Interviews Anna Jackson.” Cordite Poetry Review. Cordite, 1 Aug. 2015. Web. 6 Aug. 2015.

Wimsatt, W.K. The Verbal Icon: Studies in the Meaning of Poetry. Lexington: U of Kentucky P, 1954. Print.

Wolf, Werner. "'Cross the Border: Close that Gap': Towards an Intermedial Narratology.” European Journal of English Studies 8.1 (2004): 81-103. Taylor and Francis. Web. 5 Apr. 2013.

---. "The Lyric: Problems of Definition and a Proposal for Reconceptualisation." Müller-Zettelman and Rubik 21-56.

"Wreck of the Eunice: The Nautical Inquiry." North Otago Times 106.13989 (1917): 2. PapersPast. Web. 01 Jan. 2016. 


\section{Selected Bibliography (Creative Component)}

Anderson, Ken. Sparse Timber Sawmillers: Ellis and Burnand Ltd., Sawmillers and Timber Merchants, Ongarue. Taumarunui: Taumarunui and Districts Historical Society, 2008. Print.

Binney, Judith. Redemption Songs: A life of Te Kooti Arikirangi Te Turuki. Wellington:

Bridget Williams Books, 1995. Print.

Burgess, J.S. "Coastline change at Wanganui, New Zealand.” Diss. University of Canterbury, 1971. Web. 08 Feb. 2014.

Cooke, Ron. Roll Back the Years: The Pictorial Magazine That Builds Up the History of Taumarunui and Surrounding District. 7 vols. Taumarunui: C\&S Publications, 1980-1987. Print.

Couper, Wilf, and Ron Cooke. Kaitieke: The District, the People, the Schools. 2nd ed. Taumarunui: C\&S Publications, 1994. Print.

Fleming, C.A. The Geology of Wanganui Subdivision: Waverly and Wanganui Sheet Districts. Wellington: Dept. of Scientific and Industrial Research, 1953. Print. Horizons Regional Council. Whanganui Catchment Strategy: Updated Action Plan September 2003. Palmerston North: Horizons Regional Council, 2003. Web. 11 Apr. 2013.

Kerry-Nicholls, J.H. The King Country; Or, Explorations in New Zealand: A Narrative of 600 Miles of Travel Through Maoriland. Christchurch: Capper Press, 1974. Print.

Lowe, David, ed. The Kakahi Sawmills. Auckland: The Lodestar Press, 1978. Print. McMillan, Lyndsay, and Audrey Walker. Ongarue: A Place of the Heart. Ōngarue: Ongarue School Centenary Committee, 2005. Print.

Mead, A.D. Richard Taylor: Missionary Tramper. Wellington: Reed, 1966. Print. Munro, Jessie, ed. Letters on the Go: The Correspondence of Suzanne Aubert.

Wellington: Bridget Williams Books, 2009. Print.

---. The Story of Suzanne Aubert. Auckland: Auckland University Press/ Bridget Williams Books, 1996. Print.

New Zealand Railway and Locomotive Society, Auckland Branch. Ongarue Bush 
Tramway. Auckland: New Zealand Railway and Locomotive Society, 1955. Print.

New Zealand. Waitangi Tribunal. Wai 167: The Whanganui River Report. Wellington: Legislation Direct, 1999. Web. 12 Jun. 2013.

---. “Wai 1130 Te Kāhui Maunga: The National Park District Inquiry Report.” Ministry of Justice. Ministry of Justice, n.d. Web. 21 Jun. 2015.

Parnell, Jim. In the Wake of the Riverboats: Tales told by Whanganui Riverboat Pioneers Joshua Harris and his Sons. Wellington: Published by the author, 2005.

Reed, A.W. Place Names of New Zealand. Wellington: Reed, 1975. Print.

Reid, Alec, and David Reid. Paddle Wheels on the Wanganui. Auckland: Blackwood and Janet Paul, 1967. Print.

Smart, M.J.G., and A.P. Bates. The Wanganui Story. Whanganui: Wanganui Newspapers Ltd., 1972. Print.

Walker, Audrey, and Ron Cooke. Waimiha: People of Character. Waimiha: Waimiha Reunion 2001 Committee, 2003. Print.

Young, David. Woven by Water: Histories from the Whanganui River. Wellington: Huia, 1999. Print.

The Whanganui Regional Museum, the online encyclopedia Te Ara, the National Library's PapersPast website, New Zealand History Online and the New Zealand Electronic Text Collection have also been important sources of information. 